ARC Centre of Excellence for Creative Industries and Innovation

www.cci.edu.au

CCi Digital Futures 2014

The Internet in

Australia

Scott Ewing, Emily van der Nagel \& Julian Thomas

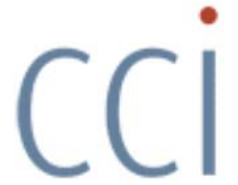

ARC Centre of Excellence for Creative Industries and Innovation Swinburne University of Technology 
CCi Digital Futures 2014: The Internet in Australia

ISSN: 1836-1250 (print); 1836-1269 (online)

This report and earlier reports in this series are available at www.cci.edu.au/projects/digital-futures

Contact us at sewing@swin.edu.au

\section{Attribution}

Excerpted material from this report can be cited in media coverage and institutional publications. Text excerpts should be attributed to Scott Ewing and Julian Thomas. Graphs should be attributed in a source line to: CCi Digital Futures 2014.

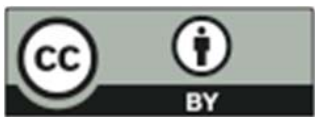

Unless otherwise noted this report is licensed under a

Creative Commons Attribution

2.5 Australia licence. You are free to copy, communicate and adapt this work, so long as you attribute the ARC

Centre of Excellence for Creative Industries and Innovation and the authors.

For more information see http://www.creativecommons. org/licenses/by/2.5/au 


\section{Contents}

Preface and Acknowledgements

Highlights of the 2013 Report

1 The basics of Internet access 1

2 The internet and social networks 11

3 The internet and the media 18

4 The internet and entertainment 28

5 Creative uses of the internet 37

6 Internet politics and policy 41

7 The internet and commerce 49

Appendix 1: Background to the World Internet Project 58

Appendix 2: About the $\mathrm{CCl} \quad 60$

$\begin{array}{ll}\text { Appendix 3: Research methods } & 61\end{array}$

Appendix 4: The World Internet Project: international contacts 67 


\section{Preface}

This report presents findings from the third survey of the Australian component of the World Internet Project. The survey was conducted in late 2013.

This research is a project of the ARC Centre of Excellence for Creative Industries and Innovation at the Swinburne Institute for Social Research, Swinburne University of Technology.

This report provides an overview of the study, presenting a broad picture of the Internet in Australia, with comparisons to our earlier 2007, 2009 and 2013 studies, and to the international findings of our partners in the World Internet Project. At the end of each section we have added some further analysis, examining aspects of the Australian data in more detail, and providing some international context using results from the findings of our international research partners.

\section{Acknowledgements}

Research for this project was supported by the Australian Research Council Centre of Excellence for Creative Industries and Innovation (ARC Grant no. CE0561908).

We would like to thank our colleagues in the ARC Centre. We are fortunate to have such a challenging and ambitious cross-disciplinary home for this project. Special thanks also to our colleagues in partner universities in the World Internet Project, who have done so much of the hard work in this field already; and to our colleagues at the Swinburne Institute for Social Research.

Finally, for all her expert assistance with the administration of the survey, we would like to thank Gordana Bruce and her staff at Swinburne's CATI Centre. 


\title{
Highlights of the 2013 Report
}

\begin{abstract}
Mobile is here and it's everywhere
In 2009 only $15 \%$ of Australian internet users accessed the internet on a mobile device such as a mobile phone. This grew strongly to 2011 and again to 2013 by which time almost three-quarters of Australian internet users accessed the internet on a mobile device. In addition, mobile access within the household has grown strongly. Eight out of ten households with an internet connection have a wireless network and ownership of devices that utilise these networks has grown very strongly in the last four years.
\end{abstract}

\begin{abstract}
Australia is more and more a nation online ... The overwhelming majority of Australians are internet users, and uptake is still growing. When we spoke to them in $2013,91 \%$ of Australians had used the internet in the past three months, up from $87 \%$ in $2011,81 \%$ in 2009 and 73\% in 2007. By international standards, Australia's level of internet use is very high.
\end{abstract}

\section{... but there is still a digital divide.}

Being offline is increasingly about being older. We didn't have anybody under 35 who did not use the internet and $97 \%$ of those aged 35-49 were internet users. In contrast more than a third of those aged 65 or more did not use the internet.

We have now reached a point where there is almost universal broadband access in Australia's more affluent households, but a large proportion of low-income households are still without home broadband access. Almost three in ten households in the lowest income group do not have home broadband. Households on lower incomes are not any more likely to be dissatisfied with the speed or reliability of their home connection, but they do appear to derive less benefit from their internet access. They are less likely to access government services or information online and more likely to see the internet as a frustrating technology.

The internet is increasingly an everyday part of Australians' lives, More than nine out of ten Australian internet users describe the internet as a 'very important' or 'important' part of their lives. In 2007, the proportion was eight out of ten.

\section{and Australians are doing more online all the time.}

Australian internet use is growing in three dimensions. First, as we've noted, the number of internet users continues to grow. Second, users are doing more online. Across many of the internet activities that we asked about, there was an increase in the proportion of people undertaking that activity. Third, the frequency of activity has also been increasing. These three elements help to explain the growth path of the internet overall. However, when we look at some specific internet applications, we find another pattern: rapid growth from 2007 to 2009, and then a levelling out from 2009 to 2011 and then growth again between 2011 and 2013. The growth between 2011 and 2013 has been accompanied by growth in internet devices in the household. Households with a tablet increased from one in five in 2009 to almost six in ten while those with an e-Reader trebled from $7 \%$ to $22 \%$.

The internet is a social technology.

The use of the internet by Australians for social networking and communicating continues to grow. In 2009 a quarter of internet users accessed a social network site daily. This grew to a third in 2011 and almost half in 2013.

\section{The internet changes the way people access and use the media.}

The internet is Australians' most important source of news and information and its importance has increased slightly in the last two years. More than eight in ten users described the internet as 'important' or 'very important' for news and information in 2013. The use of official news sites and news blogs continues to grow.

The proportion of internet users who say they watch less broadcast television because they can download television programs has grown significantly, trebling between 2007 (10\%) and 2013 (30\%). It is interesting that the proportion of users saying they watched more broadcast television because of the ability to download trebled as well, from 5\% in 2007 to 15\% in 2013.

The question of whether internet users are prepared to pay for journalism is topical, with many predictions of the demise of newspapers. We asked respondents whether and how much they would be prepared to pay to read an online newspaper. As in our earlier surveys, a clear majority of Australians said they would not consider paying for an online newspaper (61\% in 2013) although there has been some growth. Just more than one in ten said they would be prepared to pay as much as the cover price of a hard copy newspaper. 
The internet is a major source of entertainment.

The internet is an increasingly important source of entertainment, and is now challenging television as Australians' most important entertainment medium. In 2011, as in 2009, a higher proportion of users described the internet as a 'very important' source of entertainment than television. (Although if we look at sources of entertainment considered 'important' as well as 'very important', television moves ahead of the net.)

Some forms of popular online entertainment — such as downloading or listening to music online, and visiting sites dedicated to particular artists - recorded significant growth between 2007 and 2009, and then much slower growth from 2009 to 2011 but grew again in 2013, perhaps related to the proliferation of internet connected devices in the household.

\section{Australians love shopping online}

Australians are avid internet shoppers; among our comparison countries Australians, along with China, are the most frequent online shoppers. Overall, price and the variety of goods available are equal drivers of online retail for Australian consumers. Consumers do recognise that there are limits to their ability to assess the quality of products online, and that returning goods can pose more difficulties online. They declare a strong preference for dealing with websites based in Australia, and this preference strengthened between 2011 and 2013.

The internet changes politics.

A majority of both internet users and non-users agreed that the internet has become important for the political campaign process in 2013 (75\% and 63\% respectively) and this had grown from 2011. Australians remain sceptical that internet use can help people have a greater say in government policies.

Australians use of the internet to interact with government or to find out government information continues to grow.

\section{Most Australians support current regulation of the internet...}

The majority of Australians do not think that the internet is over-regulated although there is a stark contrast between users and non-users on this issue. Almost six in ten non-users would like the internet to be regulated more than it currently is, compared to three in ten of those that use the internet.

and they also support freedom of expression online.

Concern about government checking online activity remained steady between 2011 and 2013 while support for free speech dropped slightly. Three-quarters of Australians agreed that people should have the right to express their opinion online while $44 \%$ agreed that even extreme ideas should allowed (down from $53 \%$ in 2011).

There is still strong support for the NBN.

Support for the NBN grew between 2011 and 2013, with three quarters in favour in 2013 and only 11\% against. 


\section{The basics of internet access}

According to the ABS, in November 1998 just under one in five Australian households had access to the internet. This proportion had almost doubled two years later and has continued to climb steadily. In our survey undertaken in 2013 we found that $90 \%$ of Australian households had internet access.

This section investigates who now uses the internet and who doesn't. Since the popularisation of the internet and the advent of the world wide web, there has been considerable public policy interest in this issue. As the technology has matured and adoption has spread, interest has focused on where people access the net and the type of access they have.

\subsection{Current Users and Non-Users}

In $2013,91 \%$ of Australians said that they currently used the internet, up from $87 \%$ in 2011. Seven percent of our respondents had never used the internet (down from one in five in 2007), while the proportion of ex-users had also fallen to $2 \%$ ( $8 \%$ in 2007).

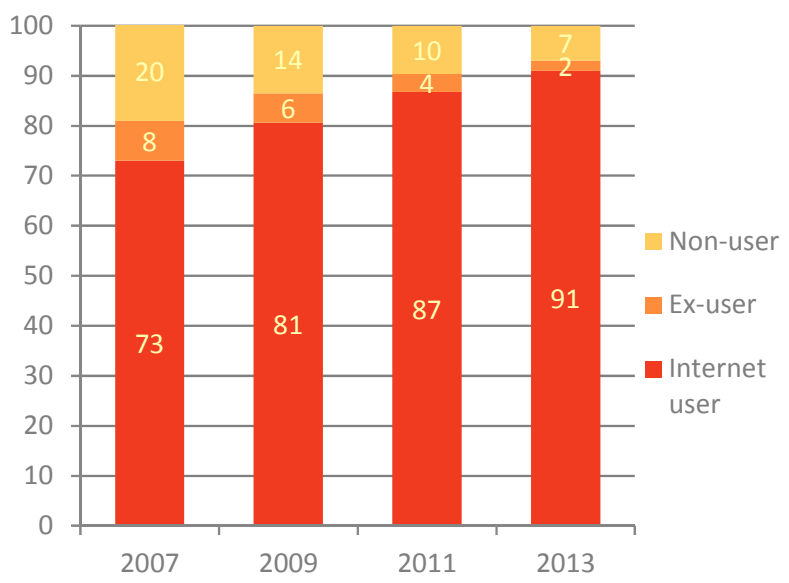

\section{Digital Divides: Users and Non-users}

One of the most fundamental questions about the internet through its development phase has been who is online and who is not? While a significant minority of the population are still non-users, the relevance of this question remains; in fact, it may become more rather than less important as services of all kinds move online. This section examines the characteristics of the two groups.

\subsection{Use by Lifestage}

There has been a sharp increase in the number of homemakers using the internet, from $79 \%$ in 2011 to $95 \%$ in 2013 . The vast majority of the employed population (97\%) and students (99\%) use the internet, indicating that computer and internet skills have become central for professional and domestic life.

Retired people still have the lowest rate of internet use: $64 \%$, up from $60 \%$ in $2011,48 \%$ in 2009, and 38\% in 2007.

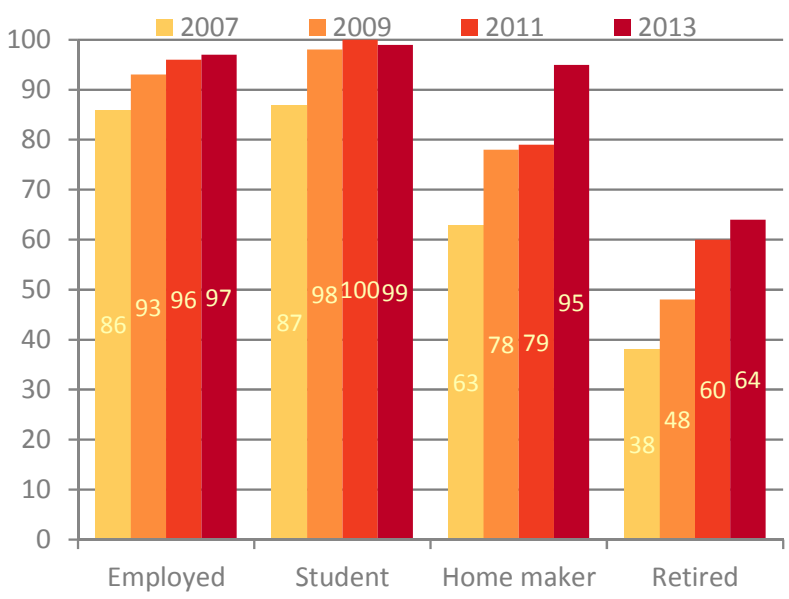




\subsection{Use by Age}

The likelihood that Australians use the internet on a regular basis decreases gradually with age.

Every respondent aged 18 to 34 was online in 2013 , and the great majority of those aged 34-49 (97\%) and 50-64 (93\%).

Those aged 65 or over were less likely to use the internet on a regular basis, although these rates are steadily increasing: from 30\% in $2007,40 \%$ in $2009,57 \%$ in 2011 , to $63 \%$ in 2013.

\subsection{Use by Gender}

In 2013, there is still a gender gap in terms of internet use, with men's participation at 93\%, up from $89 \%$ in 2011 , and women's participation at 89\%, up from 85\% in 2011.

The gap of $4 \%$ between men and women is slightly higher than it was in 2007, when it was $3 \%$. This difference is small, but persistent.
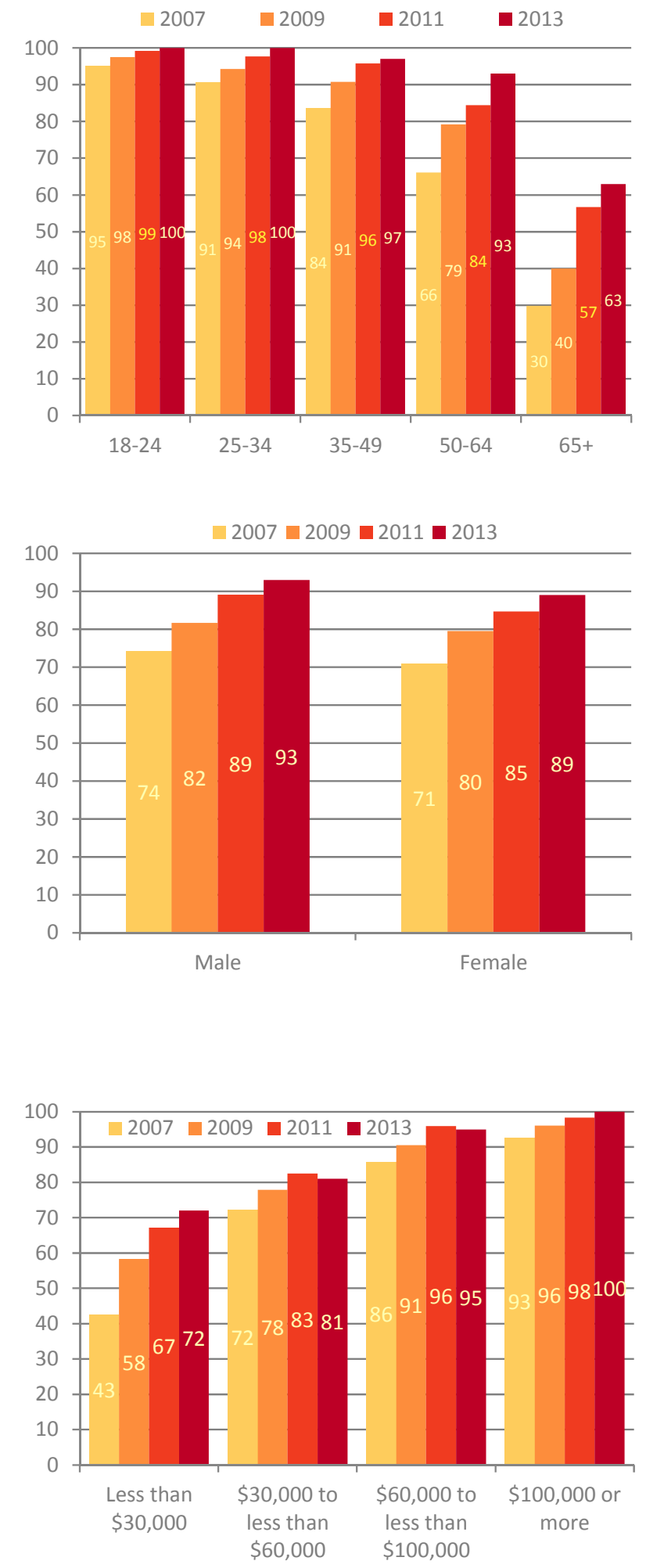

\subsection{Use by Household Income}

Internet use is directly related to household income. The higher the income, the more likely a person is to access the internet regularly.

All people surveyed in households earning $\$ 100,000$ or more use the internet. For those living in households on less than $\$ 30,000$ per annum, internet use has increased strongly over the period of analysis, although the greatest growth was between 2007 and 2009 (43\% to $59 \%)$.

2013 saw internet use decrease slightly, for the first time: from $83 \%$ in 2011 to $81 \%$ in 2013 for those living in households earning $\$ 30,000$ to less than $\$ 60,000$, and from $96 \%$ in 2011 to $95 \%$ in 2013 for those in households earning $\$ 60,000$ to less than $\$ 100,000$. 


\subsection{Use by Education}

Education level also influences internet usage although differences are diminishing.

In $2013,97 \%$ of those who had attended university were internet users, $25 \%$ more than those who had finished high school.

\subsection{Use by Location: Urban-Rural Divide}

There is still a divide between urban and rural people in terms of internet use.

The gap between those living in capital cities and non-capital cities was maintained in 2013 with $93 \%$ of those living in capital cities using the internet, compared to $87 \%$ of those living outside capital cities.
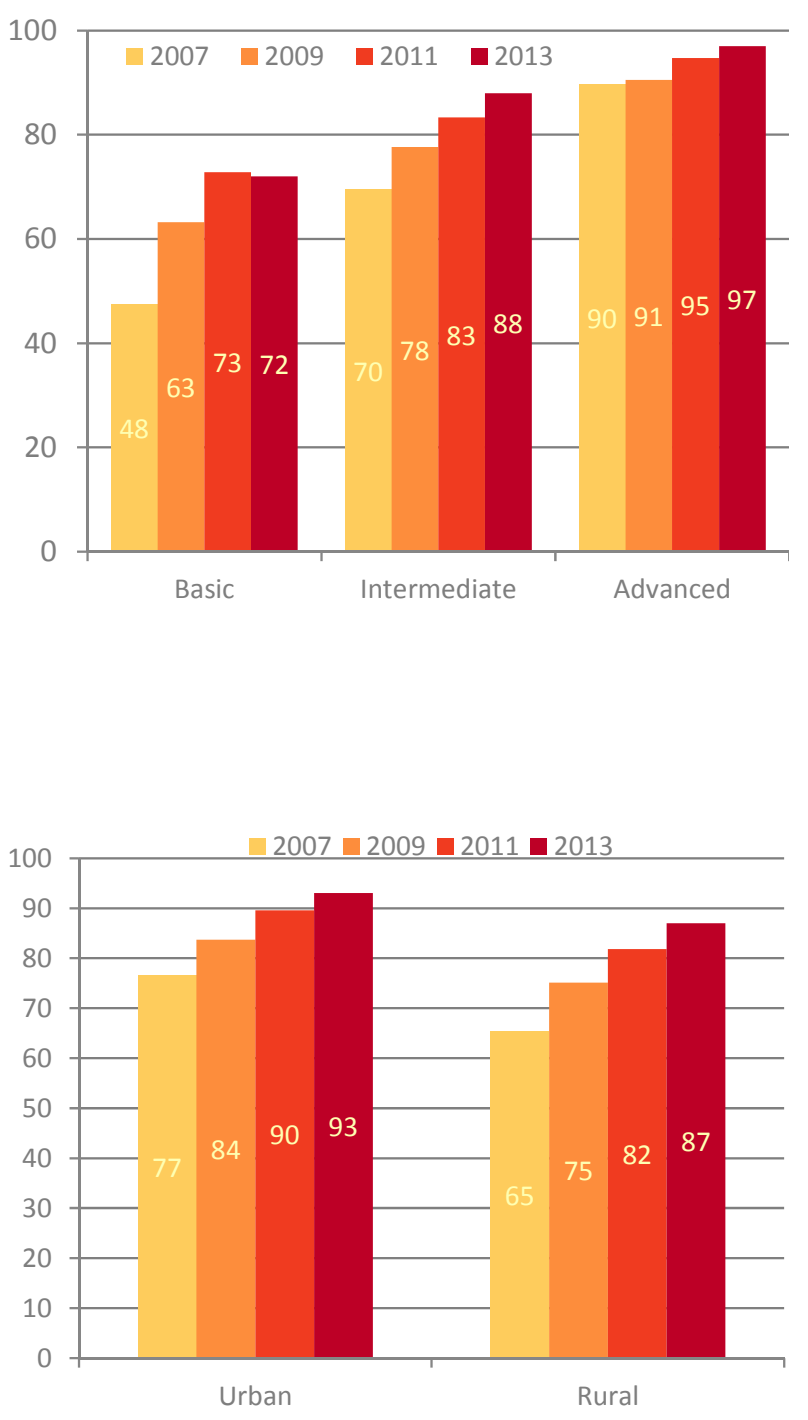

\subsection{Use by place of birth}

Whether people are born in Australia or overseas has little effect on internet use.

Although over the period of analysis, those born overseas were slightly more likely to use the internet, in 2013 there was no gap in internet use between those born in Australia and overseas.

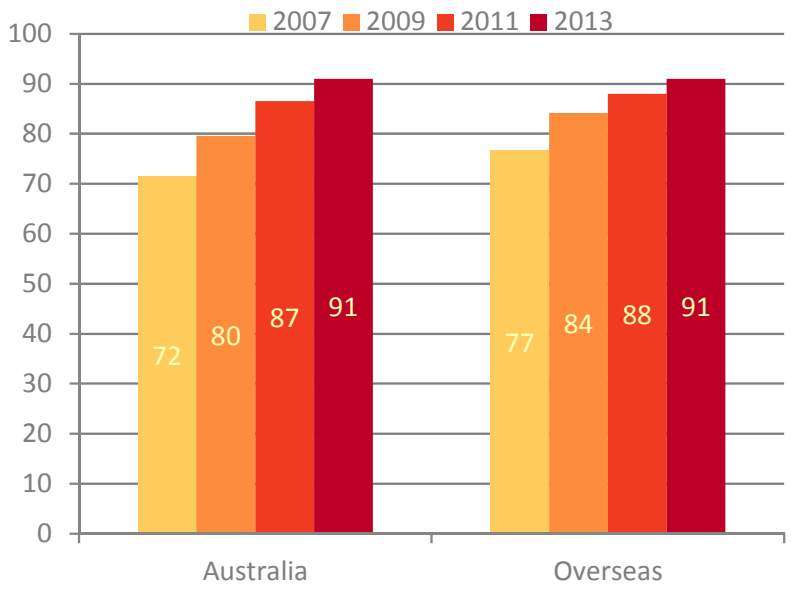




\subsection{Accessing the internet through a mobile handheld device such as a mobile phone}

The proportion of Australian internet users accessing the internet through a mobile device more than doubled between 2009 and 2011 , from $15 \%$ to $37 \%$, and more than doubled again from 2011 to 2013, from 37\% to $76 \%$.

\subsection{Have a wireless network in the household}

Households with a wireless network have gone from being relatively rare to very common over the period. In 2007 just less than a quarter of Australian households had a wireless network. This doubled to 2009 and grew strongly in the next two periods so that in 2013 just less than eight in ten households had one.
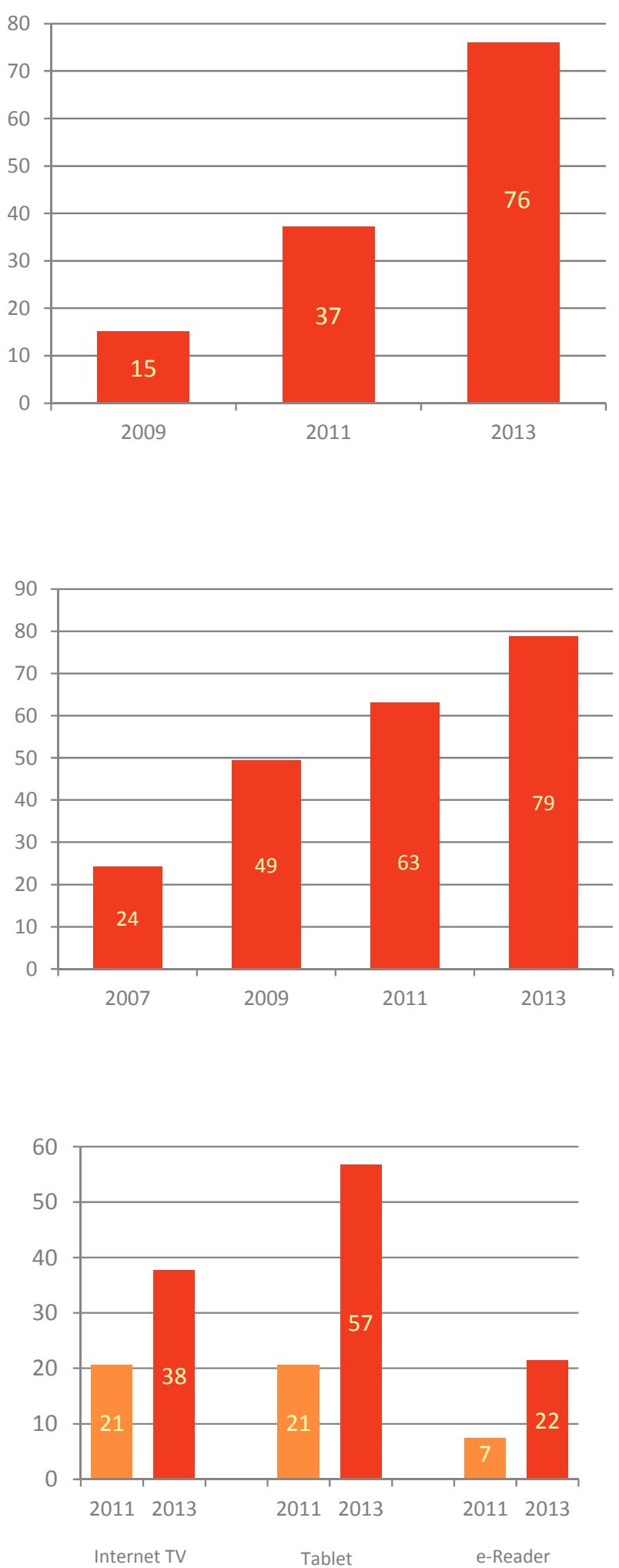


\section{Attitudes to the internet}

This section presents findings on people's attitudes to the internet: its importance in daily life, its benefits and problems.

\subsection{Importance of internet}

The internet has very quickly become an important part of people's lives. Approaching six in ten of our sample described the internet as 'very important' (58\%). This is slightly up on previous years. The importance of the internet to users is increasing steadily. Exactly $80 \%$ rated it as 'very important' or 'important' in 2007. This increased to 84\% in 2009, to $91 \%$ in 2011 and 92\% in 2013.

\subsection{The internet makes life easier}

Overall, people are very positive about the effect of the internet on their lives.

Respondents were slightly more likely in 2013 to agree that the internet makes life easier.

Just over half of our respondents (52\%) strongly agreed that the internet makes life easier, while a further 33\% agreed. Just 3\% of respondents disagreed or strongly disagreed that the internet makes life easier.
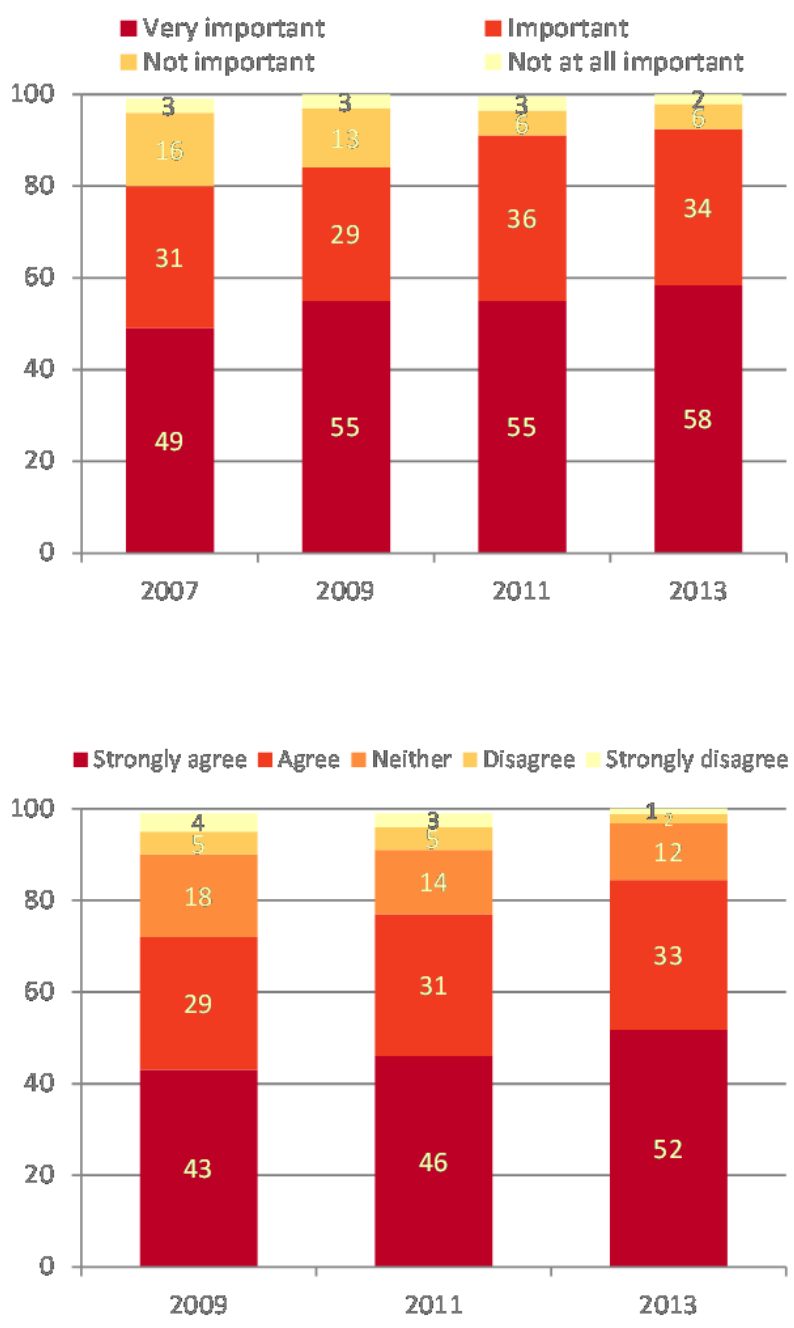

\subsection{The internet is frustrating to work with}

Frustration with the internet has remained remarkably constant over the period of analysis. In 2013, one in five Australian internet users agreed that the internet was frustrating to work with (19\%). This was down slightly on 2009 and 2013.

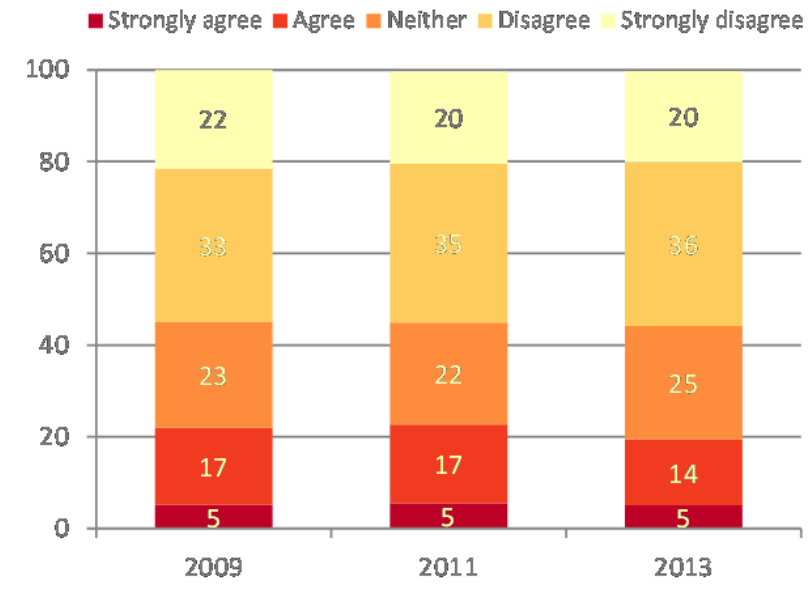




\subsection{There is too much immoral material} on the internet

A significant minority of Australian internet users think that there is too much immoral material on the internet (35\% in 2013, 38\% in 2011 and 39\% in 2009). A sizeable proportion in each of the years said that they 'don't know' if this is case (7\% in 2013). A quarter of our sample 'neither agree nor disagree' while three in ten disagreed with this contention in 2013 (31\%).

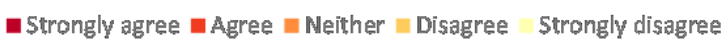

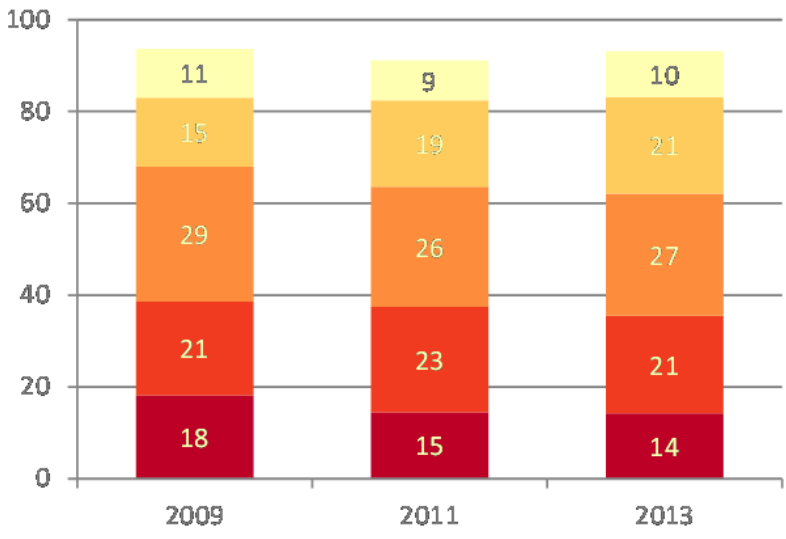

\subsection{The internet is a fast and efficient means to gain information}

There is almost unanimous agreement that the internet is a fast and efficient means to gain information.

Well over half $(63 \%)$ of our respondents strongly agreed that the internet is a fast and efficient means to gain information, and overall $93 \%$ agreed or strongly agreed. Very few $(3 \%)$ disagreed. There was little change over the period of analysis.

\subsection{The use of the internet can be addictive}

Three-quarters of our respondents agree that internet use can be addictive (74\%), while one in ten disagree (10\%). There was little change in responses to this question between 2009 and 2013.

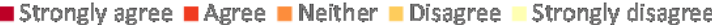
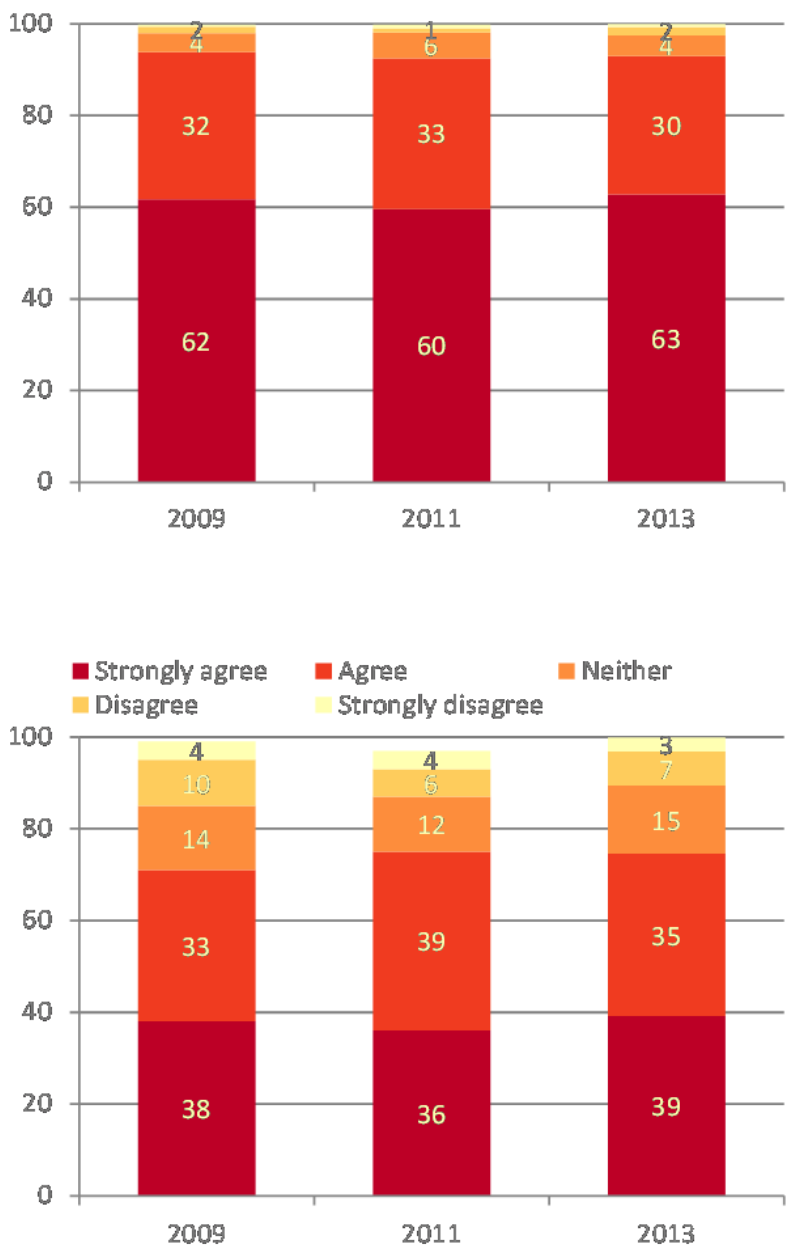


\subsection{Satisfaction with speed of home internet connection}

Around one in five Australians are unhappy with the speed of their home internet scale, one in five $(19 \%)$ are very satisfied and a further four in ten are satisfied (39\%).

Again there was little change over the period of analysis.

\subsection{Satisfaction with the reliability of home internet connection}

Reliability does not appear to be an issue for the majority of Australians with an internet connection at home.

Three in ten are very satisfied (28\%) with a further four in ten (40\%) moderately satisfied. One in ten (10\%) are dissatisfied with the reliability of their home internet connection, with just $2 \%$ very dissatisfied. connection (16\%). At the other end of the
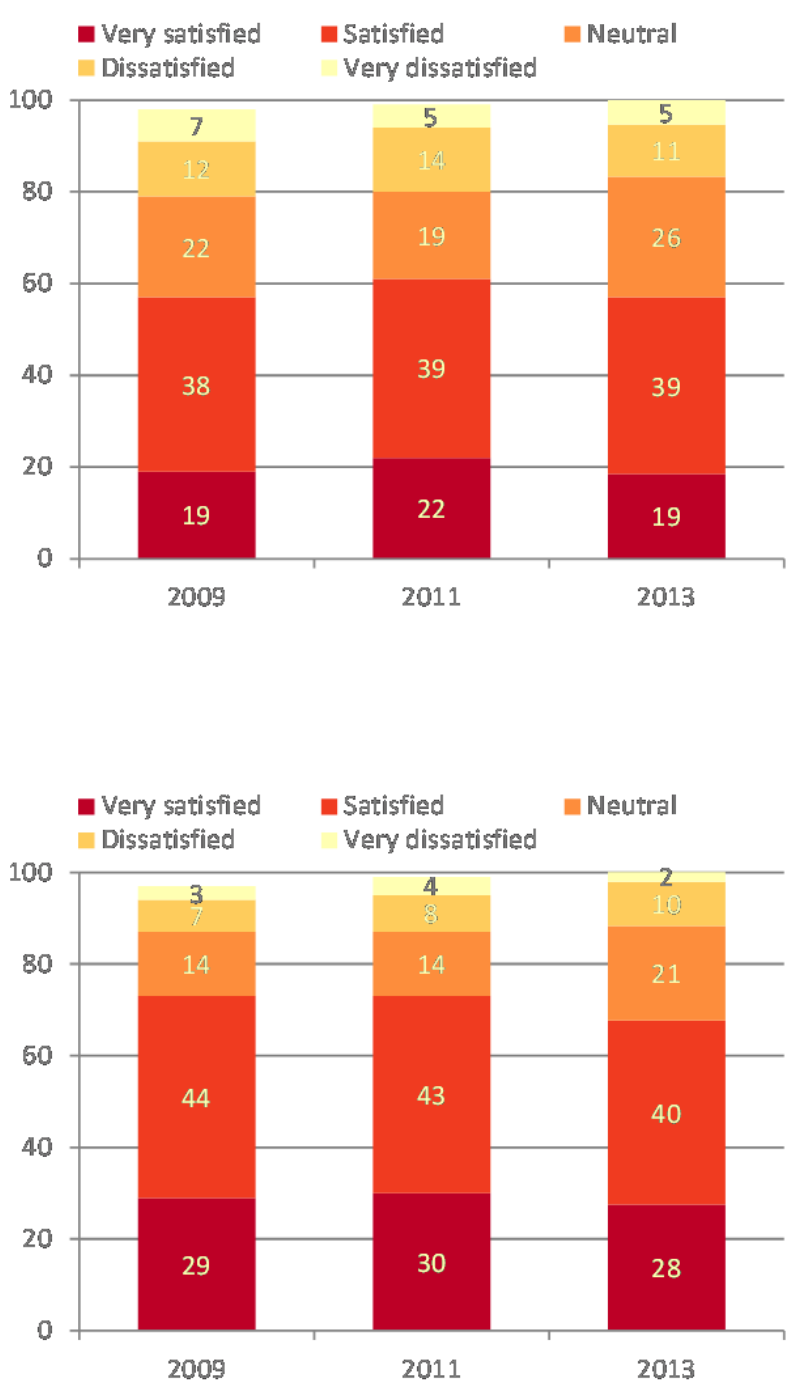

\subsection{Monthly household expenditure on home internet access}

Overall Australians are paying more for internet access in 2013 than they did in 2011. Three in ten are paying more than $\$ 80 \mathrm{a}$ month compared to just over two in ten in 2011. Two thirds of Australian households pay at least $\$ 50$ per month on internet access.

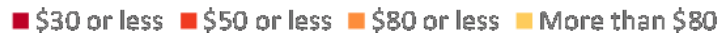

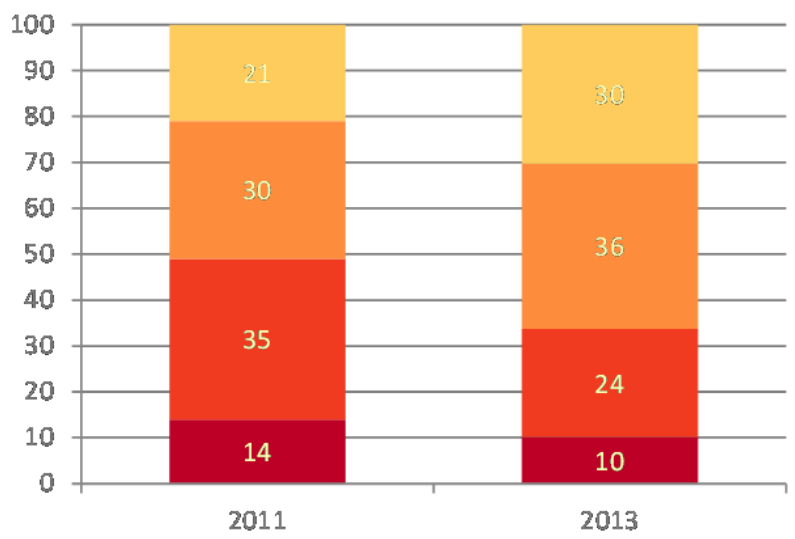




\subsection{Home internet access affordability}

There has been a slight increase in the proportion of Australians who consider their home internet access affordable, from $62 \%$ in 2011 to $71 \%$ in 2013.

Just under one in ten Australians (9\%) consider their home internet access unaffordable.

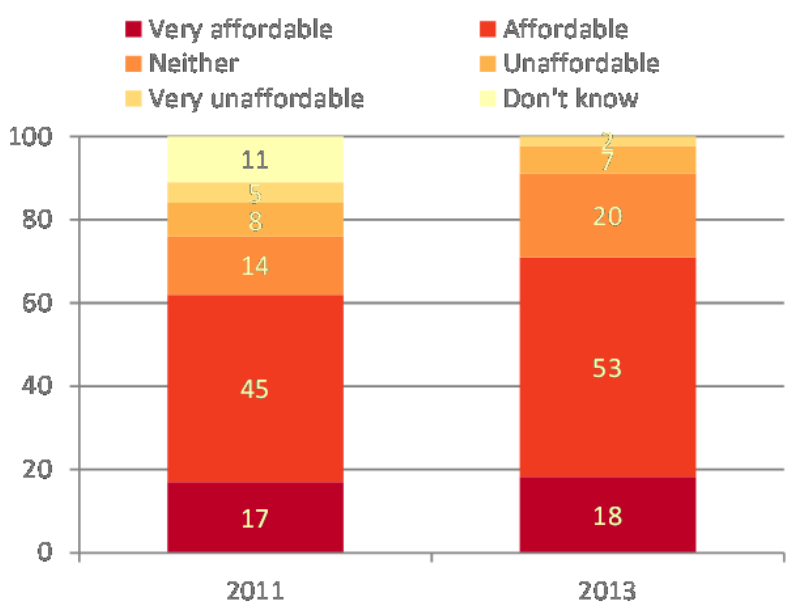

\section{Further Analysis}

1.22 Home access by income, 2007-2013

Examining home access by household income shows that the strongest growth in internet connection has been in the lower income households. In 2007 a quarter of households earning less than $\$ 30,000$ had broadband access while in 2009 this had increased to over half. In 2011 the figure was closing on two thirds and by 2013 it was $72 \%$.

We have now reached a point where there is almost universal broadband in the most affluent households but still a large proportion of those in lower income households are without home broadband access.

\subsection{Internet use, selected countries, 2013}

Of the countries in the World Internet Project who undertook surveys in 2013, Australia had one of the highest levels of internet usage. All countries exhibited the same pattern of decreasing usage as age increased. Countries with higher levels of penetration exhibited a relatively large decrease in participation amongst those aged 65 or over.

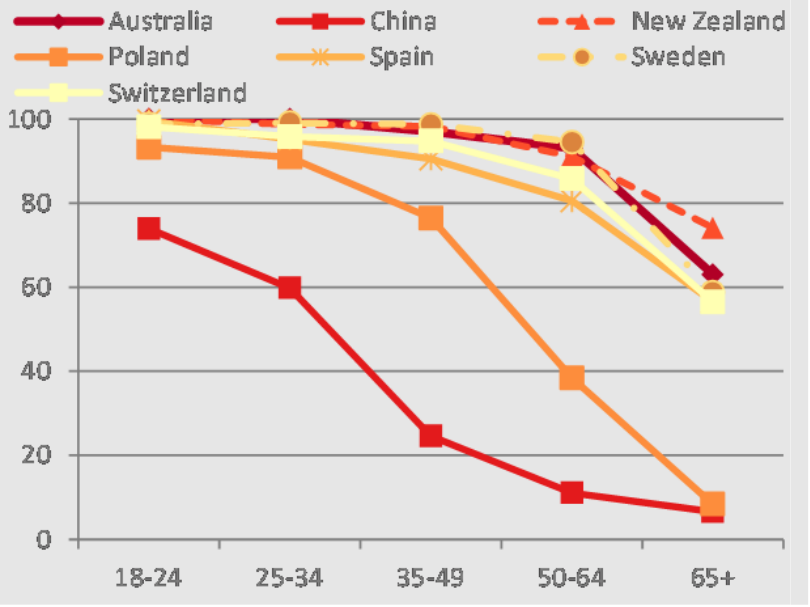




\section{The internet and social networks}

The impact of the internet on people's communication and social networks has been an area of great interest. Initially debate was polarised between those who saw the internet as a communication tool of extraordinary scope and those concerned with its possibly negative effects on face-to-face interaction. With the development of a multitude of platforms for social networking, debates have shifted to concerns about damaging uses of the network (such as cyber bullying) and the complex privacy issues raised by social software such as Facebook.

This section examines how people use the internet for communications and its impact on social networks.

\section{Communicating online}

\subsection{How often do you check your} email?

There has been an increase in Australians checking email daily, from $75 \%$ in 2007 to 85\% in 2013.

Only $1 \%$ of Australian internet users do not use email.

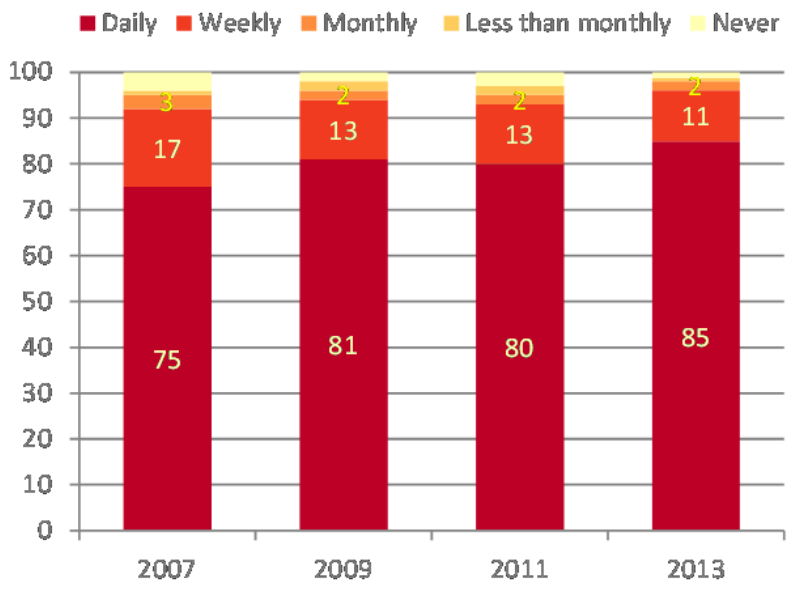

\subsection{How often do you post messages} on discussion or message boards?

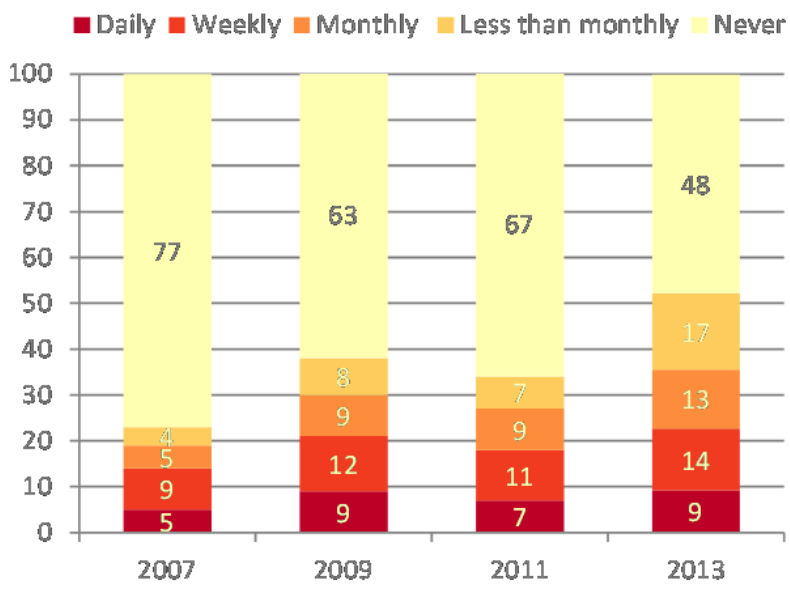

Posting messages on discussion boards rose in popularity in 2009, fell in 2011, and rose again in 2013.

Just over half of Australians posted messages on discussion boards (52\%) in 2013 , up from $33 \%$ in 2011 . Although $9 \%$ of respondents posted daily, the biggest increase was in infrequent use of message boards. Those who posted weekly, monthly, or less than monthly increased from $27 \%$ in 2011 to $44 \%$ in 2013. 


\subsection{How often do you instant message?}

A similar pattern was evident for instant messaging: Following an increase in activity between 2007 and 2009, there was a decrease in 2011, and an increase in 2013.

In $2013,63 \%$ of Australians used instant messaging, up from $45 \%$ in 2011 . The biggest increase in instant messaging was those who used it daily: $37 \%$ in 2013 , up from $21 \%$ in 2011.

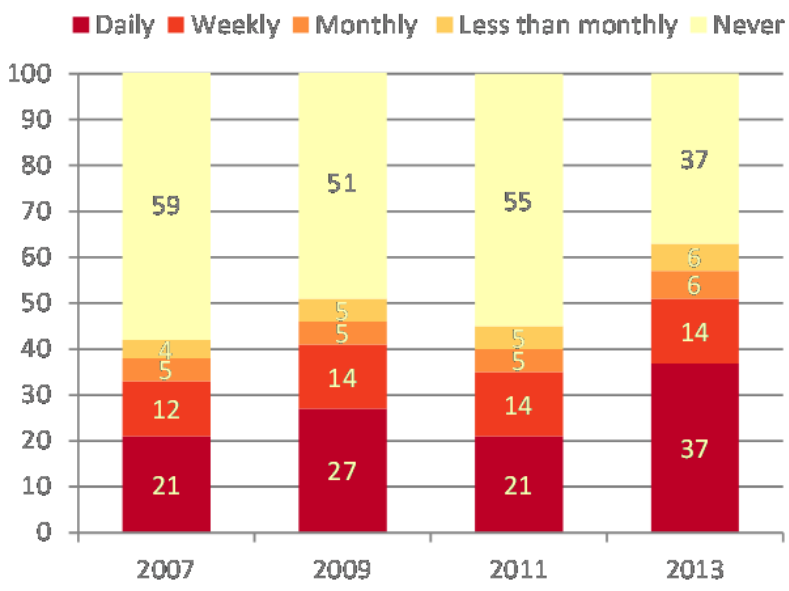

\subsection{How often do you make or receive phone calls over the internet?}

There was a strong increase in the use of the internet to make and receive telephone calls over the period of analysis, but this remained reasonably stable between 2011 and 2013.

Although in 2007 only $17 \%$ of Australian internet users were making phone calls over the internet, this had grown to $40 \%$ by 2013 , with $8 \%$ doing so daily.

\subsection{How often do you use video} communication such as Skype?

Video communication over the internet has grown between 2011 and 2013.

In $2011,47 \%$ of Australian internet users used video communication like Skype, which grew to $61 \%$ in 2013 , with $5 \%$ using video communication daily.
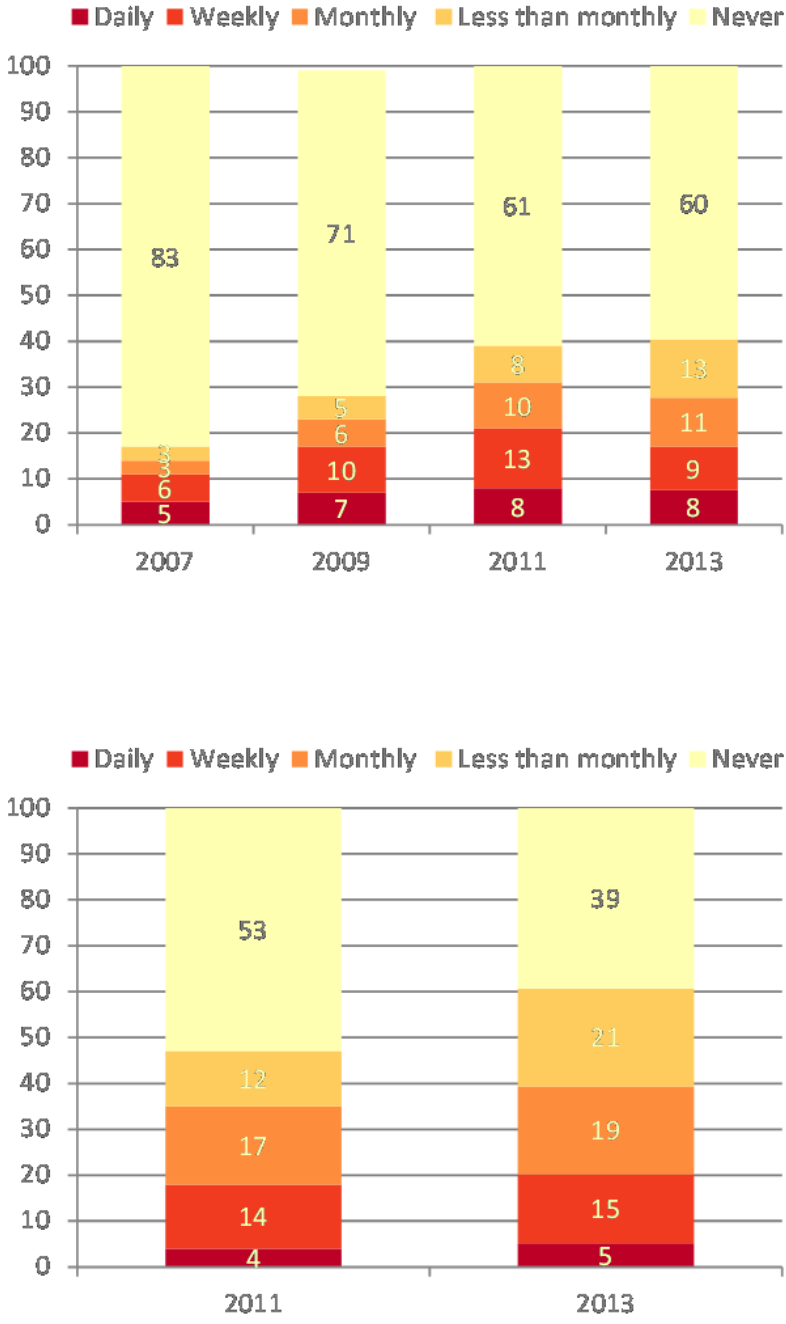


\subsection{How often do you visit social networking sites?}

Use of social networking sites grew between 2009 and 2013.

In 2009, just under a half of Australian internet users accessed a social networking site (49\%), growing to $56 \%$ in 2011 , and $68 \%$ in 2013. Those visiting daily grew from a quarter (25\%) in 2009 to almost half (48\%) in 2013.

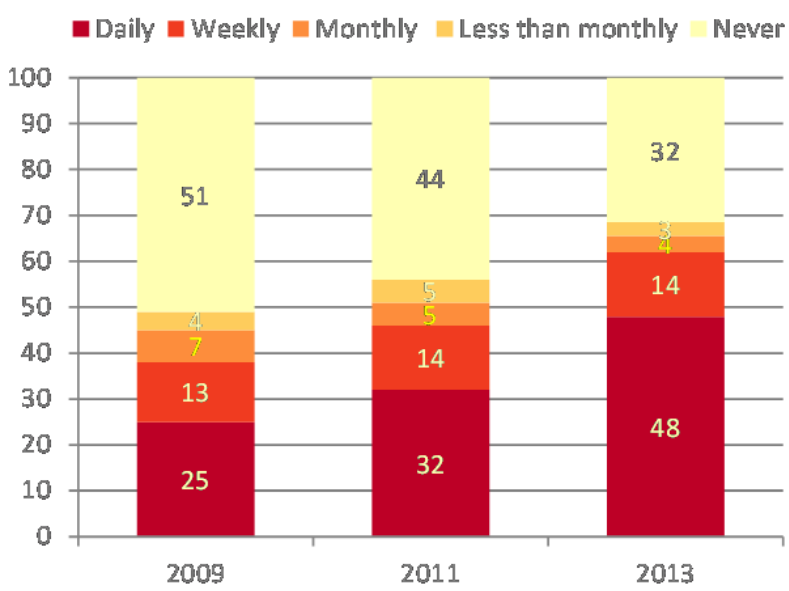

\subsection{How important is social networking?}

The importance of social networking to Australian internet users has increased slowly but steadily over the period. In 2009 just $7 \%$ rated social networking as 'very important'. This grew to $12 \%$ in 2013.

At the other end of the scale, half of internet users in 2009 thought that social networking was not at all important. This fell to a third in 2013.

\section{Further analysis}

\subsection{How often do you visit a social networking site by age, 2013}

Social networking is almost ubiquitous amongst $18-24$ year olds. Only $2 \%$ never visit a social networking site, with more than nine in ten doing so at least daily. This contrasts with the eight in ten of those aged sixty five and over who do not use a social networking site.

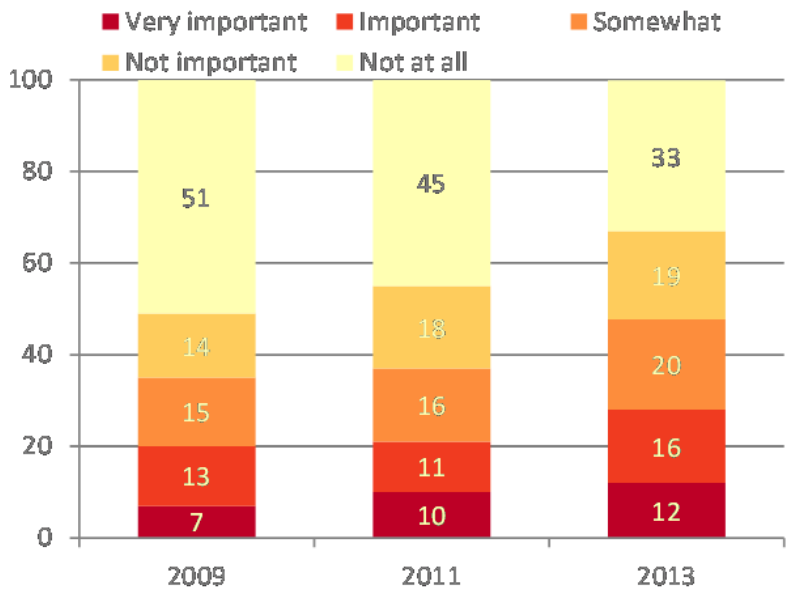




\subsection{How often do you visit a social networking site, selected countries, 2013}

Social networking varied quite markedly across the comparison countries. China was the only one of six countries where more than half of internet users never visited a social networking site. On the other hand nearly six in ten New Zealanders did so on a daily basis. Australians were the next biggest users of social networking, with two thirds visiting and just under a half doing so daily.

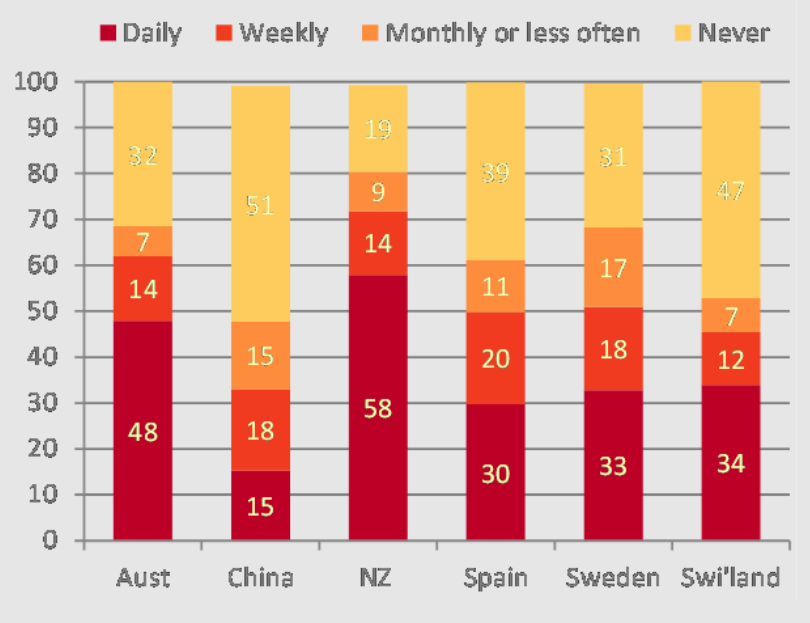




\section{The internet and the media}

One of the major debates sparked by the development of the internet has been the future of the traditional media industries. At present there is much concern regarding the future of newspapers and considerable activity in trying to develop business models to support quality online journalism. This section examines these issues and makes comparisons between internet users and non-users in their off-line behaviour.

To place the role of the internet as an information source in context, we asked participants about the importance of different kinds of media as a source of information. This section assumes a clearer delineation between internet consumption and that of traditional media than exists in practice. Where respondents are asked about newspaper reading or television watching they are referring to their offline behaviour. As the internet continues its development, this distinction will become increasingly difficult to make.

\subsection{For information in general how important is television?}

Television is an important information source for a majority of people whether they are internet users or not, although it is less important for internet users.

The main change between 2011 and 2013 is an increase in the importance of television for those who do not use the internet; $70 \%$ of non-users rated television important in 2013 , up from 57\% in 2011.

Overall, the importance of television for information has not changed greatly from 2007 to 2013.

\subsection{For information in general how important are newspapers?}

The proportion of internet users who described newspapers as important, or very important, sources of information dropped slightly between 2007 and 2009 (47\% to $39 \%$ ), rose slightly in 2011 to $43 \%$, and fell slightly again in 2013 to $39 \%$.

For non-users, opinions on the importance of newspapers was more defined in 2013: those who considered newspapers 'not important at all' increased from $4 \%$ in 2011 to $11 \%$ in 2013 , and those who considered them 'very important' increased from 16\% in 2011 to 23\% in 2013.
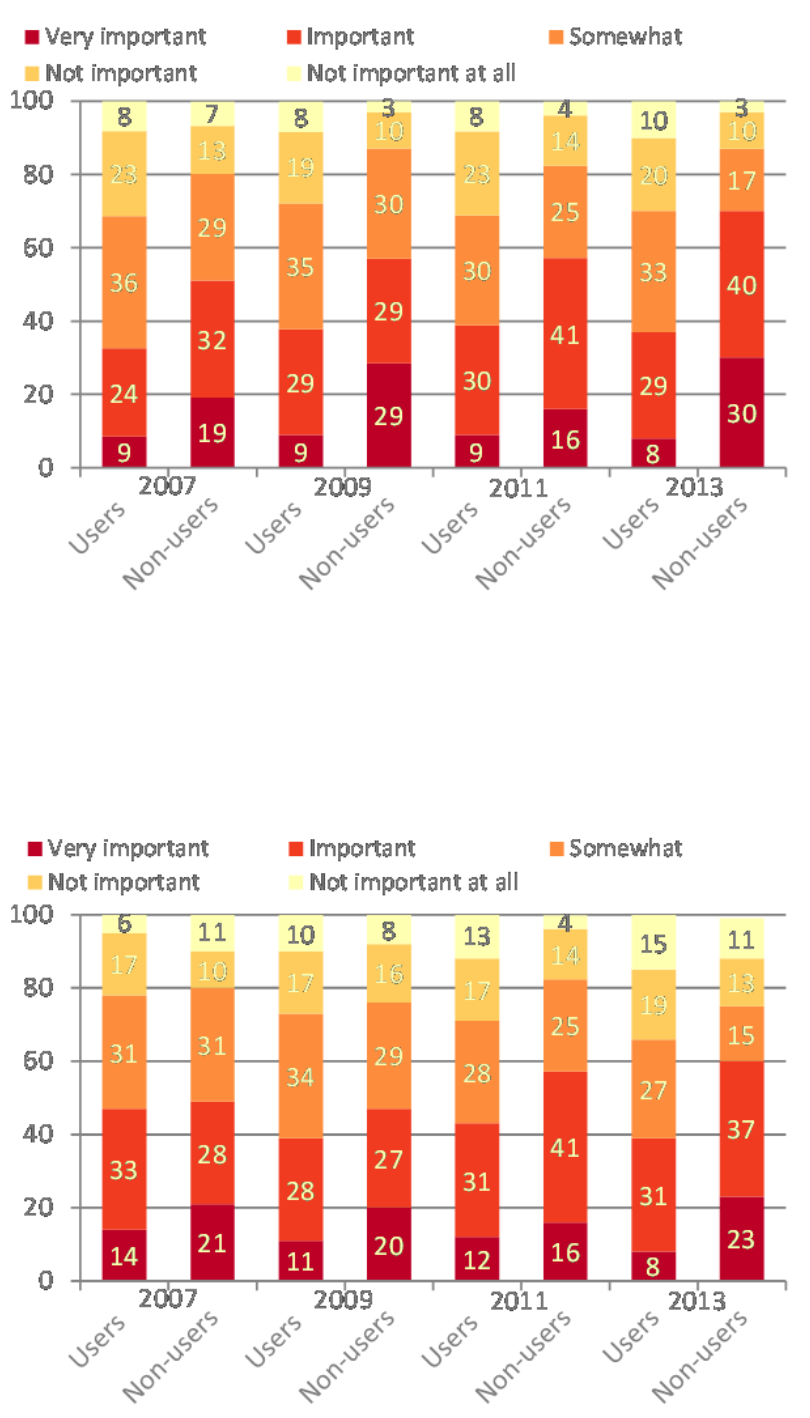


\subsection{For information in general how important is radio?}

The results for radio changed very little over the period of analysis.

In 2013, 42\% of internet users considered radio an important or very important information source, compared with $63 \%$ of non-users.

\subsection{For information in general how important are interpersonal sources?}

There was little change over the period of analysis.

Around nine in ten users and non-users in 2007, 2009, 2011, and 2013 regard interpersonal sources as at least 'somewhat important' sources of information.
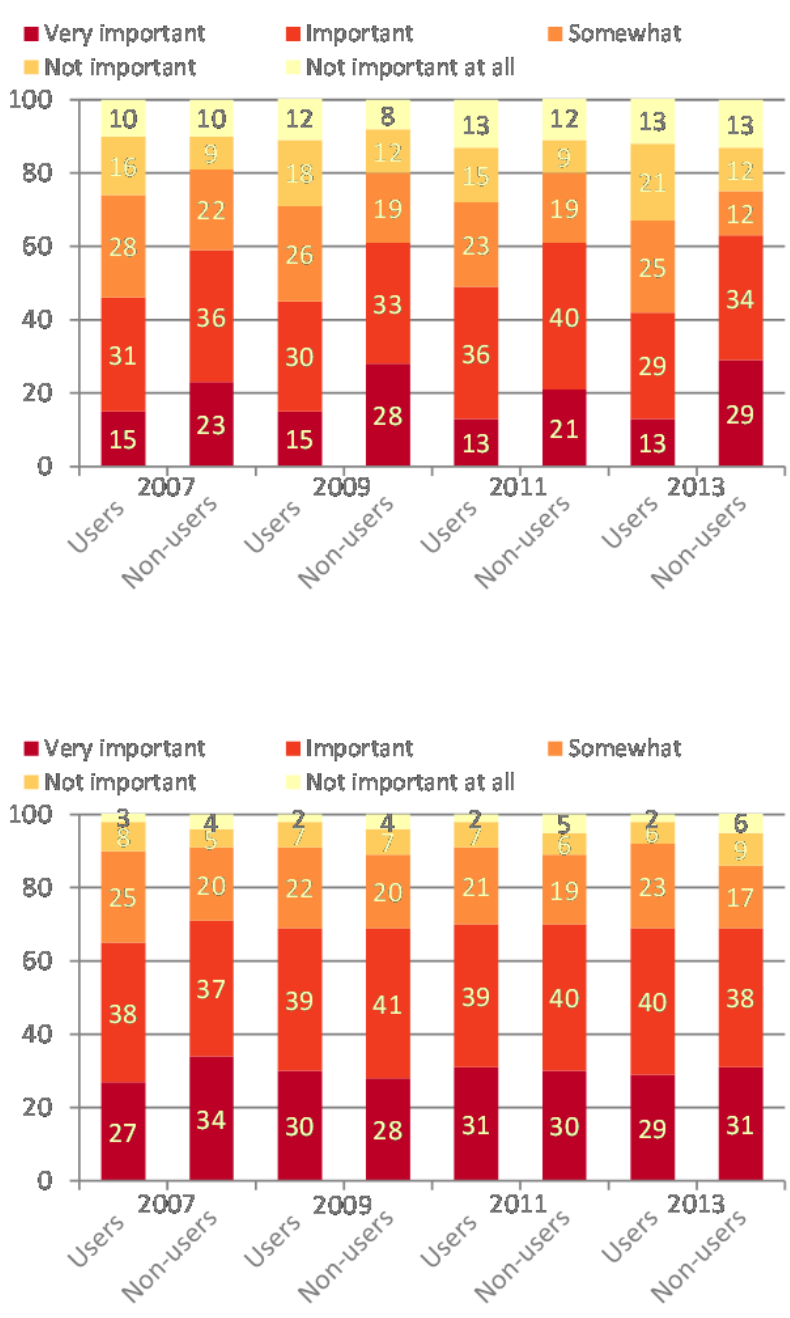

\subsection{For information in general how important is the internet?}

For users, the internet has become a very important source of information - more important than the traditional media of newspapers, radio and television - and this figure is steadily increasing.

Just over one in eight (82\%) of users described the internet as important or very important in 2013, up from $77 \%$ in 2011 . For television the corresponding figure is $37 \%$, for newspapers $39 \%$, and for radio $42 \%$.

The difference is even more marked when we look just at the 'very important' rating. The proportion of users rating the internet as very important (47\%) is more than three times that for radio (13\%) and almost six times that for newspapers (8\%) and television (8\%).

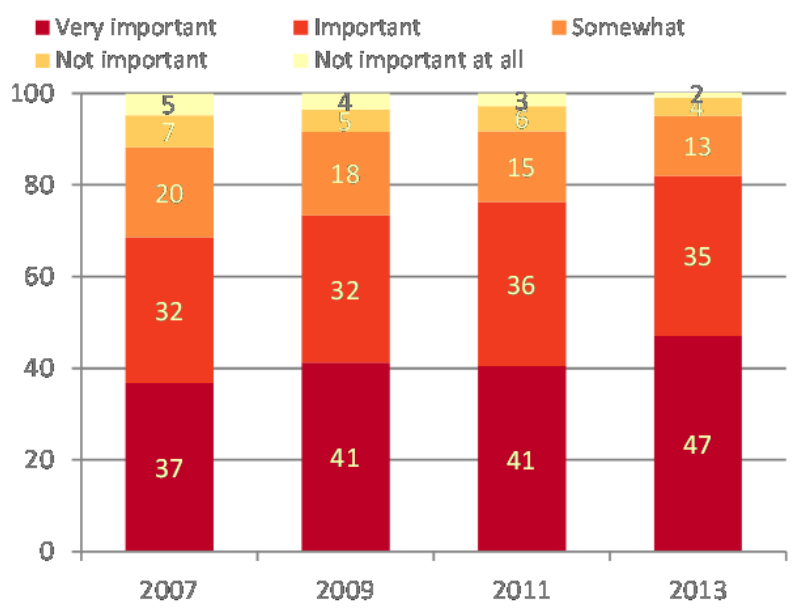




\section{Time spent on media}

This section examines the amount of time people devote to various media during a week and how internet users think that internet access has affected their use of various media.

\subsection{On average how many hours a week} do you spend watching television?

On average, internet users spend around a third less time than non-users watching television, which this stayed very consistent over the three periods.

Non-users recorded a slight increase in hours a week watching television, from 23 hours in 2011 to 24 hours in 2013.

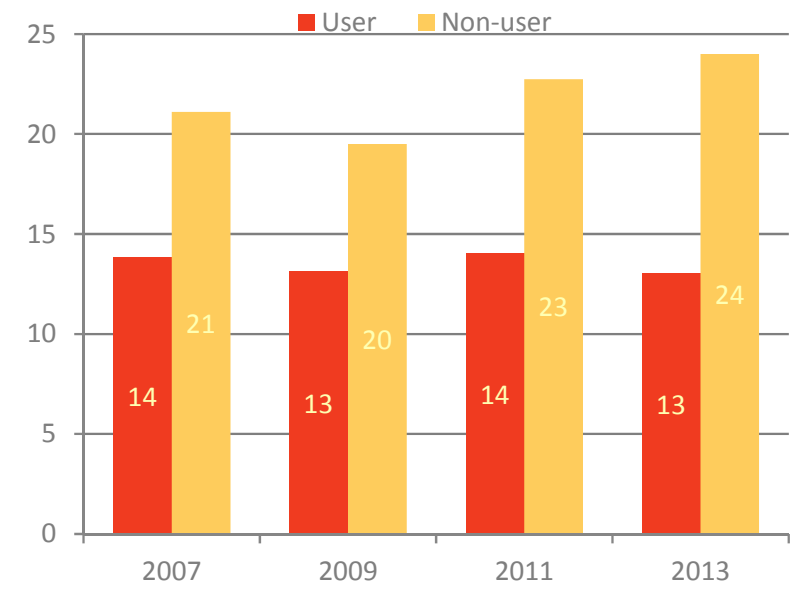

\subsection{On average how many hours a week} do you spend listening to radio?

The pattern for listening to radio is very similar to that for watching television, with non-internet users listening to around a third more radio on average.

In 2013, users listened to an average of 12 hours of radio a week, while non-users listened for around 17 hours a week.

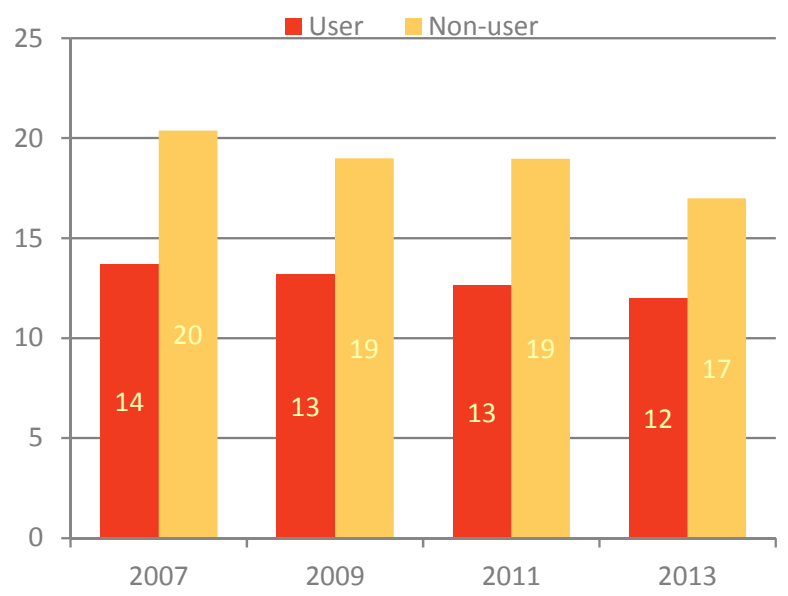




\subsection{On average how many hours a week}

do you spend reading newspapers?

Offline newspaper reading amongst internet users has fallen slightly over the period, from three and a third hours in 2007 to around two hours in 2013.

For non-users, newspaper reading has fluctuated, down to four hours in 2013 from six in 2011, four in 2009, and five in 2007.

In 2013, non-users spent twice as long reading newspapers as internet users.

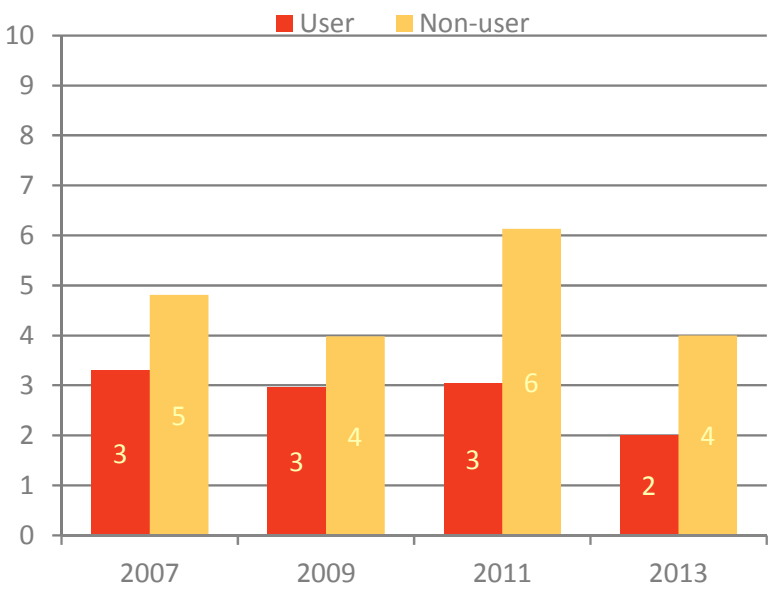

\section{Use of the internet for information seeking}

This section looks at how people seek information online.

\subsection{How often do you visit an official news site?}

Three in ten (31\%) of Australian internet users visited an official news site daily in 2013 , a slight increase from $28 \%$ in 2011 . A further one in five $(20 \%)$ visited an official news site weekly.

Just fewer than one in three never visit an official news site.

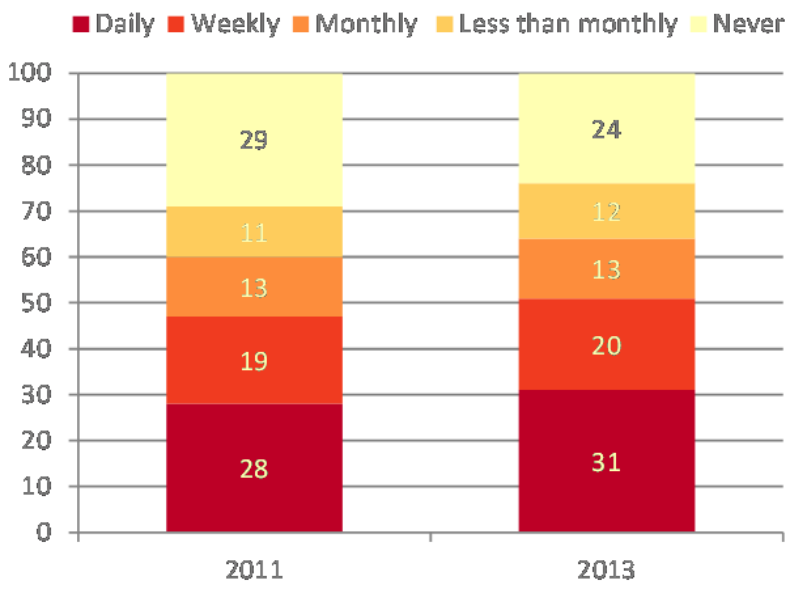




\subsection{How often do you visit a news blog?}

The proportion of Australians visiting news blogs grew strongly from in 2011 to 2013 (up from $39 \%$ to $52 \%$ ). Those who do visit news blogs are now doing so more frequently: $26 \%$ visited at least weekly in 2013 , compared with 15\% in 2011.

Australians are much more likely to visit an official news site than a news blog: in 2013, $76 \%$ of internet users visited official news sites, while only $52 \%$ visited news blogs.

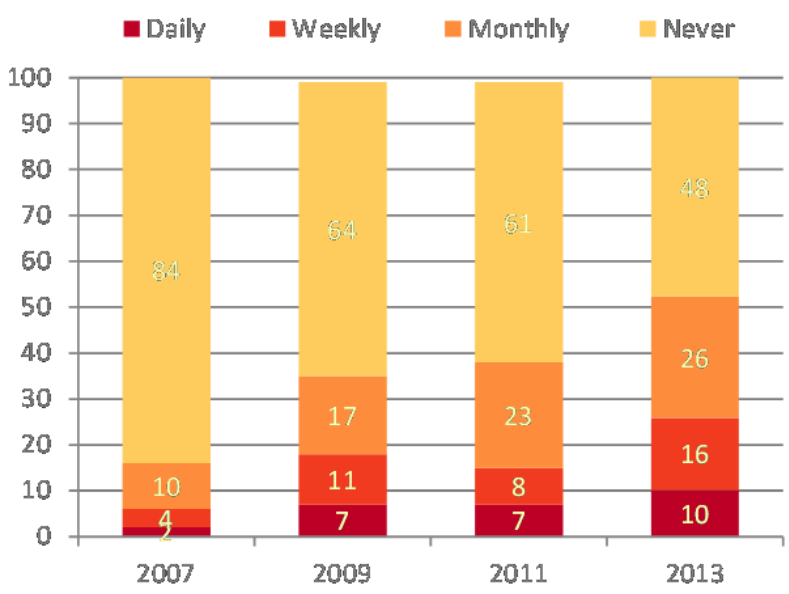

\subsection{How often do you check weather forecasts on the internet?}

The proportion of internet users checking weather forecasts online has been steadily increasing: $87 \%$ in 2013 , up from $81 \%$ in $2011,74 \%$ in 2009 , and $63 \%$ in 2007.

Just over four out of ten (41\%) internet users check weather forecasts daily.

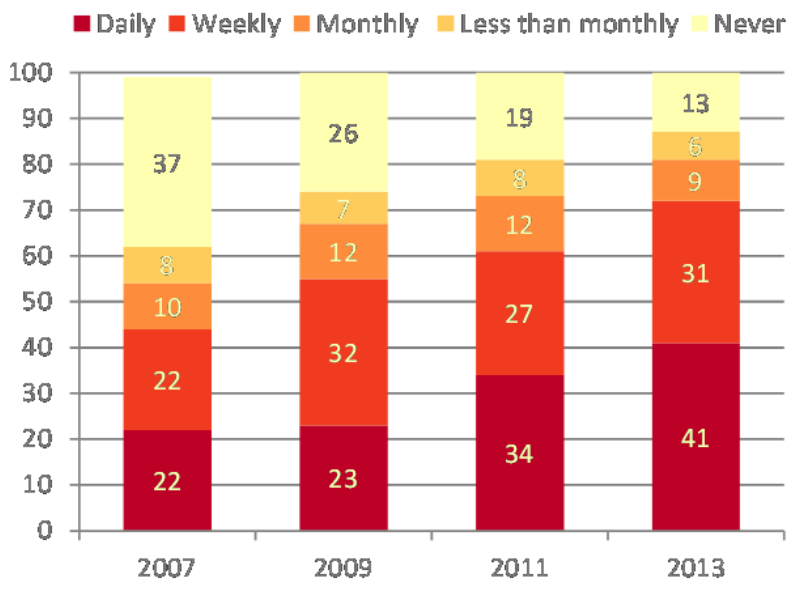

\subsection{How often do you look for health information on the internet?}

Looking for health information on the internet has increased over the period of analysis.

In $2013,84 \%$ of internet users looked for health information online, up from $78 \%$ in $2011,75 \%$ in 2009 , and $65 \%$ in 2007.

Of those who looked for health information in 2013, it was most common to do so monthly (32\%).

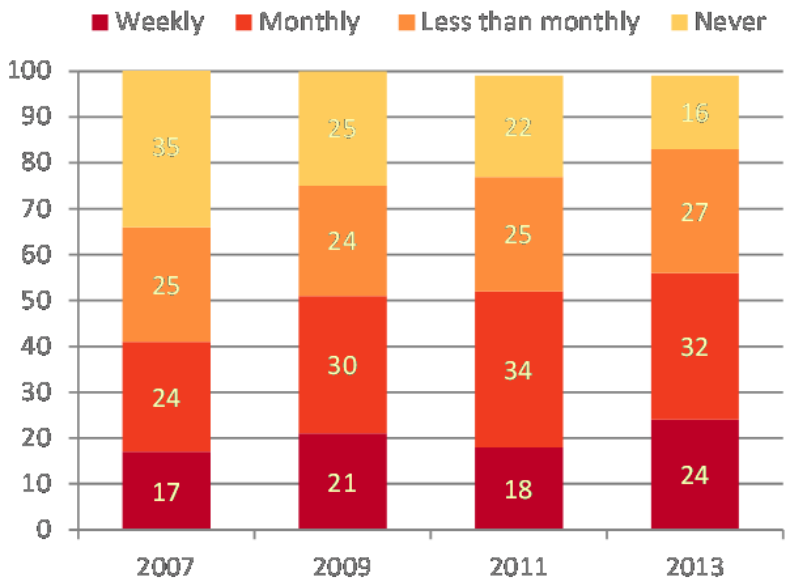




\subsection{How much would you be prepared to pay to read an online newspaper?}

The uncertain future of newspapers and the search for an online business model is a continuing public policy concern.

To investigate this issue we asked respondents whether and how much they would be prepared to pay to read an online newspaper.

A clear majority of Australians would not consider paying for an online newspaper (61\% in 2013), and only $11 \%$ would pay the cover price of a hard copy newspaper.

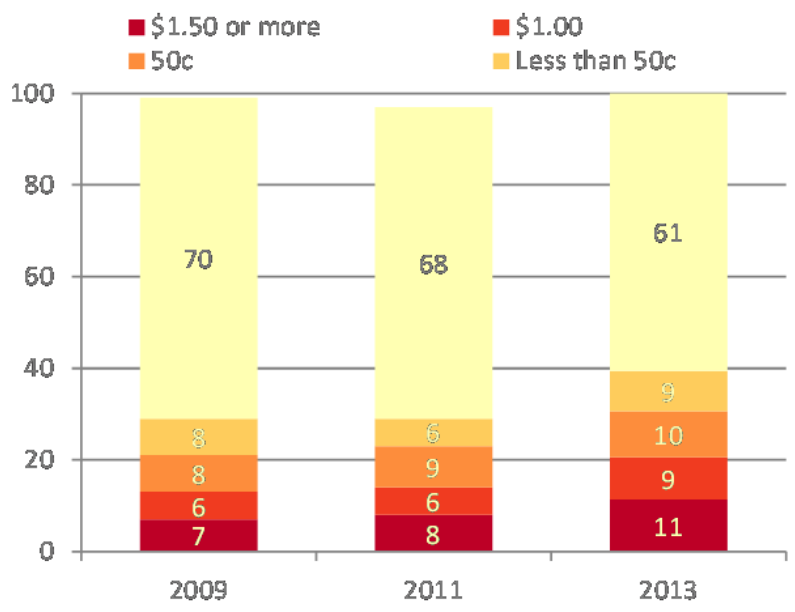

\section{Trust in media}

The ease with which information can be posted on the net by large numbers of people raises the issue of reliability and trust. This section examines this issue by looking at internet users' and non-users' perceptions of the reliability of information on the web and on other forms of media.

\subsection{How much of the information on the world wide web is reliable?}

There has not been a great deal of change in the response to this question over the period of analysis. Non-users are more likely to say that they don't know (24\% in 2013) and less likely to think that 'most of the information' on the web is reliable. In 2013 38\% of users chose this response compared to just $21 \%$ of non-users.

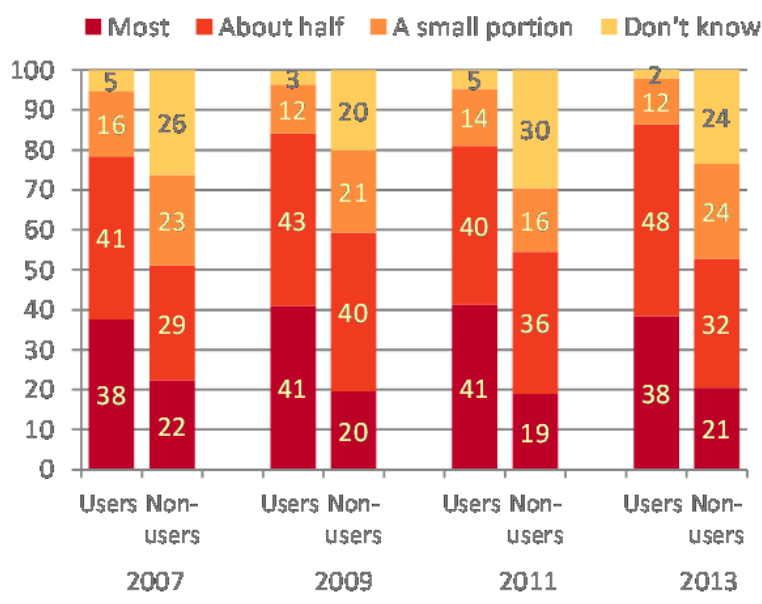




\subsection{How much of the information on the television is reliable?}

While in 2007 there was very little difference between internet users and non-users in their perception of the reliability of information presented on television, in 2009 internet users had become a little more trusting and non-users less so. This pattern was replicated in 2011 and 2013. More than a third of users felt most of the information on television was reliable compared to just one in five non internet users (35\% to $28 \%$ ). At the other end of the scale, $32 \%$ of non-users thought that only 'a small portion' of the information on television was reliable compared to $21 \%$ of internet users.

\subsection{How much of the information in newspapers is reliable?}

Internet users are much more likely than nonusers to think that most of the information in newspapers is reliable (43\% to $31 \%$ in 2013). This has been consistent over the three periods.
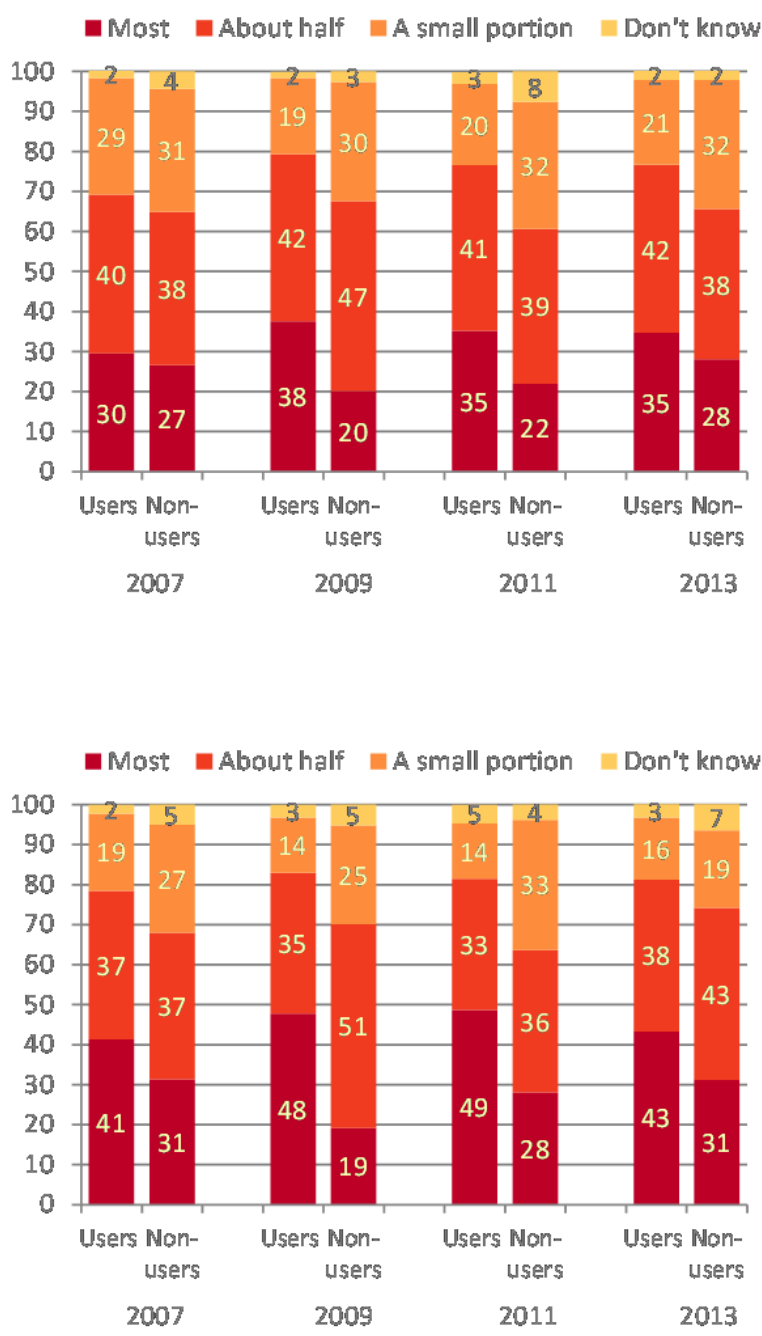

\section{Further analysis}

\subsection{Visiting official news sites and news blogs by age, 2013}

News blogs are a more important part of the news gathering behaviour of younger Australians than older Australians. Around three in ten 18-24 year olds visit an official news site daily compared to $14 \%$ visiting a news blog. A higher proportion of those aged 35-49 visit an official news site daily (36\%) but only $7 \%$ visit a news blog daily.

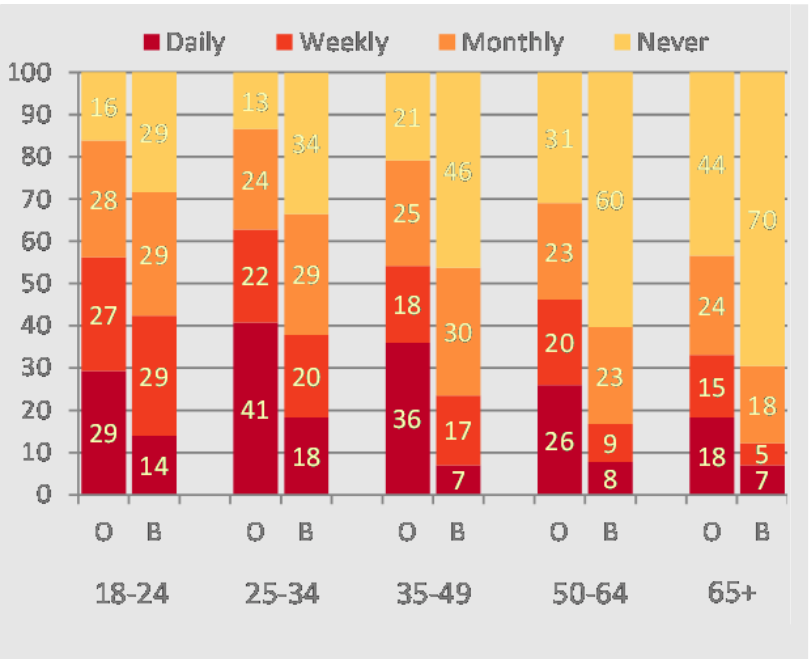




\subsection{Looking for news online, selected}

countries, 2013

In all of the comparative countries, the internet has become an important source of news. In China just under two thirds of internet users searched for news daily. In Spain the figure was $58 \%$ and New Zealand $53 \%$. Switzerland had the lowest proportion with $28 \%$ and just under a third of users never looking online for news.

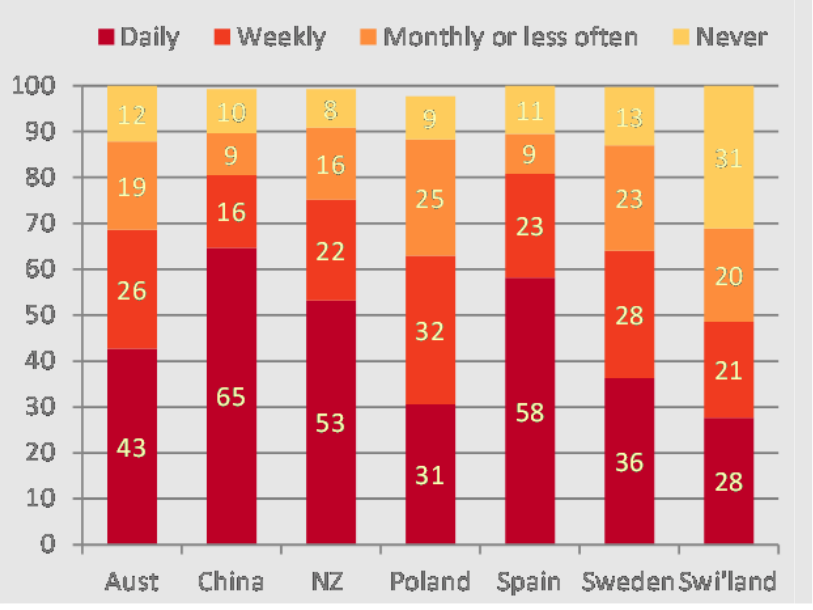




\section{The internet and entertainment}

The emergence of YouTube and other online video services has underlined the importance of the internet as an entertainment medium. This section looks at how Australians are using the internet to entertain themselves and pursue various hobbies and recreational pursuits.

\subsection{For entertainment in general how important is television?}

Television's role as an entertainment source has changed very little for both internet users and non-users.

Between 2011 and 2013, there was little change in the way internet users valued television as an entertainment source. However, non-users who rated television as very important for entertainment grew from $27 \%$ in 2011 to $47 \%$ in 2013 , compared with only $22 \%$ of internet users in 2013.

\subsection{For entertainment in general how important are newspapers?}

Non-users continue to be more likely to consider newspapers as an 'important' or 'very important' entertainment source than internet users.

In 2013, 17\% of internet users thought newspapers were an 'important' or 'very important' entertainment source compared to $43 \%$ of non-users.

\subsection{For entertainment in general how important is radio?}

Radio continues to be an important source of entertainment for both internet users and non-users.

Between 2011 and 2013, the proportion of non-users rating radio as very important halved, from $46 \%$ in 2011 to $23 \%$ in 2013 , while there was little change for internet users.

In 2013, $60 \%$ of non-users considered radio important or very important for entertainment, compared with $39 \%$ of internet users.
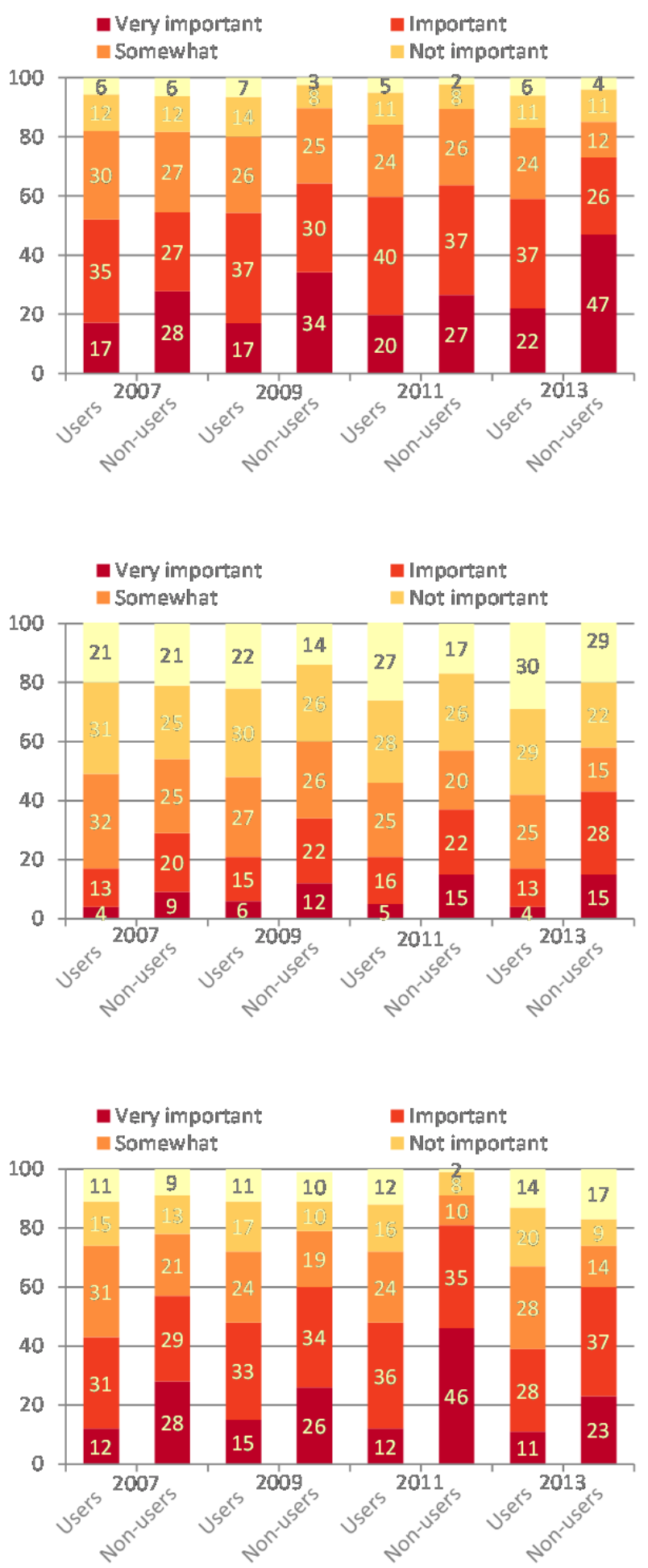


\subsection{For entertainment in general how} important is the internet?

The importance of the internet as an entertainment source has increased in each survey year.

In 2007, around a third of internet users considered the internet as an important or very important source of entertainment. This grew to $43 \%$ in $2009,45 \%$ in 2011 and $56 \%$ in 2013.

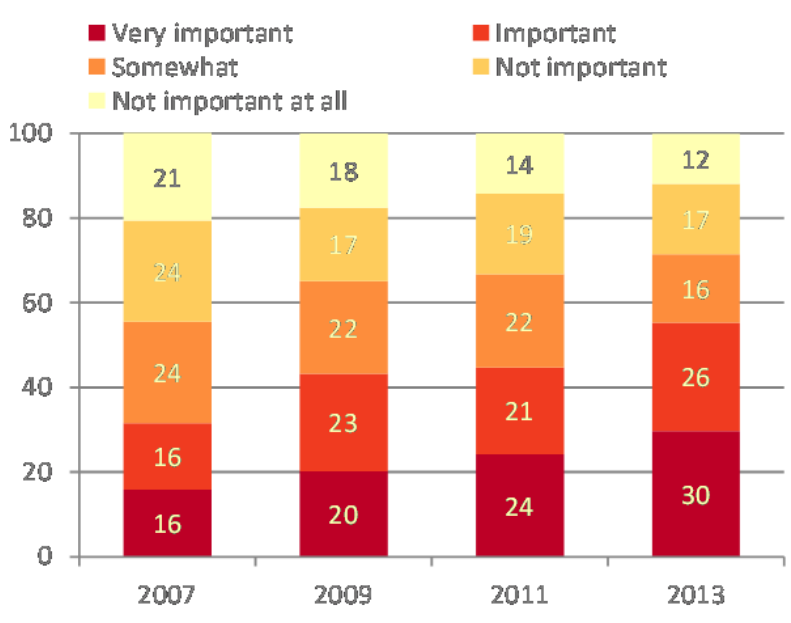

\section{The internet as entertainment}

This section looks at how people use the internet for entertainment purposes.

\subsection{How often do you download or listen to music online?}

Downloading and listening to music online has grown steadily over the period. In 2007 $27 \%$ were doing so at least weekly. This $35 \%$ in 2011 and then grew again to $42 \%$ in 2013. grew to $35 \%$ in 2009 , remained steady at

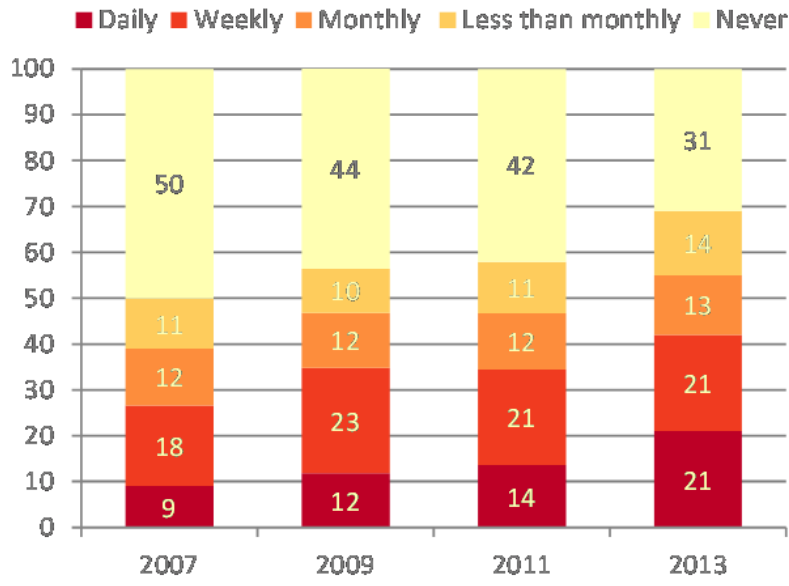

\subsection{How often do you listen to a radio station online?}

While use of the internet to listen to the radio has been growing, it is still not a very popular activity among internet users.

In 2013,38\% of internet users listened to a radio station online, up from $30 \%$ in 2011 , $69 \%$ in 2009 , and $27 \%$ in 2007 . Only $6 \%$ of internet users listen to online radio daily.
-Daily - Weekly a Monthly wess than monthly Never

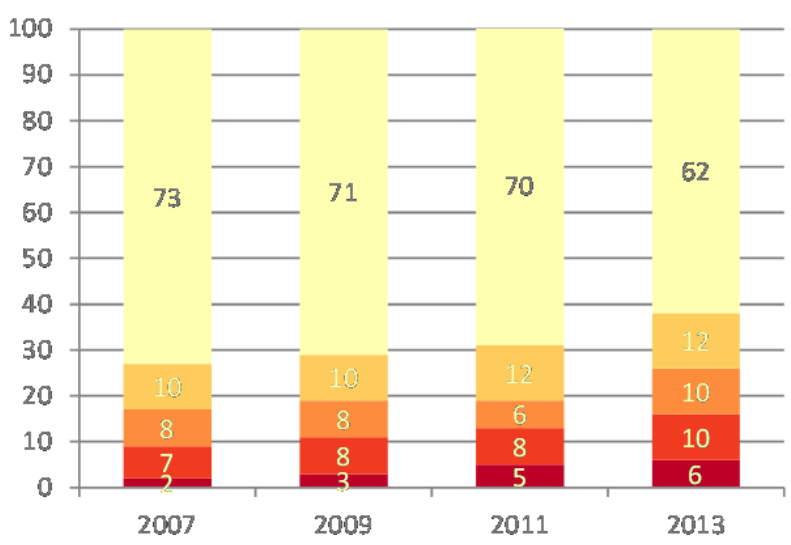




\subsection{How often do you bet, gamble or} enter sweepstakes on the internet?

Online gambling has remained a rare activity over the period of analysis.

Less than one in twenty of our respondents used the internet to gamble in $2007(5 \%)$, and this increased to $7 \%$ in 2009 , and less than one in ten in 2011 and 2013 (9\%).

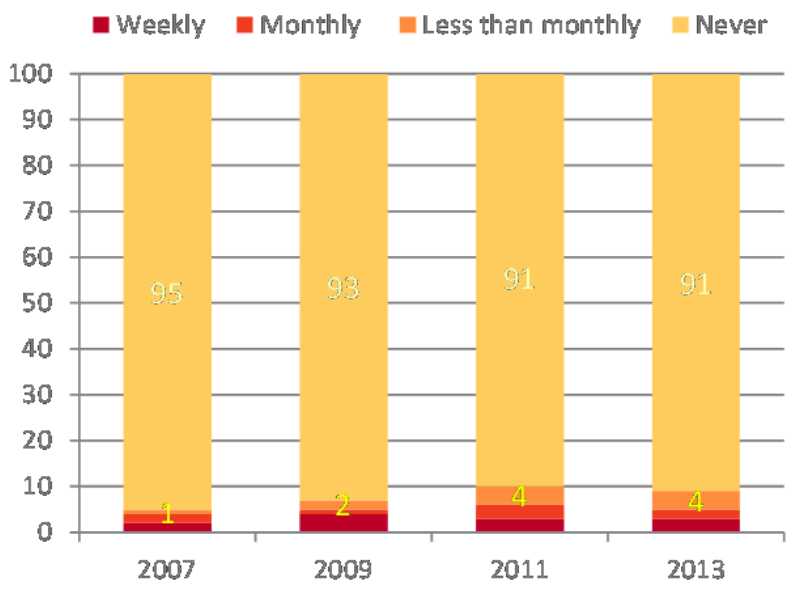

Daily a Weekly a Monthly a Less than monthly Never

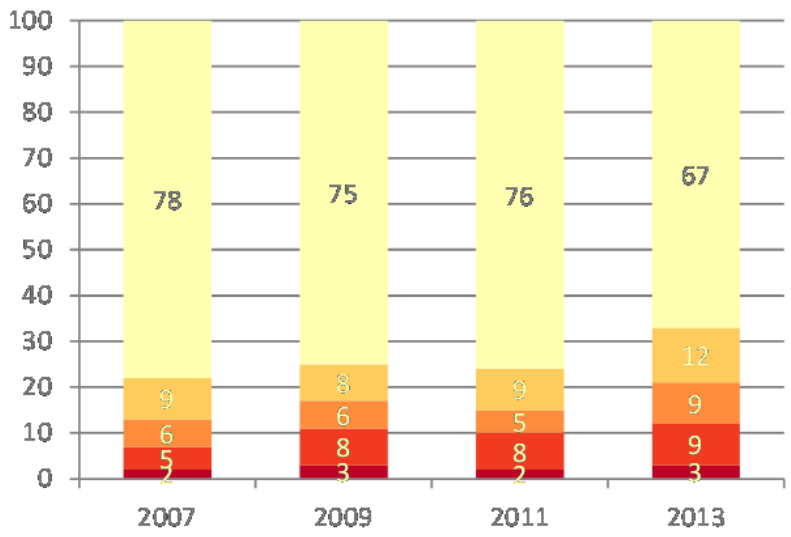
that they looked at sites with sexual content in 2013, a figure which has grown slowly over the period of analysis.

Just under one in ten do so at least weekly.

\subsection{How often do you download or listen to podcasts?}

Downloading or listening to podcasts has increased over the period of analysis: from $17 \%$ in 2007 to $28 \%$ in $2009,31 \%$ in 2011 , and 37\% in 2013.

Growth between 2011 and 2013 has been slight, with just $6 \%$ more internet users downloading or listening to podcasts in 2013 compared with 2011.

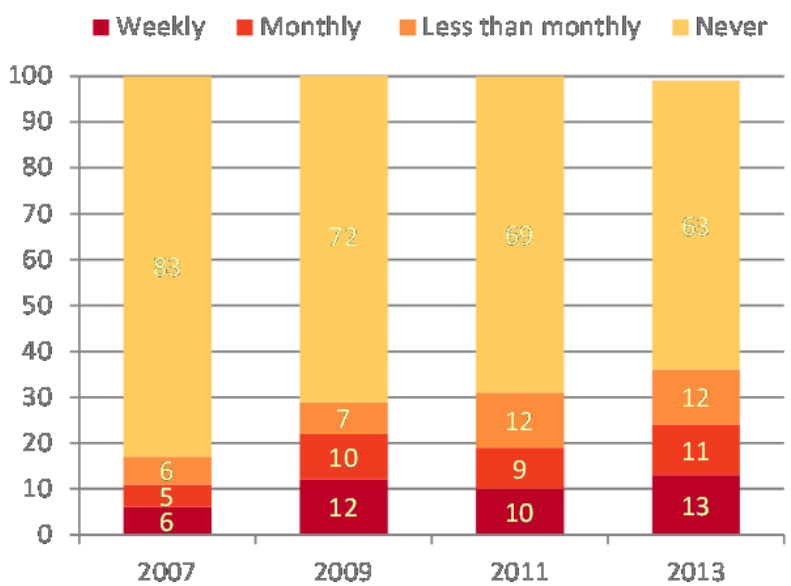




\section{Downloading entertainment}

This section presents findings from a series of questions that asked respondents in more detail about their consumption of online music, movies and other entertainment.

\subsection{Where do you usually buy your music?}

The proportion of users who usually buy online doubled from 2007 to 2009 ( $7 \%$ to $16 \%$ ), doubled again from 2009 to 2011 (16\% to $31 \%)$, then increased by $15 \%$ from 2011 to 2013 (31\% to 46\%).

By 2013, around half of internet users bought their music online, and half from a traditional 'bricks and mortar' store.

\subsection{How often do you use file-sharing services like bitTorrent?}

The use of file-sharing services has

fluctuated from $23 \%$ in 2007 , up to $27 \%$ in 2009 , back down to $23 \%$ in 2011 , and then up to $33 \%$ in 2013 .

Just 5\% of internet users in 2013 were using file-sharing services daily.
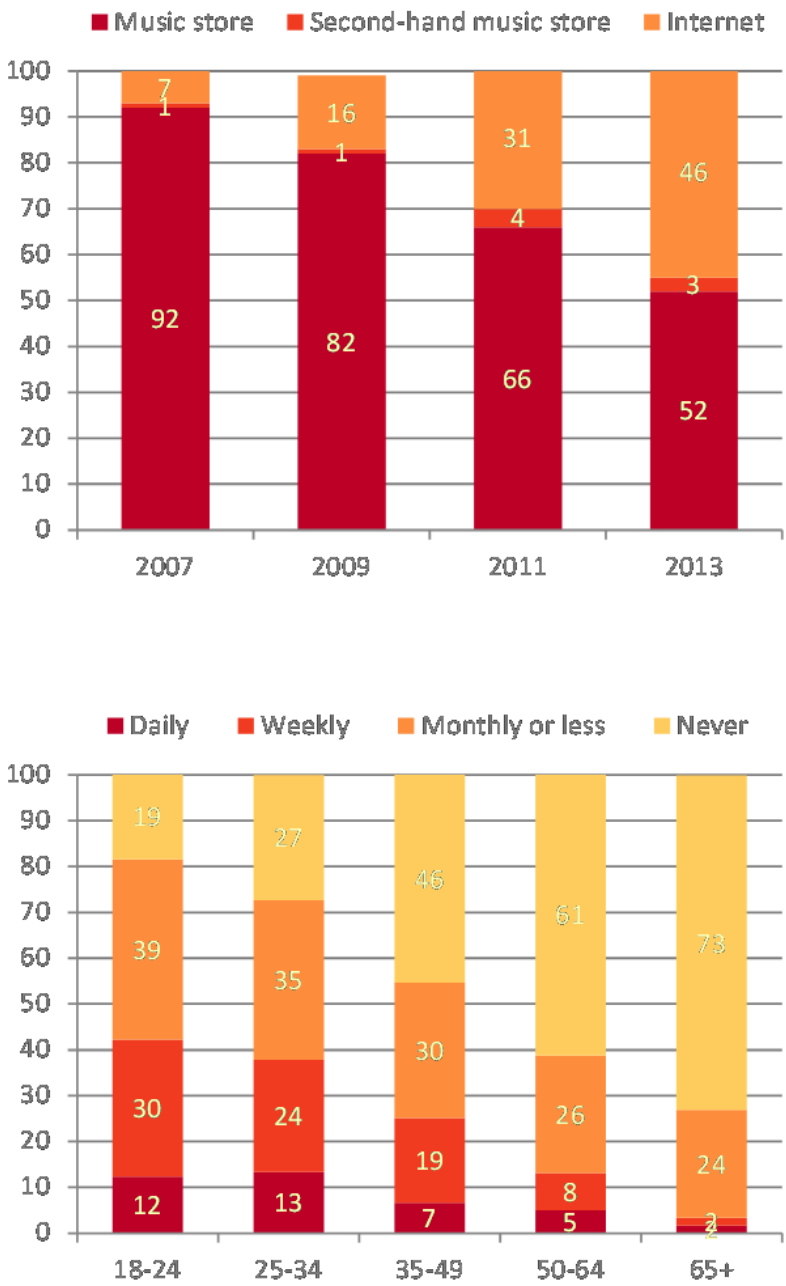

\subsection{Why do you use file-sharing services?}

There was little change in the most important reasons for using file-sharing services between 2011 and 2013: that they are free, give access to content, and simple and practical to use.

'Free content' remains the most pressing reason for using file-sharing services, with $42 \%$ rating this very important in 2013 . This was followed by 'content hard to get' (very important to $34 \%$ ) and 'simple and practical' (very important to $30 \%$ ).

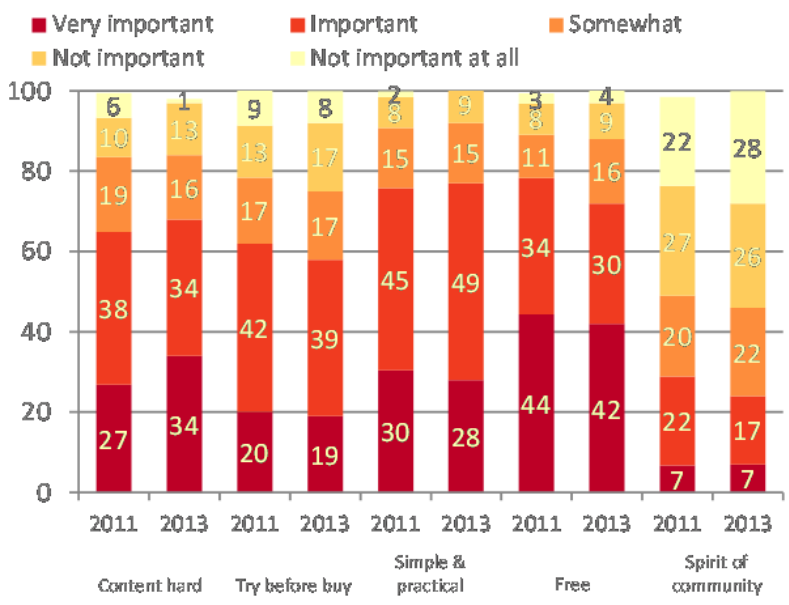




\subsection{How has the ability to download music from the internet influenced your purchases of music?}

There has not been much change on how people's ability to download music has influenced their purchases of music since 2007. In 2007 one in five users (21\%) said they bought less and this had increased to a quarter in 2011 (24\%) and 27\% in 2013. On the other hand, in $200718 \%$ said they now bought more which rose to $21 \%$ in 2011 and to $27 \%$ in 2013 . Interestingly the same proportion of users thought that being able to download increased their purchases of music as thought it decreased it.

\subsection{How has the ability to download} movies from the internet influenced your total consumption of movies via purchase from stores, video rental and visits to cinema?

There was more change for this question than for music consumption. In $200784 \%$ of users reported that the opportunity to download did not influence their purchasing of movies, but this fell to $74 \%$ in $2009,71 \%$ in 2011 and just $50 \%$ in 2013. Mostly this change was people buying less ( $9 \%$ to $16 \%$ to $19 \%$ to $34 \%$ in 2013 ) although in 2013 $15 \%$ said they now bought more.
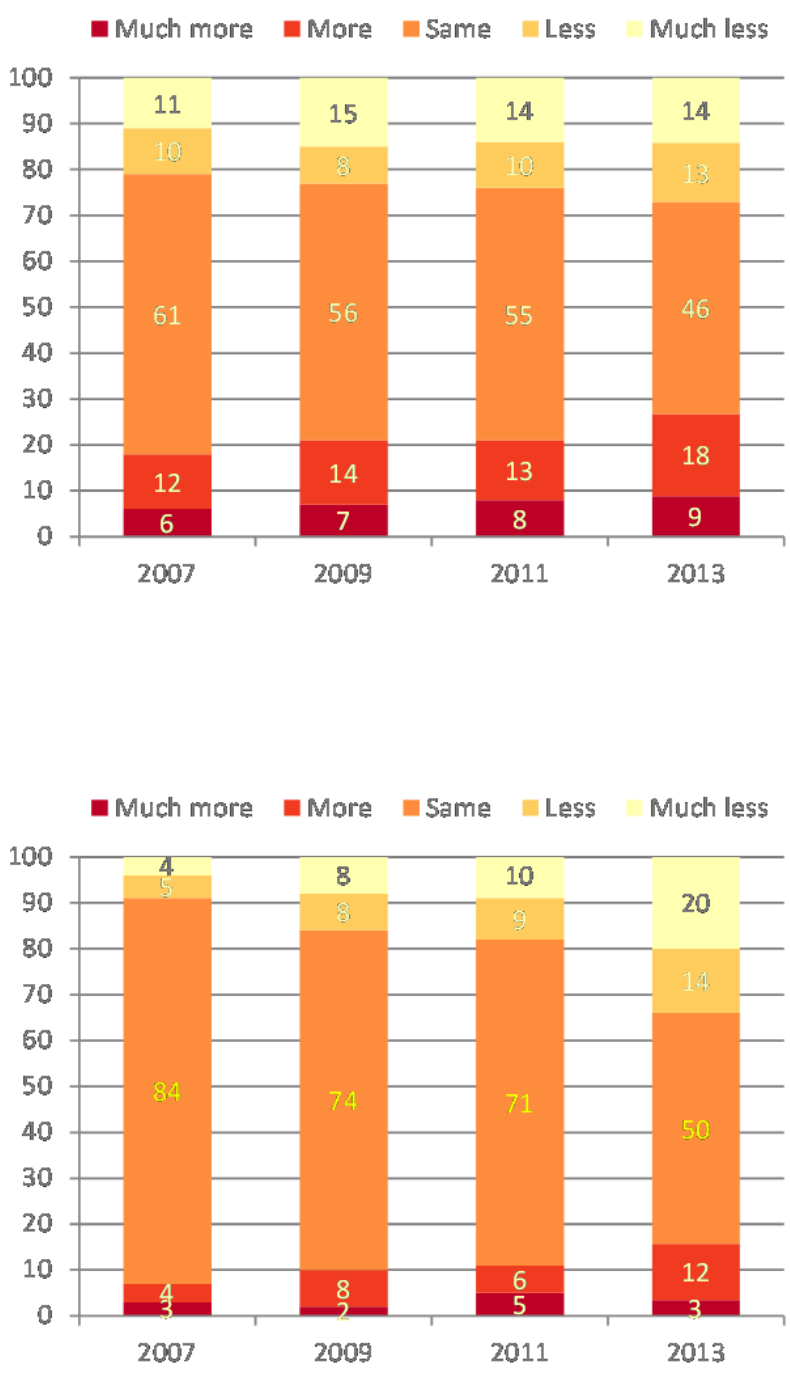

\subsection{How has the ability to download television programs from the internet influenced the amount of time you spend watching broadcast television?}

The proportion of users who felt that they watched less broadcast television due to being able to download television programs has increased over the period. In 2007 one in ten internet users said that the ability to download television programs had decreased the amount of broadcast television they watched. This increased to $18 \%$ in 2009 to one in five in 2011 and to one in three in 2013. The proportion who said that they watched more increased also from $5 \%$ in 2007 to $15 \%$ in 2013.

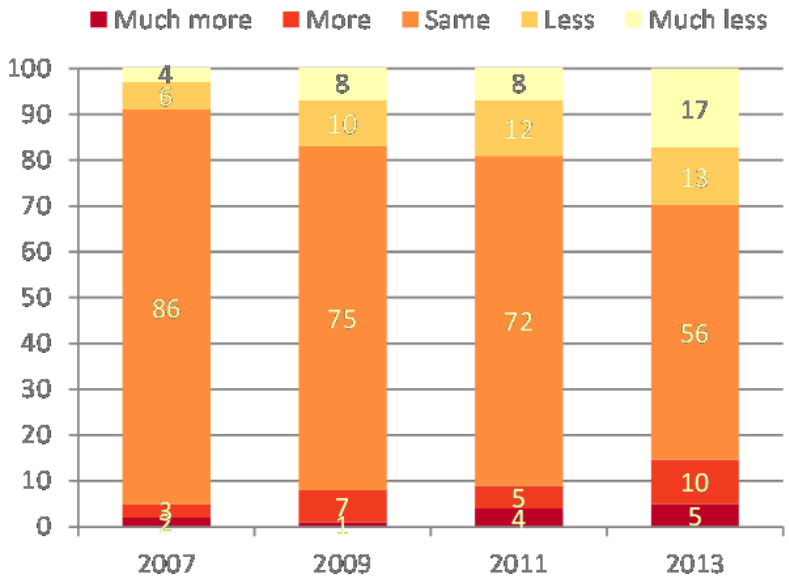




\subsection{Where do you get your digital music?}

Copying one's own CDs remains the main (54\%), followed by copying CDs from friends (42\%), and paid sites (37\%). way that people get their music in digital form

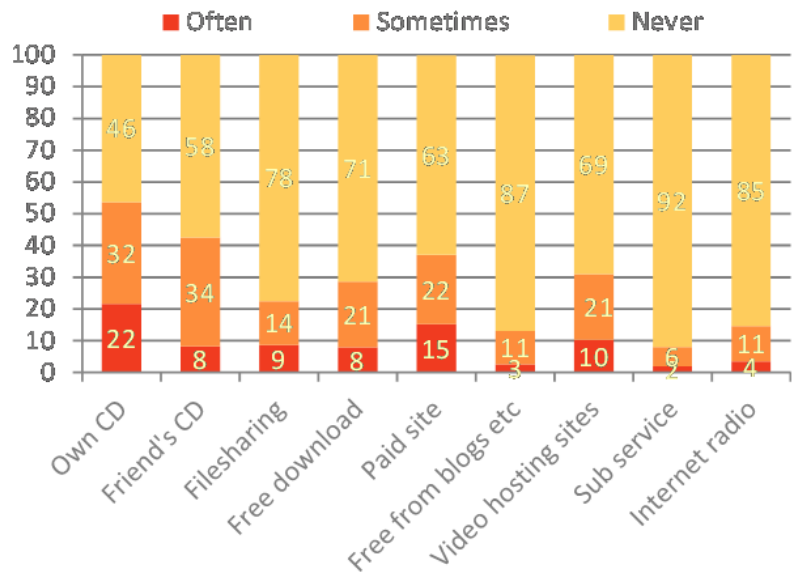

\subsection{Why do you use pay services to get music from the internet?}

Internet users in 2013 rated 'simple' and 'choice' as the most important reasons to use pay services to get music from the internet.

Ninety-four percent of users rated 'choice' as at least somewhat important to their use of pay services. The next most popular factors were 'simple' (93\%), 'legal' (90\%), 'high quality' (88\%), and 'price' (87\%). Only 69\% considered 'bonus content' to be important when using pay services to get music from the internet.

\subsection{Where do you get your digital movies?}

Copying or downloading movies is still a minority activity. Video hosting sites were the most popular option, with $32 \%$ using their services, while $23 \%$ watched a friends' DVD, and $19 \%$ watched their own DVD.

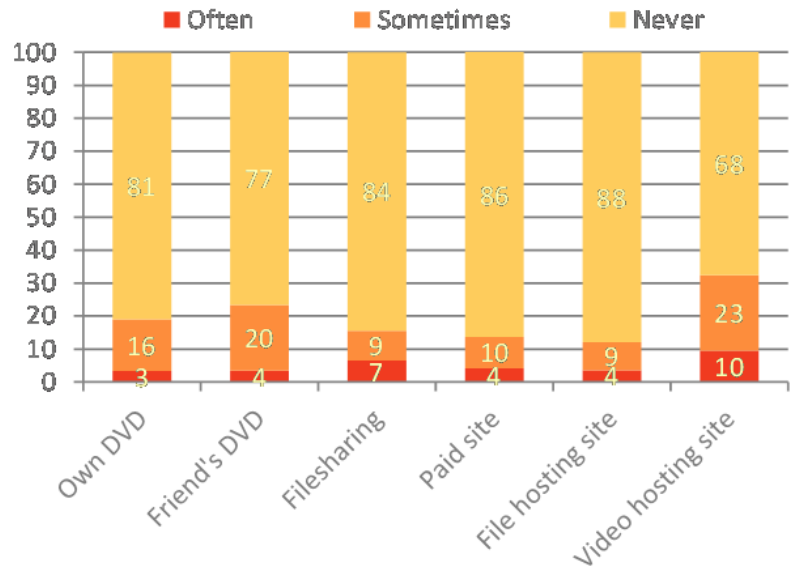




\subsection{If a boxed DVD or CD set was on} sale for $\$ 40$, for what price would you consider downloading a digital copy instead?

There has been some change in people's willingness to substitute 'hard-copy' products for digital between 2007 and 2013.

Half of our internet users (49\% in 2013 compared to $59 \%$ in 2011) would not consider downloading music or movies instead of buying hard copy at any price. A small proportion (7\%) would be prepared to pay more than $\$ 30$.

\section{Further analysis}

\subsection{Weekly hours of television viewing by how often watch television while online, 2013}

For all age groups those who often watch television while on the internet watch more television overall than those who never do. The difference between these groups is greater for younger age groups. Those aged 18 to 24 who often watch television while on the internet watched four times more television on average than those who never watched television while online.

\subsection{Downloading or streaming video, selected countries, 2013}

Of the five countries for which we have data, Australia has the highest incidence of downloading or streaming video. One in five Australians does this daily, with a further three in ten weekly. Spain has the second highest usage followed by New Zealand and Switzerland. Sweden has a considerably lower level of usage.
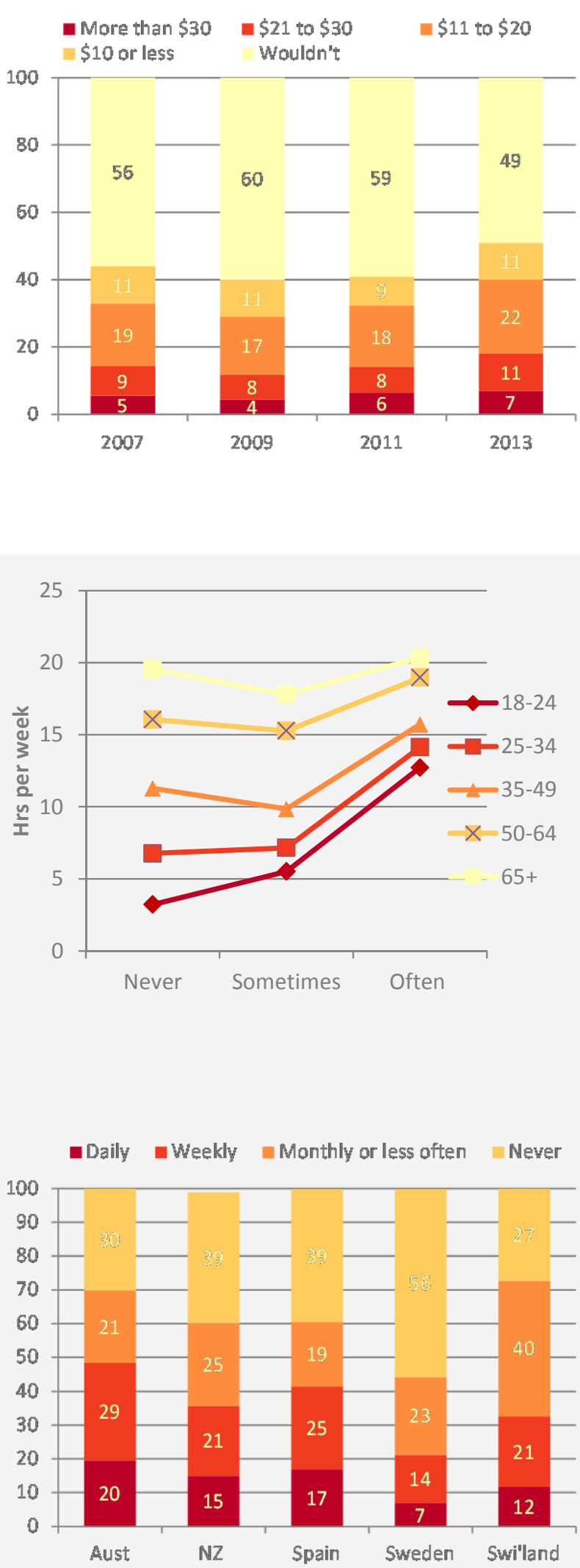


\section{Creative uses of the internet}

We are interested in people's creative uses of the Internet, and particularly in the role of Internet users as producers of content. What are the characteristics of those people who are producing online content? How is creative activity related to age, gender, experience and skills or speed of access?

There are also a series of further issues we are keen to pursue: the influence here of the diffusion of broadband, and any factors that may be hindering take-up; the effects of internet usage on the consumption of other media; the uptake of social web technology; video usage; news consumption online and how it is changing; and the impact of the 'always on' element of broadband.

People's creative uses of the net are of interest for two broad and related reasons:

- Creative uses tend to require more skill on the users' part and are an important marker of increasing digital literacy;

- Increasing user-generated content implies that users are gaining more from their online experience and that the resulting increase in online content will also enrich the online experience of others.

\subsection{How often do you post your own} content (pictures, video, writing) that you created?

More than half of Australian internet users post content that they have created. Nearly one in ten do so daily while a further $17 \%$ post weekly.

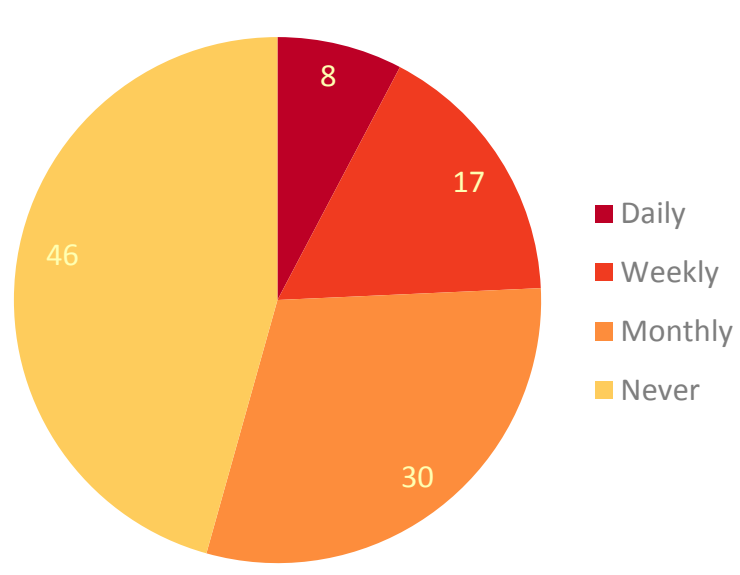

\subsection{How often do you re-post or share} links or content created by others?

Just less than two thirds of Australian internet users share content created by others. Fourteen percent do so daily with a further $21 \%$ sharing weekly.

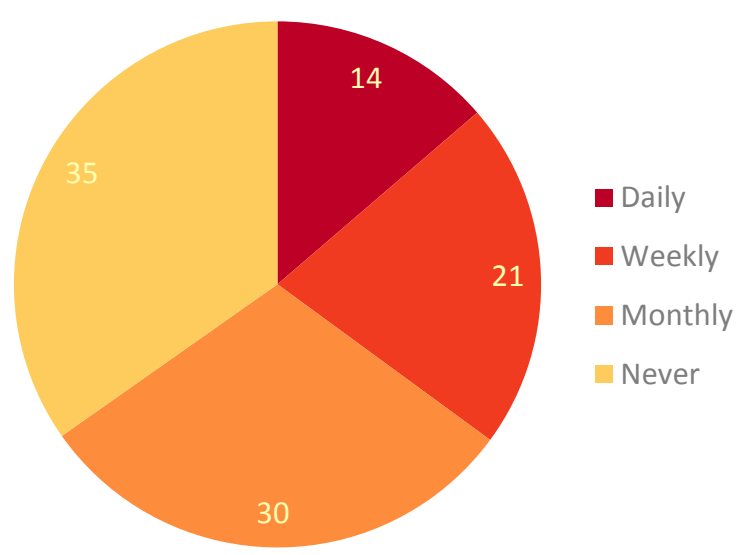




\section{Attitudes to the impact of the internet on respondents' creativity and productivity}

\subsection{How do you feel your Internet access has affected your work performancel productivity?}

There has been very little change over the period of analysis - respondents on the whole are positive about the effect of internet use on their productivity.

In all years, more than half of users felt that internet access had either improved their productivity: either a lot (29\% in 2013) or somewhat (40\% in 2013).

Just four percent felt the internet had negatively influenced their productivity.

\subsection{The internet enables me to share} creative work I like with others

Although in earlier years, sentiment about sharing creative work fluctuated, there has been little change between 2011 and 2013.

Around half of internet users in 2013 agreed that the internet enabled them to share creative work they liked with others: $53 \%$, up from 47\% in 2011.
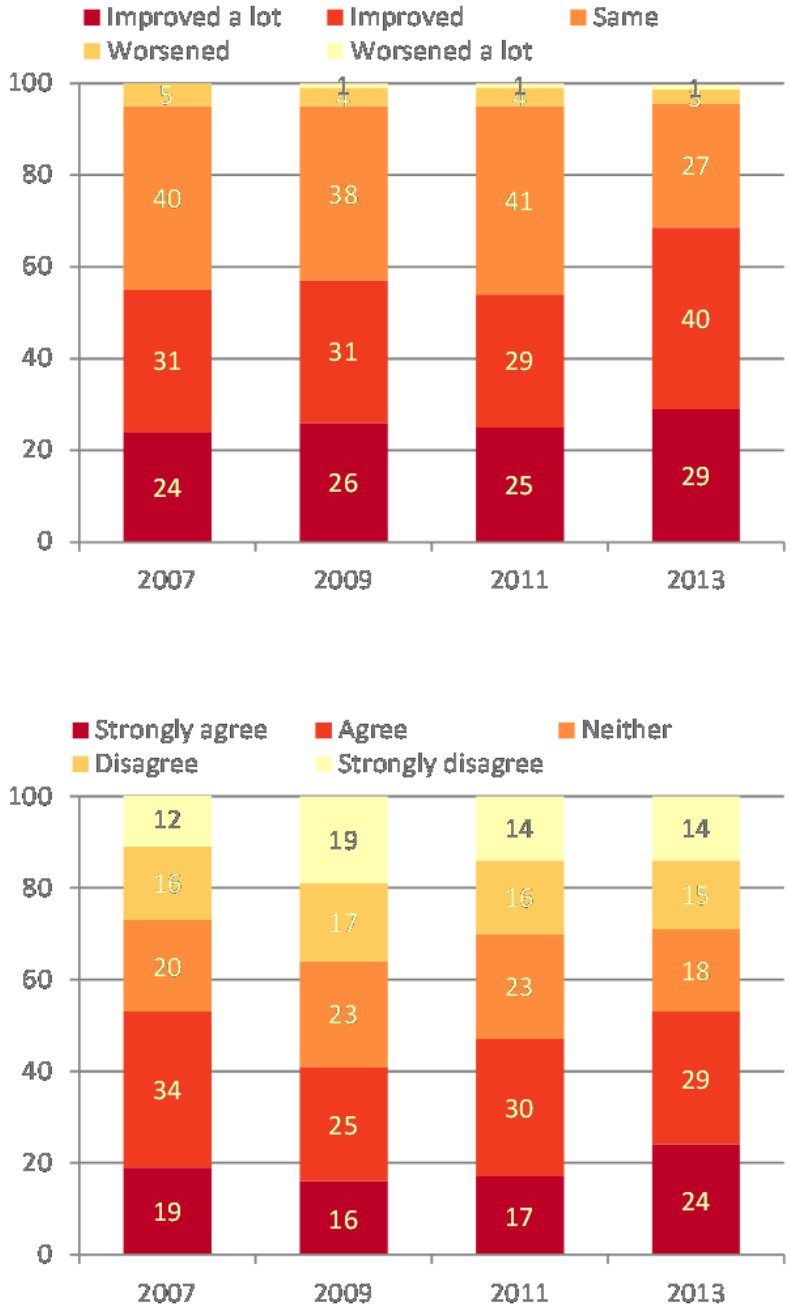

\subsection{The internet enables me to share my own creative work with others}

The same pattern was evident for this question: after initial fluctuations, this had evened out by 2011.

In $2013,48 \%$ of users agreed that access had enabled them to share their own creative work, up from $41 \%$ in 2011 . Those who strongly agreed that the internet was important increased from 15\% in 2011 to $21 \%$ in 2013.

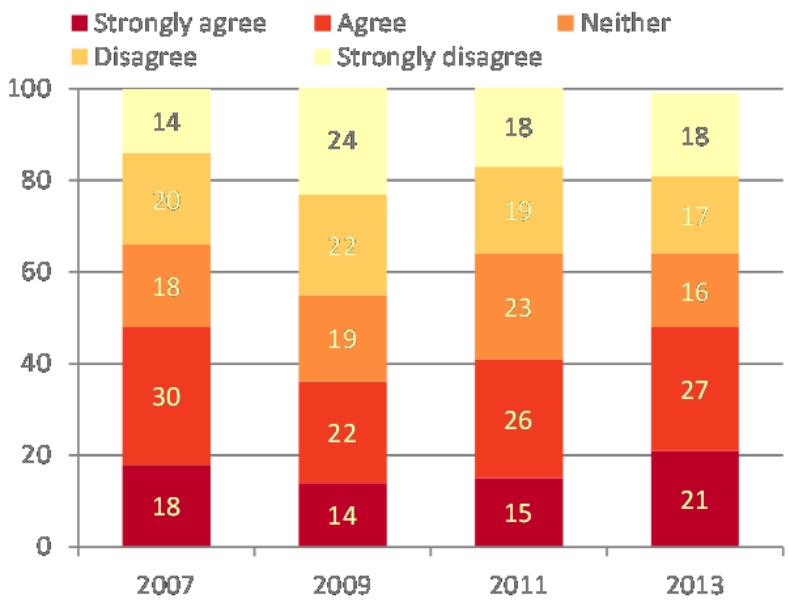




\subsection{The internet has encouraged me to produce my own creative work and share it with others}

Throughout the period of analysis, roughly one in four respondents agreed that the internet has encouraged them to produce and share their creative work: $24 \%$ in 2007 , $25 \%$ in $2009,26 \%$ in 2011, and $27 \%$ in 2013.

The majority of respondents did not feel that the internet had actively encouraged their creative work.

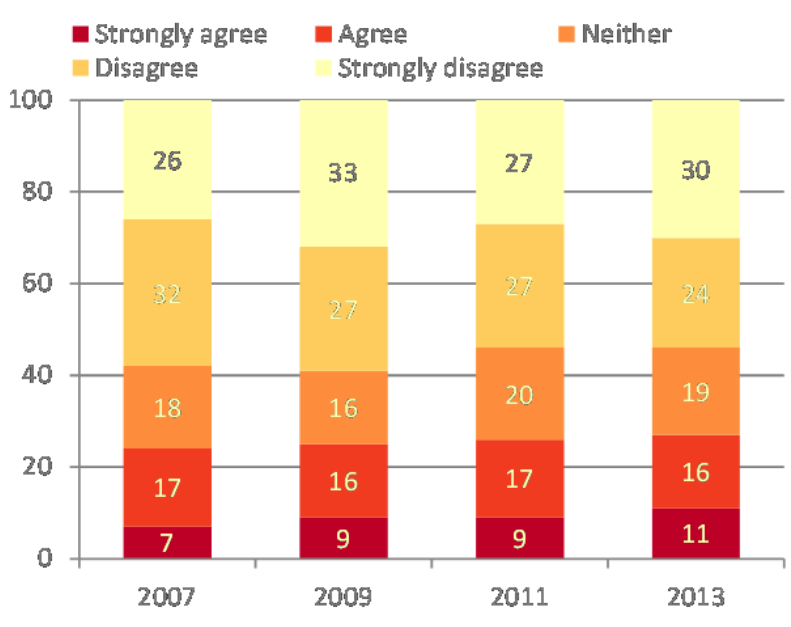

\section{Further analysis}

\subsection{How often do you post your own} content (pictures, video, writing) that you created, by age, 2013?

Younger Australians are more likely to post their own content than older Australians. Less than one in five 18-24 year olds never posted content they had created compared to nearly three-quarters of those aged and 65 and over. Forty two percent of the youngest cohort were posting at least weekly as were $37 \%$ of $25-34$ year olds.

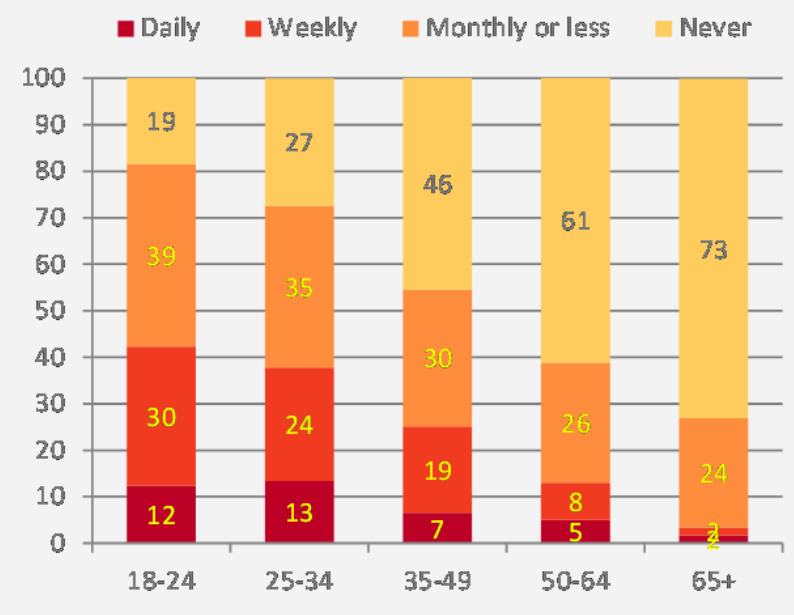




\section{$6 \quad$ Internet politics and policy}

We asked a series of questions about peoples' attitudes to the internet and politics, and the broad issues of contemporary internet policy and regulation. In general, non-users were more sceptical than users about the internet's capacity to empower citizens. Perhaps more importantly, a sizeable proportion of non-users said they didn't know what impact the internet was having on politics and the role of citizens. Respondents generally supported the National Broadband Network and the regulation of the Net.

\subsection{By using the internet people like you can have more political power}

Both internet users and non-users were generally sceptical about the idea that the internet could give people more political power.

While in 2007 a third of users (34\%)

disagreed that the internet could give you more political power, in 2009 just under a half of users disagreed (49\%), in 2011, 38\% disagreed, which remained the same in 2013.

Non-users were slightly more sceptical: $45 \%$ disagreed that the internet could give you more political power in $2007,54 \%$ in 2009 , $41 \%$ in 2011 , and $56 \%$ in 2013.

\subsection{By using the internet people like you will have more say about what the government does}

In 2007, just under a third of users agreed that the internet can give users more say about what government does (32\%), with $17 \%$ of non-users agreeing with this proposition.

In 2009, fewer users agreed (26\%), while more non-users agreed (23\%). In 2011, 33\% of users and $31 \%$ of non-users agreed, and in $2013,37 \%$ of users and $32 \%$ of non-users agreed.
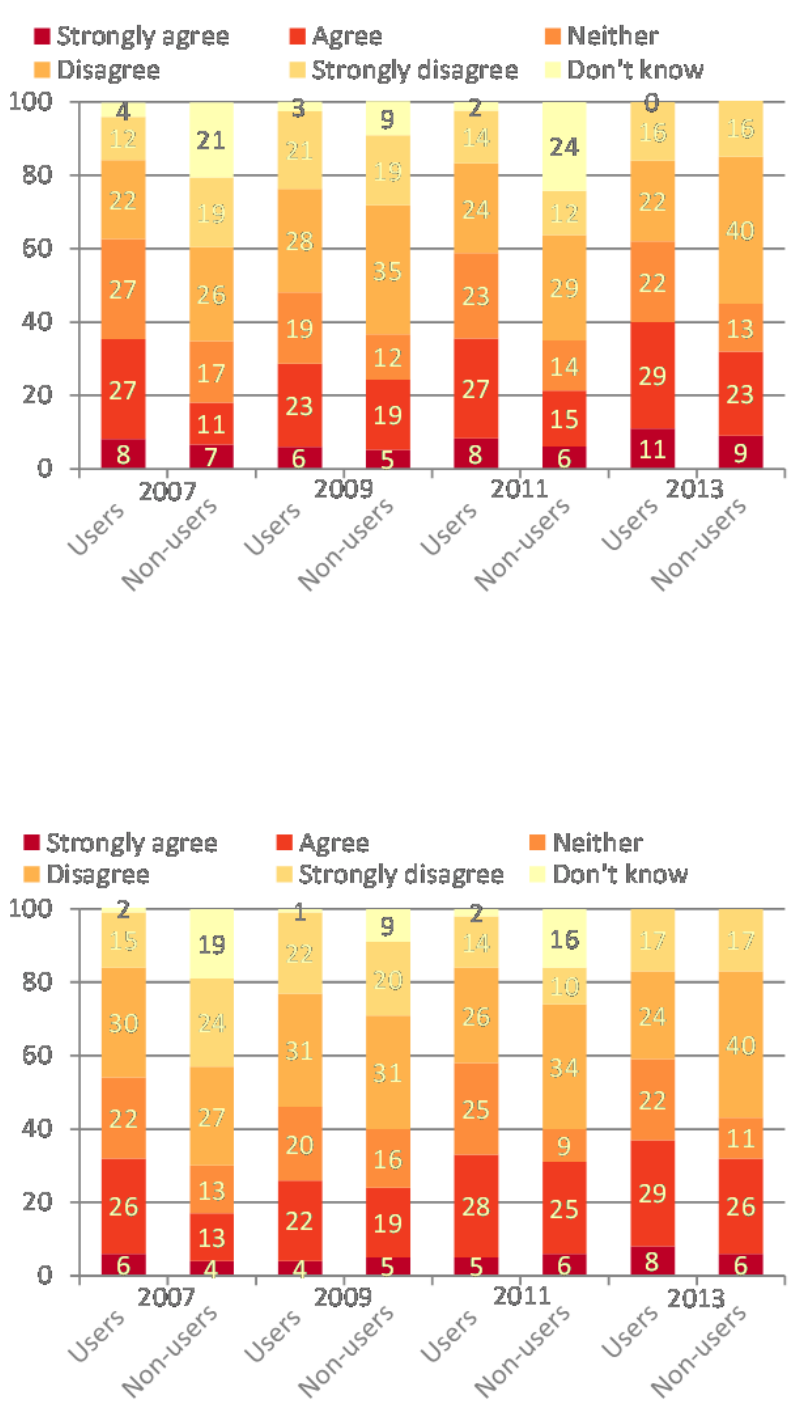


\subsection{By using the internet people like you can better understand politics}

The pattern over time was similar to the previous statement.

In $2013,57 \%$ of users agreed that the internet helps them better understand politics, up from $50 \%$ in 2011 and $44 \%$ in 2009 , which was slightly down from $51 \%$ in 2007.

For non-users, most agreed in 2009 (33\%), compared to $29 \%$ in $2013,27 \%$ in 2011 , and 26\% in 2007.

\subsection{By using the internet public officials} will care more what people like you think

Around a quarter of users agreed with this statement in 2007 (25\%) and 2009 (24\%), while around three in ten did in 2011 (31\%) and 2013 (35\%).

Agreement among non-users was greatest in 2013 (31\%), compared to $28 \%$ in $2009,21 \%$ in 2011, and 20\% in 2007.

\subsection{The internet has become important} for the political campaign process

A majority of both internet users and nonusers agreed that the internet has become important for the political campaign process in 2013 (75\% and 67\% respectively). Aside from non-users in 2011, this statement has grown each year for both groups.
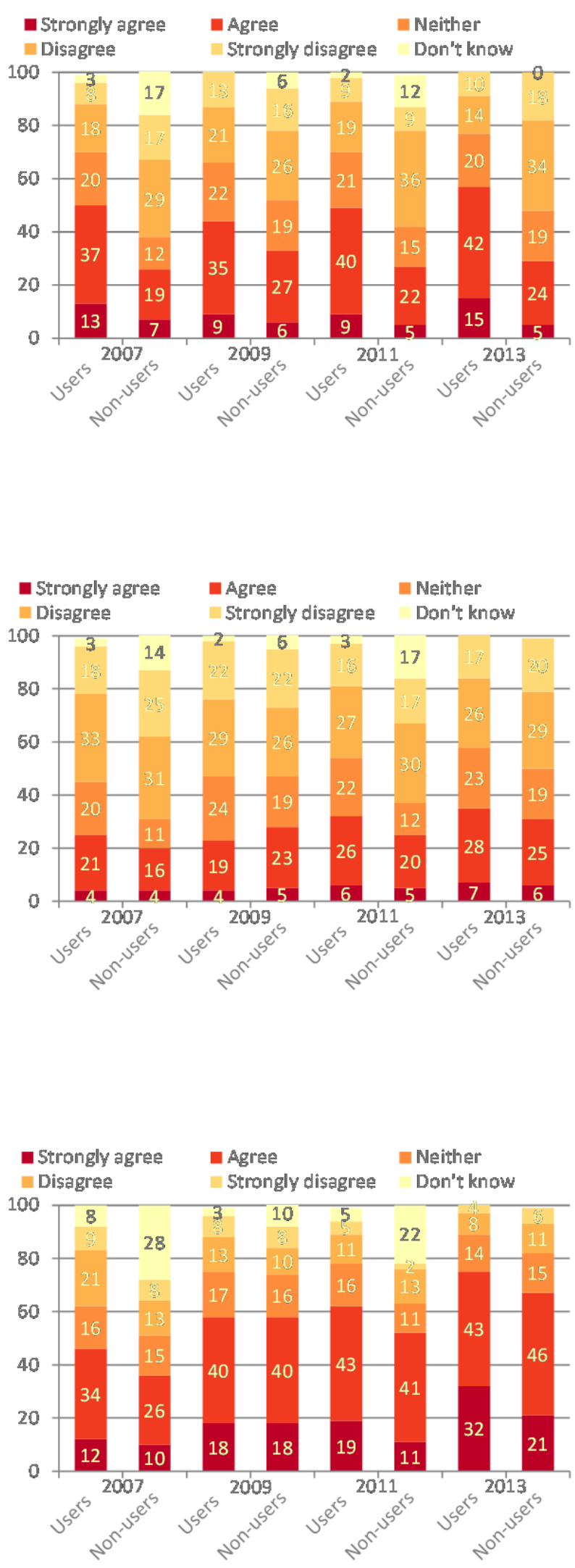


\subsection{The government should regulate the}

internet more than it does now, 2013

There is a stark contrast in attitudes to internet regulation between internet users and non-users. A clear majority of non-users believe the government should regulate internet more than it currently does (59\%) while a bare majority of users believe the opposite (51\%).

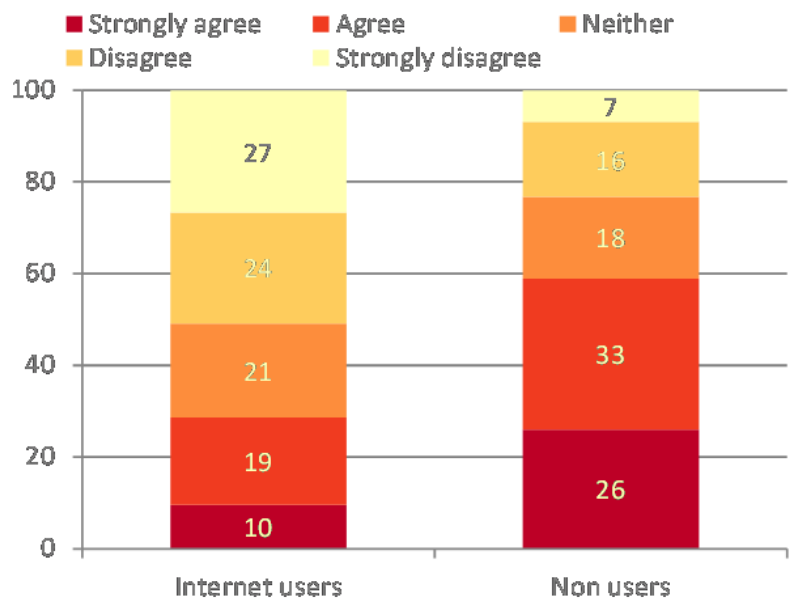

\subsection{People should be careful what they} say about politics on the internet.

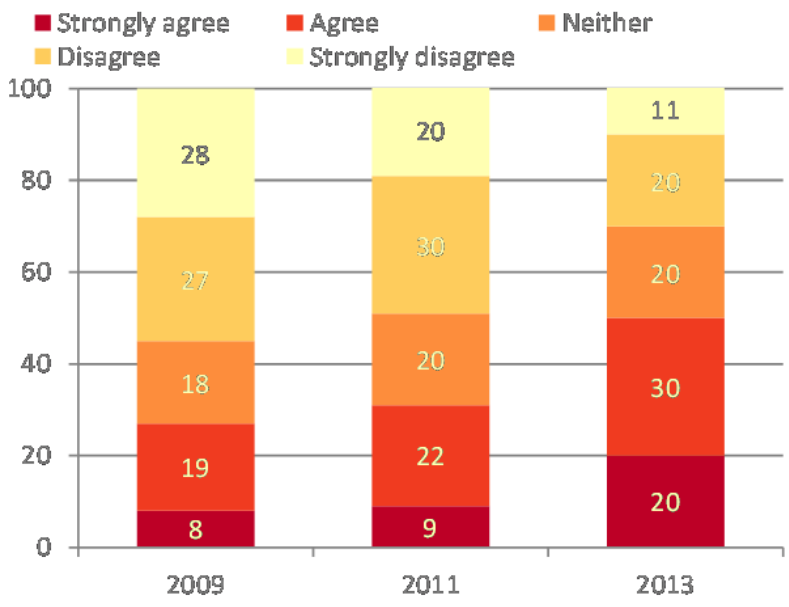

Australians are increasingly more convinced that people should be careful what they say about politics on the internet.

In 2009, $27 \%$ of Australians agreed or strongly agreed with the statement, which grew to $31 \%$ in 2011 , and $50 \%$ in 2013 .

\subsection{People should be free to criticize} their government on the internet.

Australians overwhelmingly agree people should be free to criticize government online. Almost four in ten strongly agree while a further $36 \%$ agree. One in ten (9\%) disagree. There was little change from 2009.

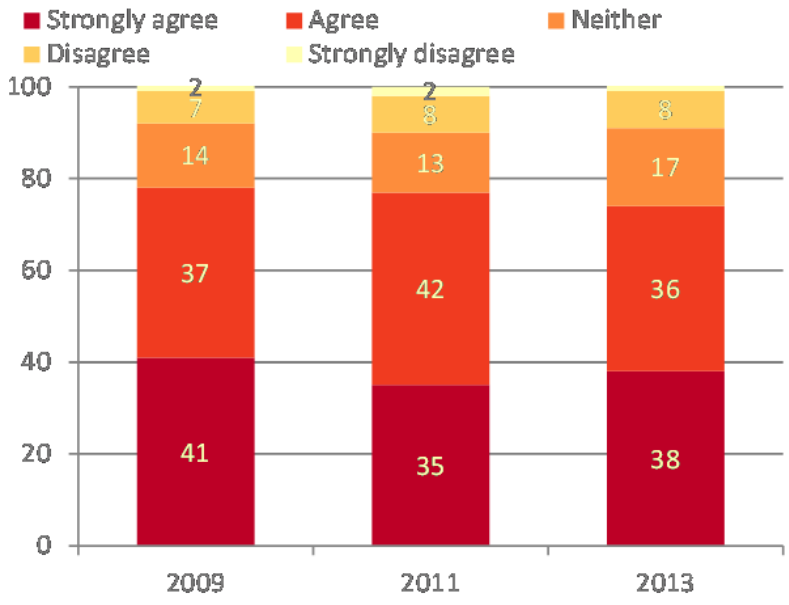




\subsection{People should have the right to express their opinion on the internet.}

Most Australians agree that people should internet, although this sentiment has decreased slightly since 2009.

In 2009, $84 \%$ of Australians agreed or 2013. have the right to express their opinion on the strongly agreed with the statement, which decreased to $83 \%$ in 2011 , and $74 \%$ by

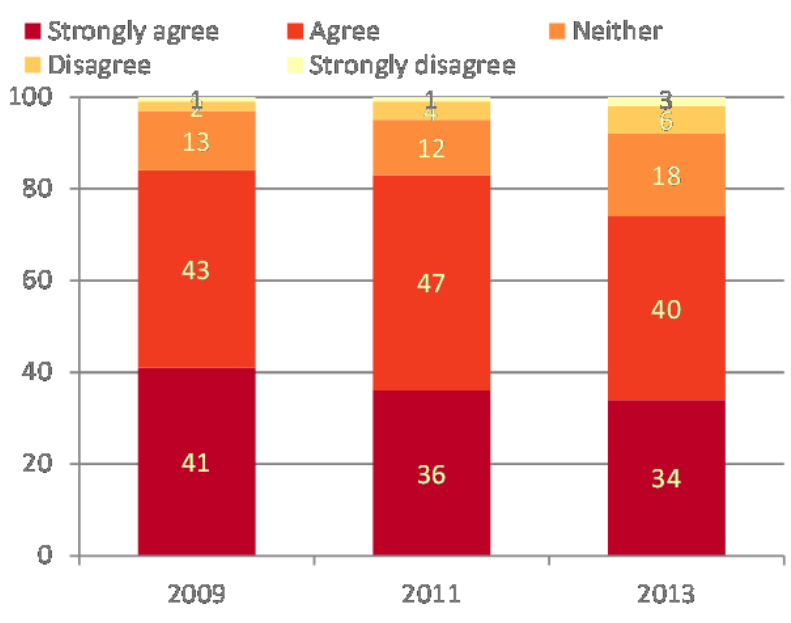

\subsection{It is okay for people to express their} ideas on the internet even if they are extreme.

This statement attracted a greater level of disagreement than the previous, but still just under half of our sample agreed (44\%).

Only $9 \%$ of the sample disagreed strongly, which has remained reasonably stable over the period of analysis.
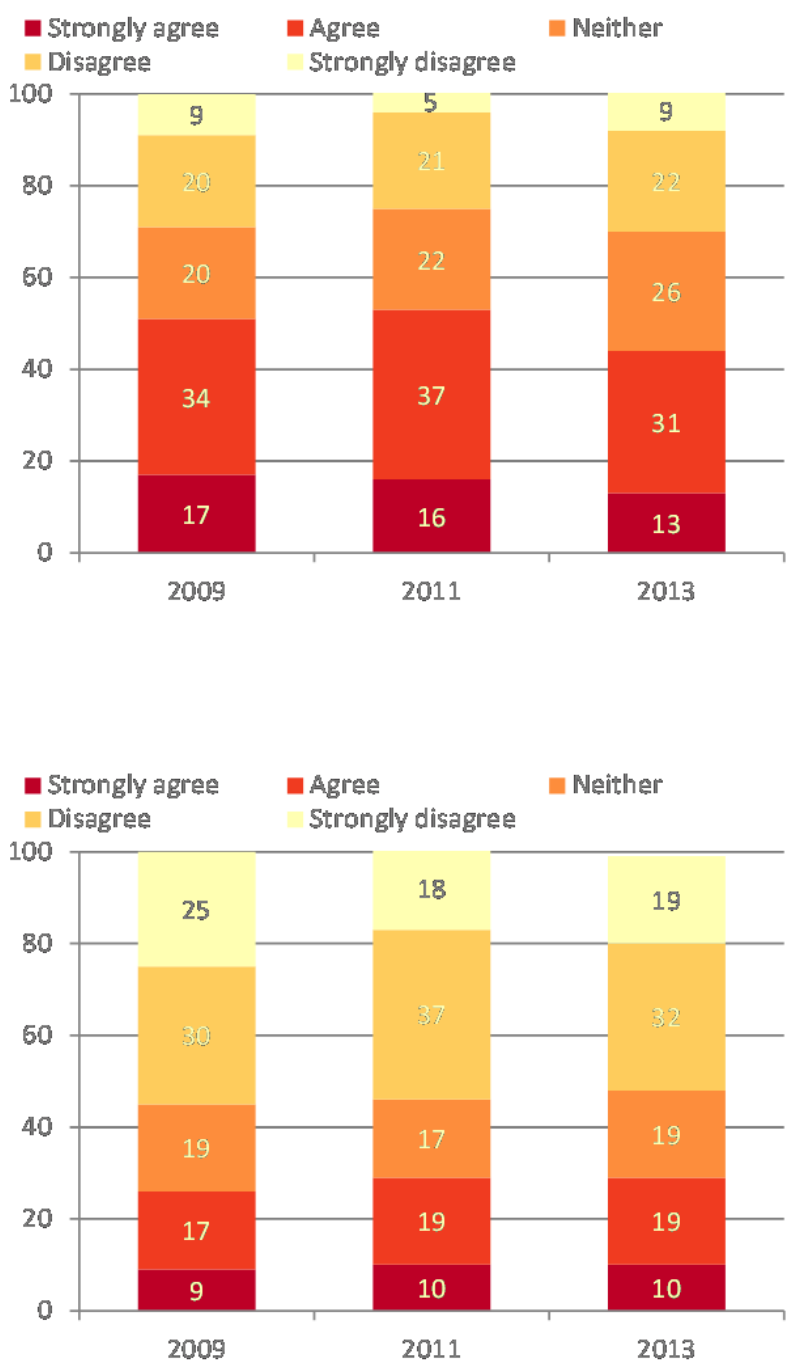


\subsection{I am worried that people who are not supposed to see them might read my email messages.}

Just over a third (35\%) of Australians were concerned about the security of their email messages in 2013.

A slightly higher proportion (44\%) were not concerned. There was little change over the period.

\subsection{The Australian government should allocate funds to enable all Australians to have access to internet services.}

Agreement with this statement has strengthened between 2009 and 2013.

Just over a third (38\%) of Australians strongly agree with this contention, while a further third (33\%) agree. Sixteen percent do not think that government should play this role.
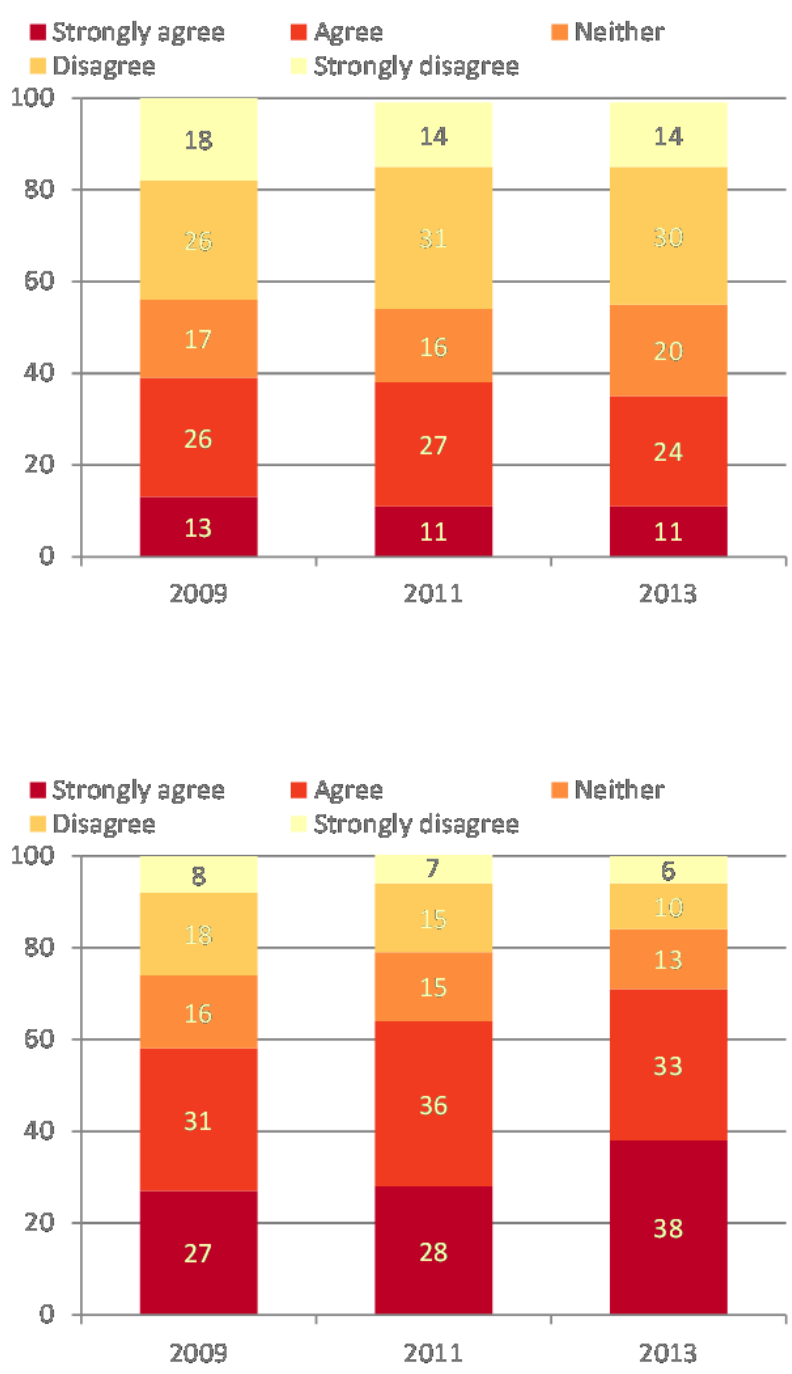

\subsection{Do you think that the development of a National Broadband Network is a good idea?}

There is wide agreement that the development of the NBN is a good idea. The proportion of Australians that strongly supported the NBN fell slightly, from $43 \%$ in 2009 to $35 \%$ in 2011 , then rose again to $45 \%$ in 2013.

The proportion agreeing that they supported it stayed at around three in ten: $32 \%$ in 2009 and 2011, and 31\% in 2013.

Overall, in 2013, $76 \%$ of Australians were in favour of the NBN. Just $11 \%$ disagreed that the development of the NBN was a good idea.

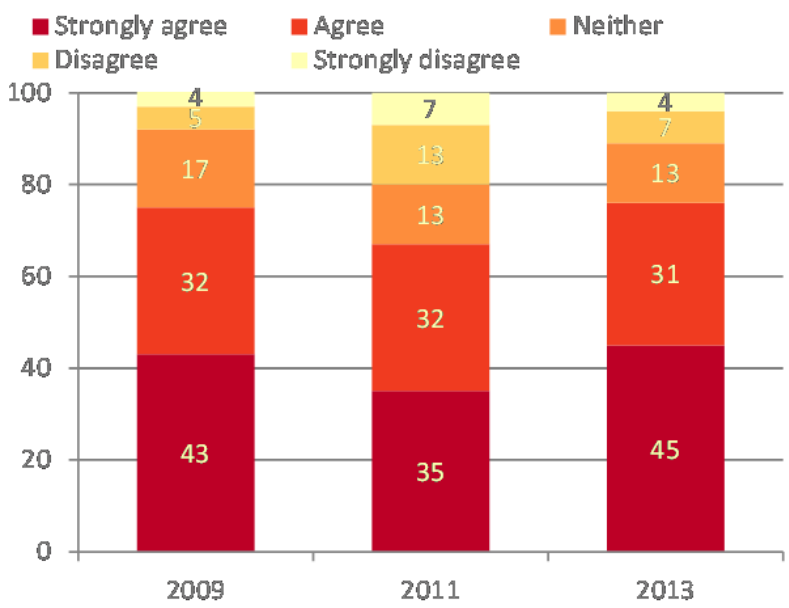




\subsection{Do you intend to connect to the NBN when it is available in your area?}

Just over two fifths (42\%) of our respondents said that they would definitely connect to the NBN, while a further quarter said they probably will (26\%).

Seventeen percent will probably or definitely not do so.
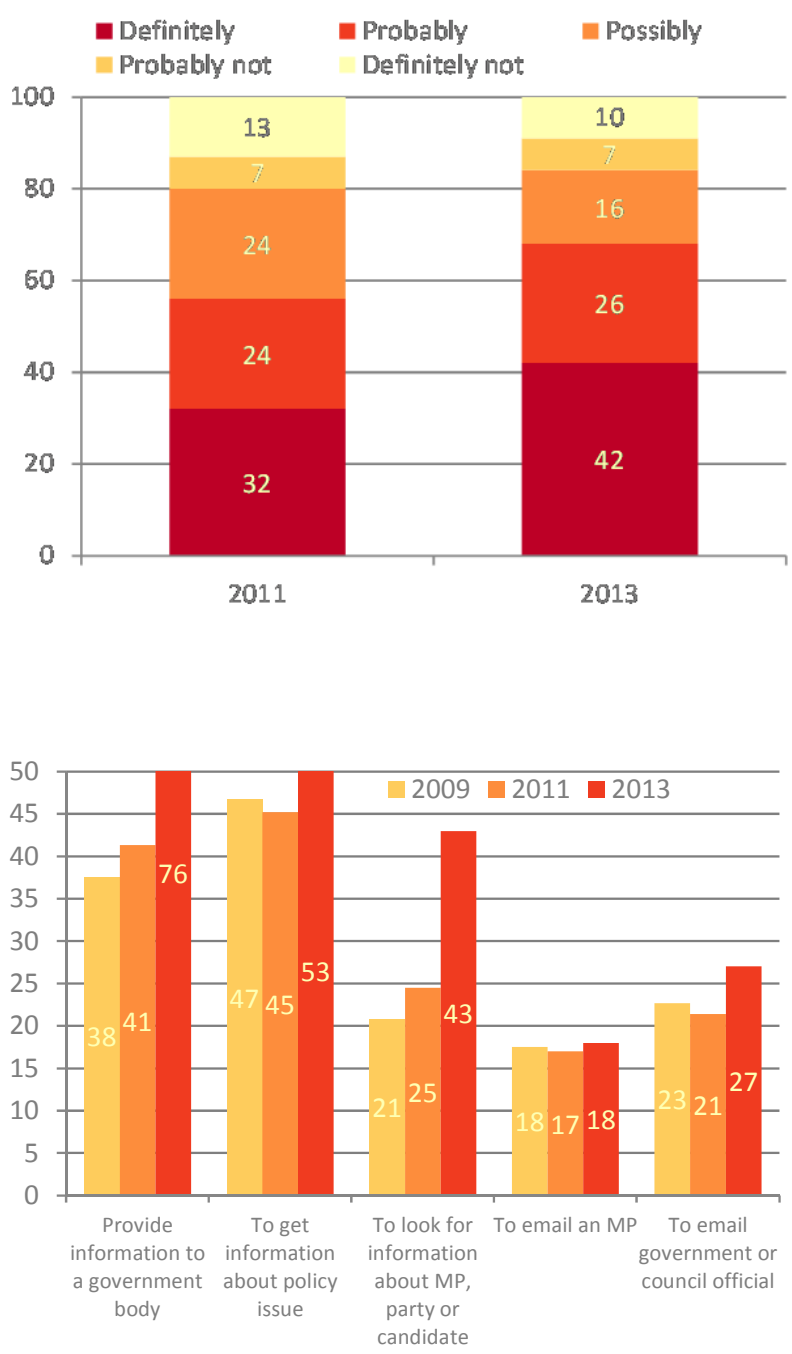

council officials, and $18 \%$ (up from $17 \%$ in 2011) emailed an MP.

\subsection{Political uses of the internet}

More Australians are using the internet for political reasons in 2013. The biggest increase in activity was those using the internet to provide information to a government body: $76 \%$ of Australians said they did so, up from $41 \%$ in 2011. Looking for information about an MP, party, or candidate had also risen to $43 \%$, up from $25 \%$ in 2011 .

Other ways in which Australians use the internet for political reasons remained reasonably steady over the period of analysis: in 2013, 53\% (up from $45 \%$ in 2011) got information about policy issues, $27 \%$ (up
from $21 \%$ in 2011) emailed government or

\subsection{Accessing government services}

Accessing government services had risen only slightly since 2009 .

In $2013,76 \%$ (up from $67 \%$ in 2011) had got information about government or council services, $61 \%$ (up from 54\% in 2011) paid taxes, fines, or licenses, 56\% (up from 50\% in 2011) used government services online, and $50 \%$ (up from $44 \%$ in 2011) logged in to secure areas on government websites to access services.

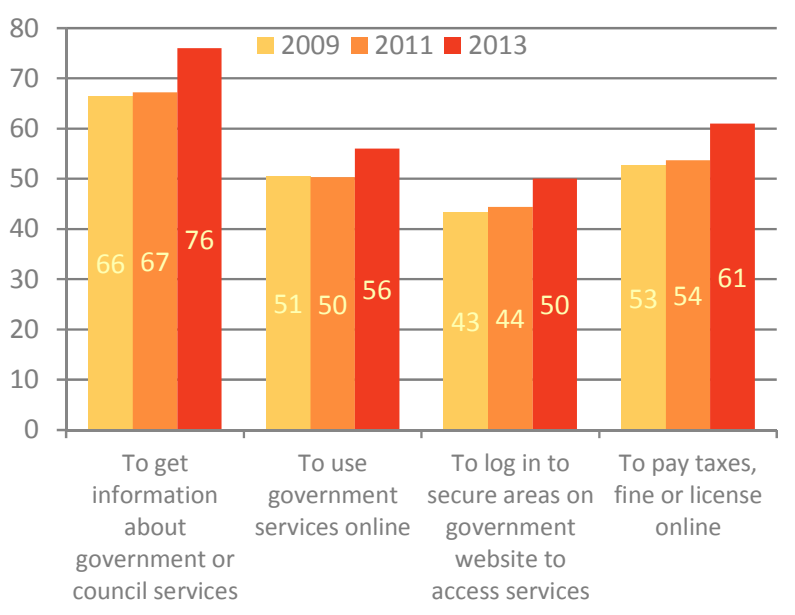




\section{Further analysis}

\subsection{Number of government uses of the internet, 2009 to 2013}

Only a small proportion of Australian internet users do not use the internet for one of the nine government interactions we asked about (9\% in 2013). Use of the internet for these purposes increased slightly between 2009 and 2011 and then more markedly in 2013. In 2013 , almost four in ten used the internet for six or more of the government related activities.

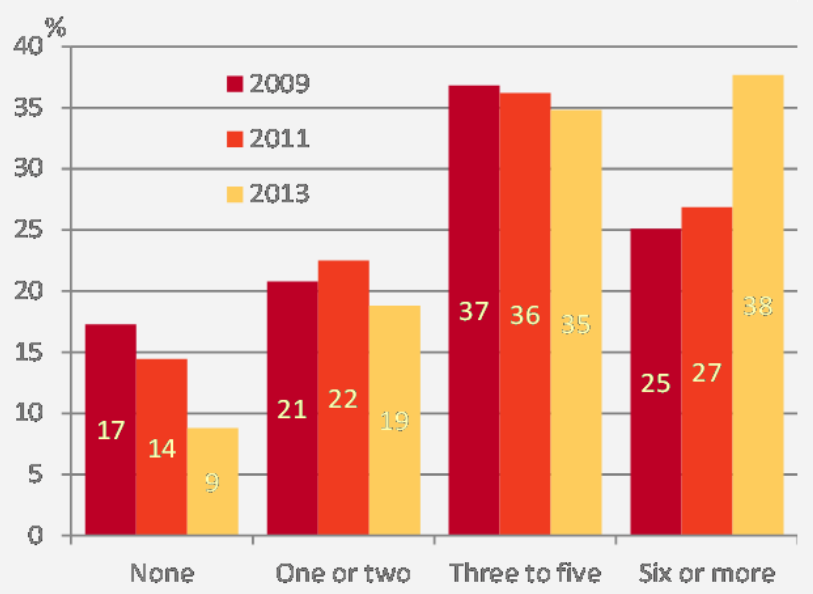

6.19 The government should regulate the internet more than it does (internet users only), 2013

There was a lot of variation between countries for this question. A quarter of Spanish respondents 'agreed strongly' as did $21 \%$ of Chinese respondents. The corresponding figure for Sweden was $5 \%$, New Zealand $7 \%$ and Australia 10\%. An overwhelming $56 \%$ of Swedes disagreed strongly with this contention.

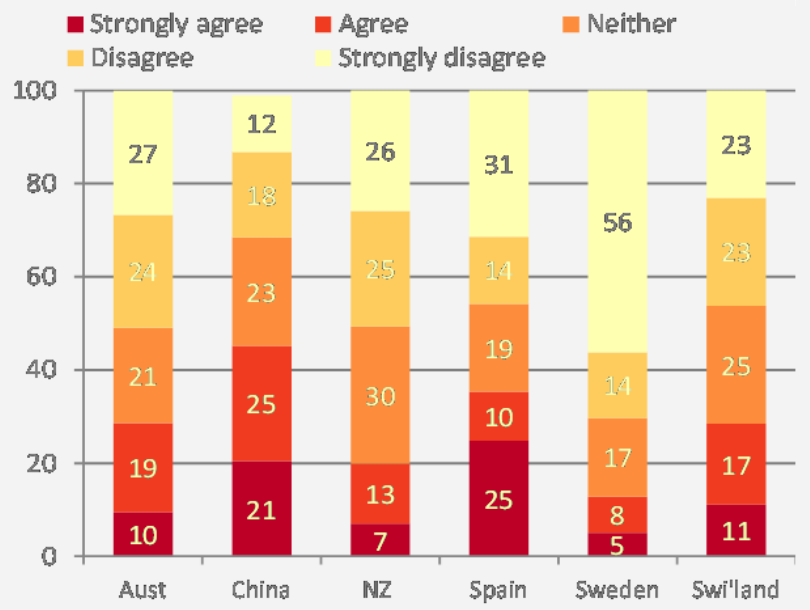




\section{$7 \quad$ The internet and commerce}

From the web's early days, there has been much speculation and interest in commercial and retail applications. Many books have been written on strategies to maximise online sales; Amazon and eBay are spectacular success stories. This section presents our findings on consumer activity online and peoples' perceptions of online transactions.

\subsection{How often do you use the internet to} get information about products?

The vast majority of users use the internet to research products. This proportion has been increasing from $83 \%$ in 2007 to $88 \%$ in 2009 , $89 \%$ in 2011, and 93\% in 2013.

Those researching product information daily increased from $12 \%$ to $16 \%$ to $21 \%$ to $28 \%$ in 2013. Most users research product information weekly: $41 \%$ in 2013, compared with $28 \%$ of users researching daily.

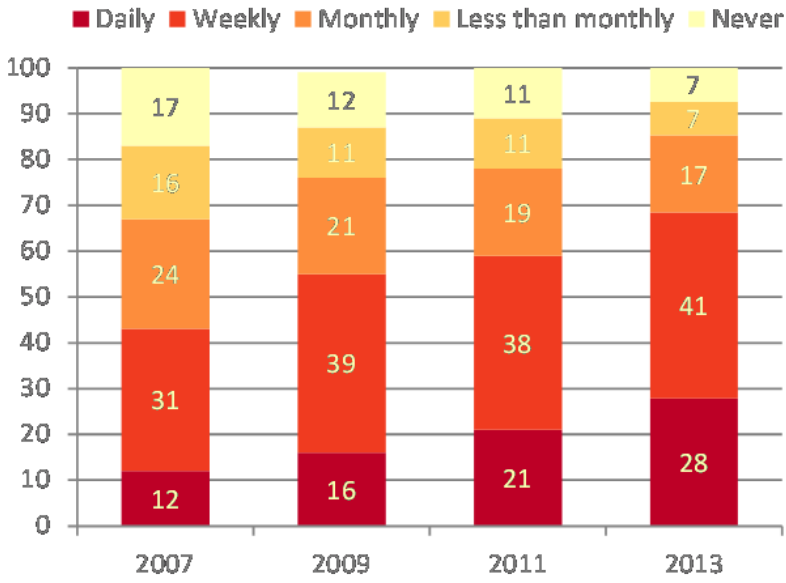

\subsection{How often do you buy products online?}

The proportion of users who buy products online rose from $57 \%$ in 2007 to $73 \%$ in 2009 to $78 \%$ in 2011 to $85 \%$ in 2013.

Few Australians buy products online daily, but the proportion of shopping online at least weekly has increased from one in ten $(10 \%)$ in 2007 to almost a third (30\%) in 2013.

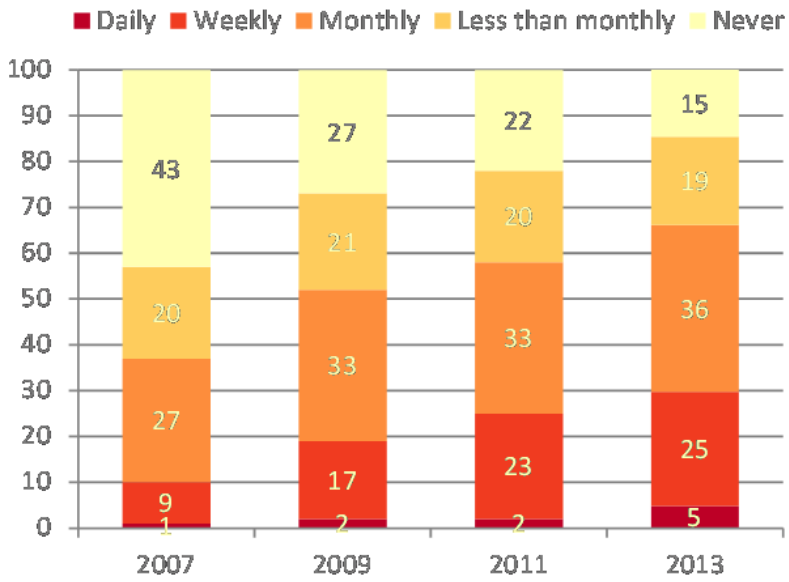




\subsection{How often do you make travel reservations/bookings online?}

Making travel bookings online has fluctuated slightly over the period of analysis, but between 2007 and 2013 grew from 67\% to $80 \%$.

Most Australians make travel bookings online less than monthly: $52 \%$ in 2013 , up from $44 \%$ in 2011. Those booking monthly or more often increased from $18 \%$ in 2007 to $28 \%$ in 2013.

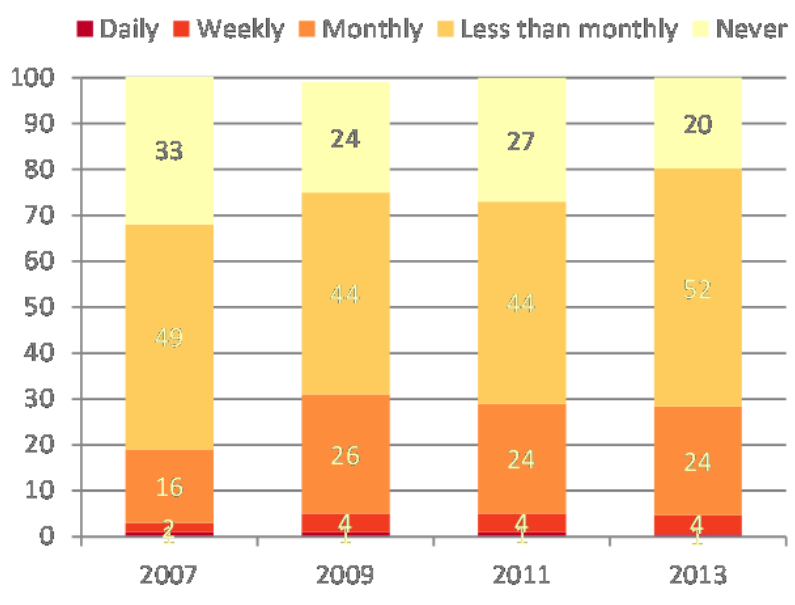

- Daily a Weakly a Monthly = Less than monthly Never

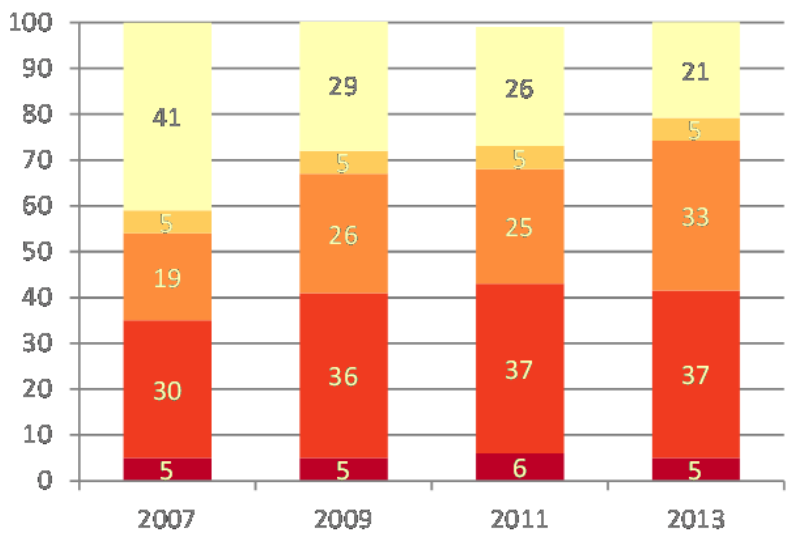

\subsection{How often do you use your bank's online services?}

In 2007, two thirds (67\%) of users banked online. By 2009 this had increased to three quarters (75\%), by 2011 four in five (79\%), and by $2013,85 \%$.

The highest proportion of internet users bank online weekly: $39 \%$ in $2007,44 \%$ in 2009 , 45\% in 2011 and 2013.

The most growth in online banking was those who did so daily: from $15 \%$ in 2007 , this increased to $24 \%$ by 2013 .

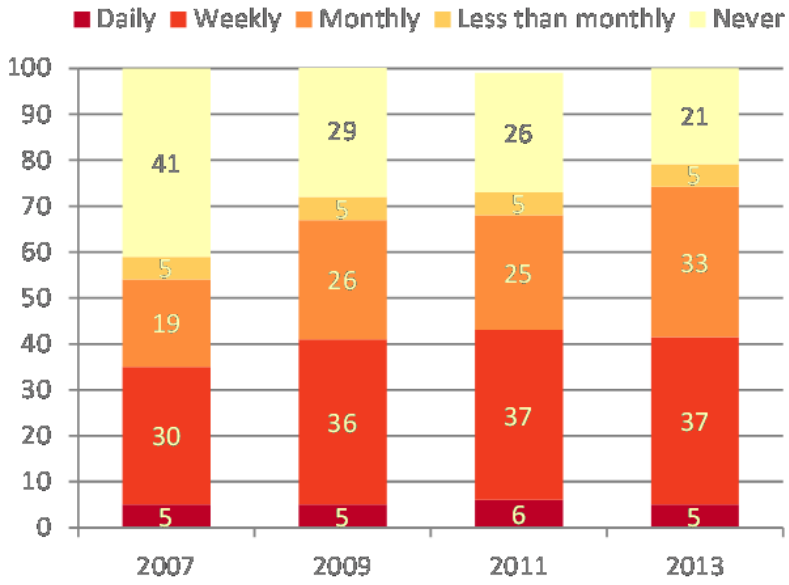




\subsection{How often do you invest in stocks/funds/bonds online?}

The majority of users do not invest online, and this did not change much over the period.

In $2007,86 \%$ did not invest, which grew to $81 \%$ in 2009 and remained at $81 \%$ in 2011 and 2013.

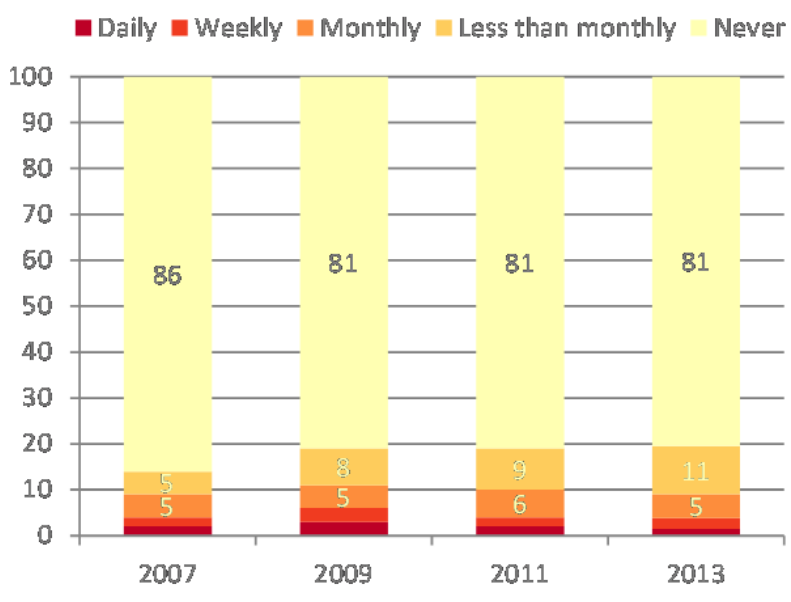

\subsection{How often do you purchase event} tickets online?

A greater proportion of internet users were purchasing event tickets online in 2013 than 2007.

In 2007, just under half of internet users did so $(49 \%)$, while in 2009 this figure was almost two thirds (63\%). As with travel bookings, there was a small decrease in usage in $2011(62 \%)$, before an increase in 2013 (71\%).

Those purchasing at least monthly increased from $15 \%$ in 2007 to $25 \%$ in 2013.

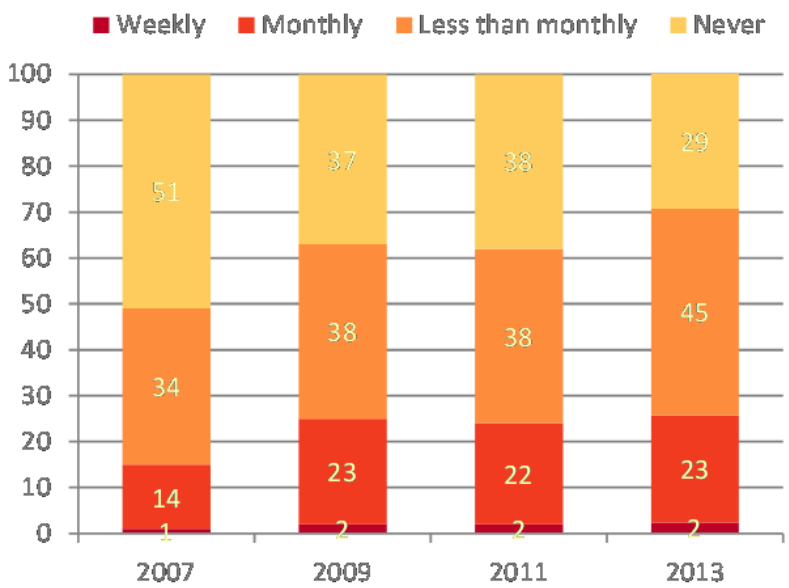

\section{Tactics}

This section examines the interaction between online and off-line purchasing.

\subsection{How often do you look at goods on the internet but when it comes time to buy, you purchase from local stores?}

Researching online but buying offline is an activity that peaked in popularity in 2009 , and has been tapering off since.

In 2007, almost two thirds of our sample had done this (65\%), while in 2009 it was close to three quarters (73\%). By 2011 this had reduced to $70 \%$, and by 2013 only $55 \%$ were researching online but buying offline.

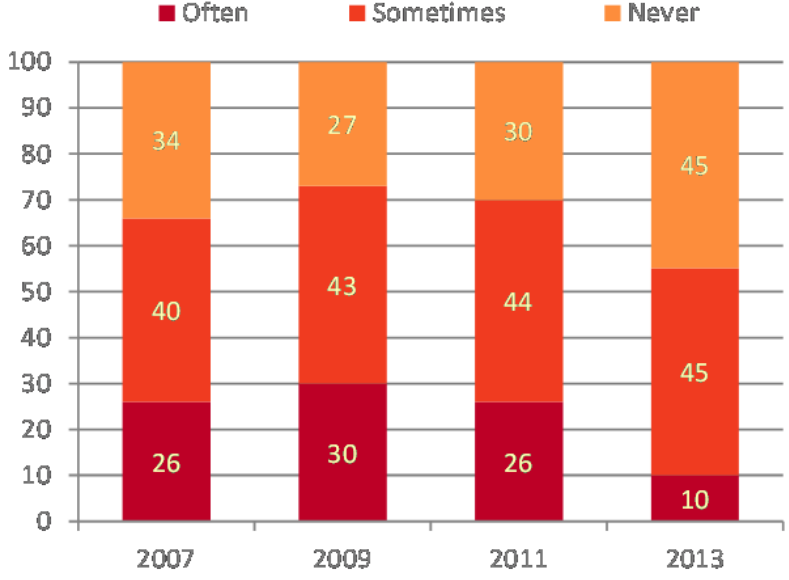




\subsection{How often do you look at goods in} local stores but when it comes time to buy, you purchase online?

In 2007, only a quarter of our users reported looking at goods in local stores then purchasing them online, but this has been increasing steadily since. By 2009 , this figure had risen to $41 \%$, in 2011 it was almost half (48\%), and by 2013 three quarters (76\%) of Australians were doing this.

In 2013, a quarter (25\%) of Australians were comparing goods in local stores then purchasing them online often.

\section{Concerns about internet security}

\subsection{Have you ever bought something that has been misrepresented on a website, had your credit card details stolen in an internet transaction or been contacted by someone asking you to provide bank details?}

A relatively small proportion of Australians have bought something online that had been misrepresented, which has increased slightly since 2009. Just $16 \%$ of internet users have had this problem in 2013 , up from $12 \%$ in 2009.

In 2013, almost one in ten internet users had their credit card details stolen, nearly double the rate in 2011. Almost half (47\%) the sample had been contacted to provide bank details in 2013.

\subsection{It's difficult to return or exchange goods ordered on the internet.}

Most of our respondents agreed that it was difficult to return or exchange goods ordered online, although slightly fewer thought it was difficult in 2013.

Almost one in five agreed strongly (16\%, down from $17 \%$ in 2011), while a further third agreed (35\%, down from 39\% in 2011). Around one in five disagreed that this was the case (23\%, consistent with 2011).
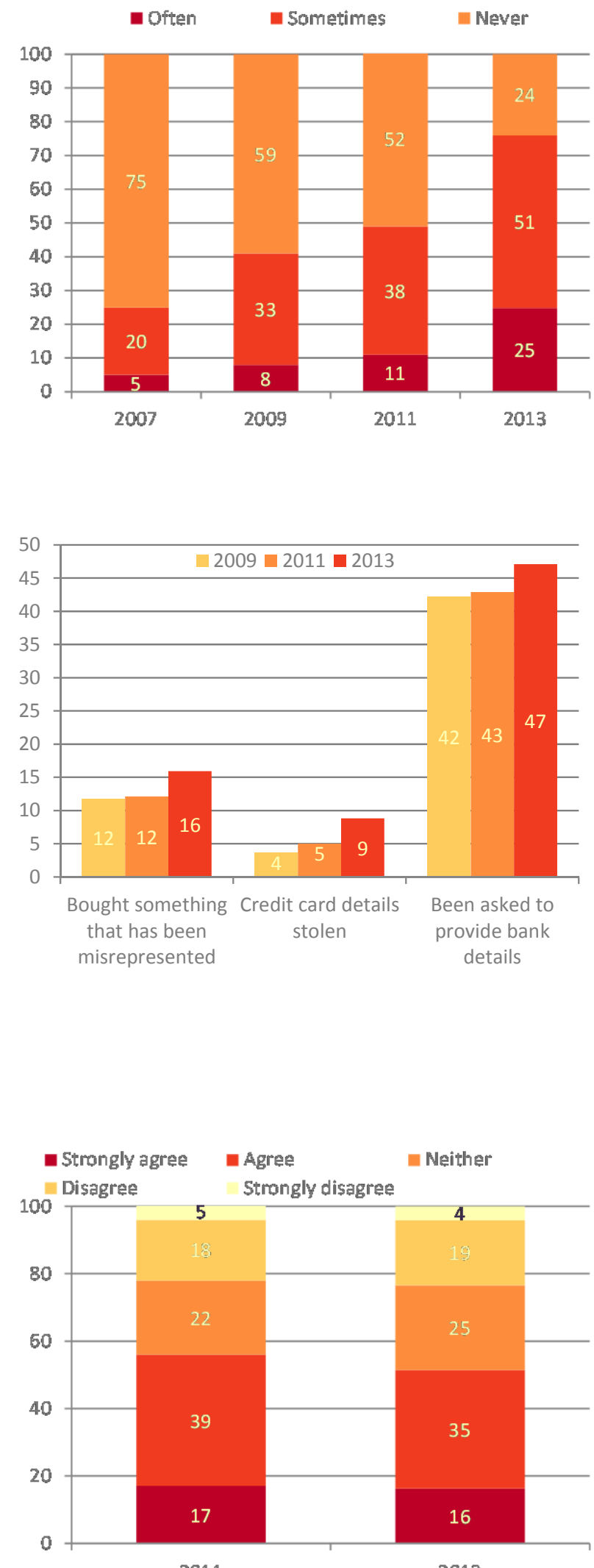

2011

2013 


\subsection{It's difficult to assess product quality when shopping on the internet.}

Three quarters of our respondents agreed that it was difficult to assess product quality online $(73 \%$, down from $75 \%$ in 2011), with a quarter agreeing strongly (25\%, up from $21 \%$ in 2011).

Over one in ten disagreed in 2013 (13\%, up from $10 \%$ in 2011).

\subsection{I buy things online because they are cheaper.}

More than two thirds of our internet users said that shopped online because it is cheaper (69\%, up from $64 \%$ in 2011). One in five strongly agreed that this was the case (25\%, up from $21 \%$ in 2011).

This remained reasonably steady between 2011 and 2013.

\subsection{I buy things online because I can't find them in stores.}

The proportion of our sample who agreed with this statement was very similar to the previous statement: $68 \%$ in 2013, up from 64\% in 2011.

It would seem that lower prices and greater choice are equal drivers of Australians' online shopping.
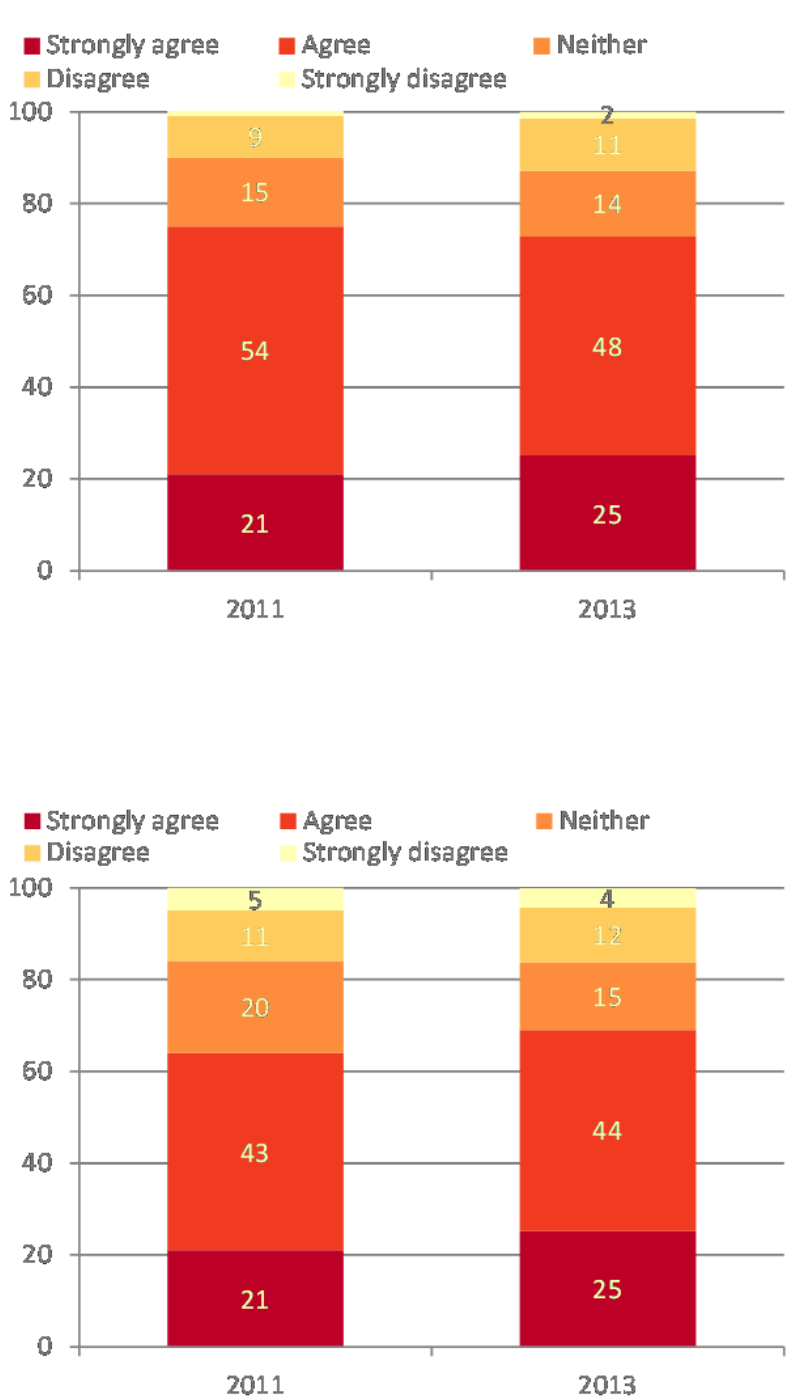

2011

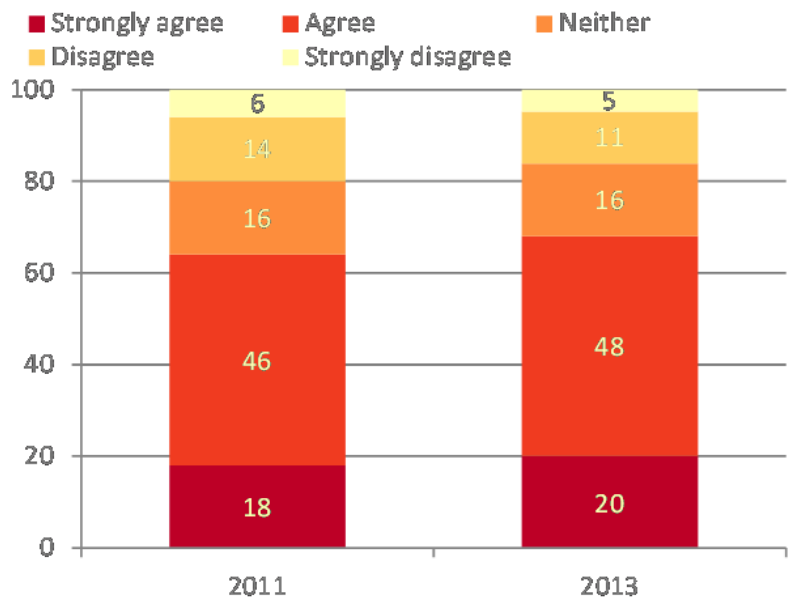




\subsection{I would prefer to shop with Australian-based websites}

Most Australians have a preference for shopping with Australian-based websites (78\%, up from $74 \%$ in 2011).

Only around one in ten (11\%, down from $13 \%$ in 2011) said they did not have a preference for Australian-based websites.

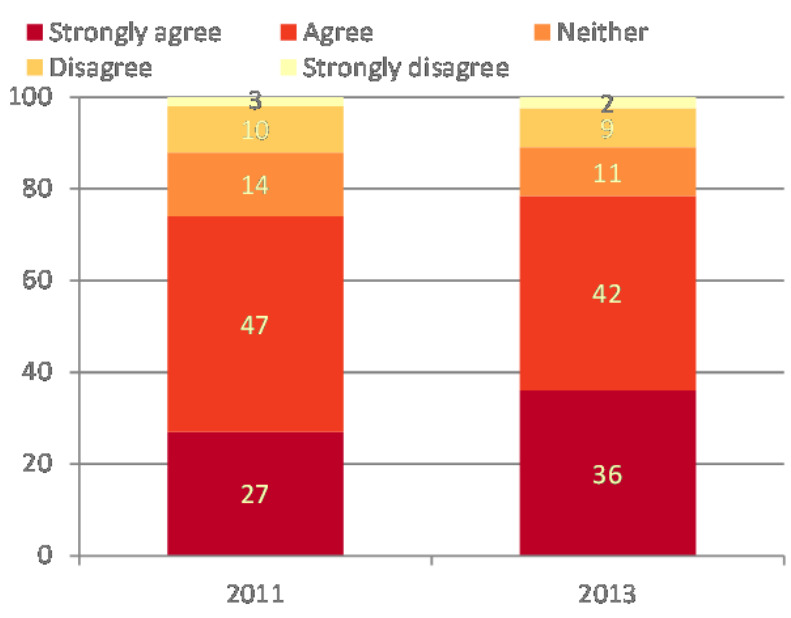

\subsection{Proportion of online expenditure} with Australian-based websites.

Despite their preference for shopping with Australian-based websites, fewer than one in ten online Australians make all their online purchases with Australian-based sites (9\% in 2011 and 2013), while almost a quarter (38\%, up from $36 \%$ in 2011) make most of their purchases locally.

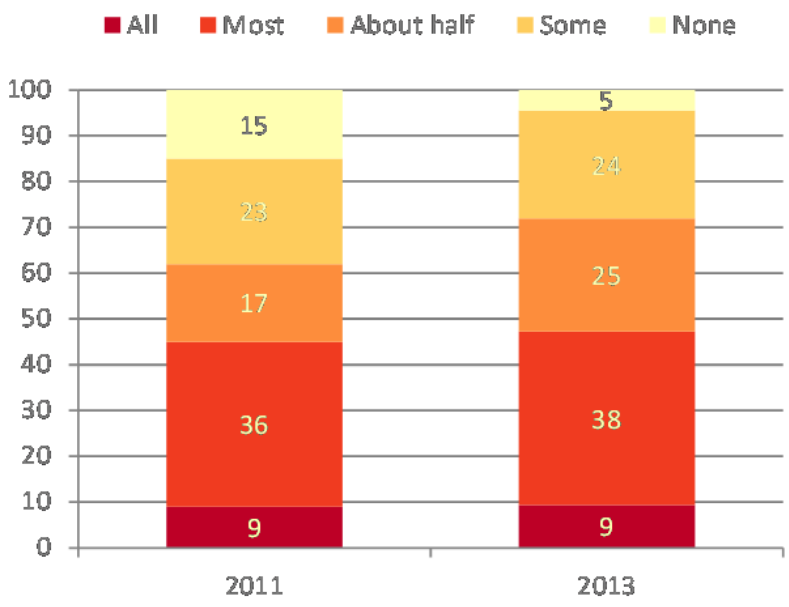




\section{Further analysis}

\subsection{Value and number of monthly online} purchases by gender, 2007-2013

Expenditure by males and females was almost identical in 2007 but in the next two periods a gap developed. In 2009 men spent on average $\$ 219$ per month compared to just $\$ 187$ by women, a difference of $17 \%$. This gap grew further in 2011. Expenditure by males grew to $\$ 242$ while mean expenditure by women actually fell to $\$ 165$, a difference between the two of $46 \%$. Between 2011 and 2013 the gap narrowed with men's mean expenditure falling and women's increasing but men's expenditure was still $12.3 \%$ more than women's in 2013.

Looking at mean number of purchases by gender there is still a gap but it narrowed considerably in 2013. Starting out at similar points in 2007, men's and women's purchasing patterns changed dramatically over the period. Men's average purchases almost doubled between 2007 and 2011 while women's increased by $41 \%$. By 2011 men were purchasing 3.0 times per month on average compared to 2.2 times for women. Women's purchasing increased strongly between 2011 and 2013 to 3.6 times per month compared to men with 3.9 purchases on average.

\subsection{How often do you purchase online, selected countries, 2013}

Australian and China had the highest proportion of internet users shopping weekly or more often online (three in ten). Australia and New Zealand have a similar level of overall participation, although Australians are more likely to purchasing weekly or more often.
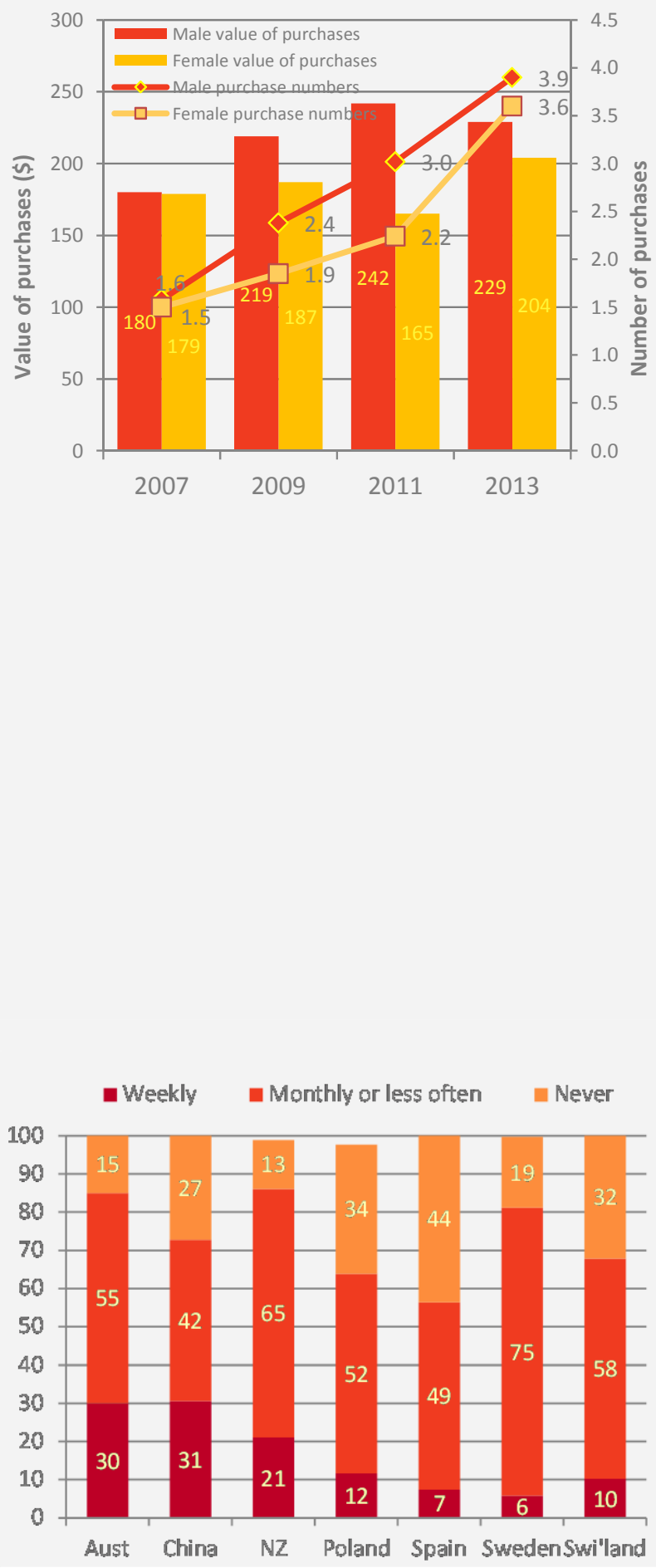


\section{Appendix I}

\section{Background to the World Internet Project}

The first report produced by what has become the World Internet Project was the work of a group of researchers based at the University of California at Los Angeles. The UCLA study team set out their guiding objective as follows:

Our goal is to explore how the Internet influences social, political, cultural, and economic behaviour and ideas, as measured by the attitudes, values, and perceptions of both Internet users and non-users.

They went on to outline how they thought their work could contribute:

We hope our findings about the Internet will have broad implications for government policymaking, corporate planning, and social and cultural study. To begin this project now is critical if we hope to fully understand the Internet as it evolves. Had this type of research been conducted on the evolution of television as it emerged in the late 1940s, the information would have provided policy makers, the media, and ultimately historians with invaluable insights about how broadcasting has changed the world.

The first report produced by the US partners was concerned with a number of emerging questions around the social, economic, political and cultural dynamics of the Internet. Who was online, who was not, what were users doing online? How was the Net changing patterns of media consumption, consumer behaviour, and communication patterns? What social and psychological effects were apparent?

From its beginnings, the main research activity of the project has been a sample survey of internet users and non-users. The survey is administered in different ways by the different partners. Most partners undertake the survey by telephone with a significant minority opting for face to face interviews. Samples are collected on various bases, with some partners choosing cluster samples and some engaging in stratification to make sure that their sample reflects the population on key variables. Sample sizes range from 900 respondents to 4,000 . In addition the minimum age of respondents varies from 12 up to 18 years.

Given the range of countries involved in the collaboration there are significant differences in the stage of internet development. There are large differences in internet penetration and the prevailing forms of access. For example in many countries public access points are becoming increasingly less important while in developing countries public access points are still the main means for people to access the internet.

A related issue is that of broadband take-up. This is becoming the key issue in many countries in which the internet is a 'mature' technology, but there is no consensus regarding what constitutes broadband and this definitional problem is exacerbated when looking across countries. Similarly the evolution of the internet has varied between countries in terms of technologies adopted.

Public policy framing of internet development also varies between the partner countries. Regulating the perceived negative effects of the internet is given more emphasis in some jurisdictions while others are more interested in the economic benefits of the net.

Just as importantly for a project such as this, there is great variation in the amount and type of research conducted on internet use and its impact in the various partner countries. In the US for example, the Pew Internet and American Life project, commenced in 1999, is a major ongoing surveybased project examining the internet and its impact on households and communities. In Australia, however, research on the social impact of the internet has been piecemeal at best. While there are 
many surveys that have been conducted on internet use and non-use in various countries, the World Internet Project is the only attempt to undertake coordinated survey work across countries. The combination of longitudinal data and international comparison makes this project extremely useful for identifying and tracking trends.

In the United States there has been a lot of survey research concentrating on the diffusion of new technologies. The Department of Commerce's Falling Through the Net project, begun in 1995 and then rebadged as A Nation Online, is the best example of this type of research. It began in response to concerns about the digital divide more generally and is now focused on the issue of broadband diffusion. The research includes some limited consideration of uses of the internet by individuals and households but does not investigate 'social impact' in any detailed way. In this research the positive effect of the internet is assumed.

The Pew Internet and American Life Project is a more ambitious and larger project that aims to 'explore the impact of the Internet on families, communities, work and home, daily life, education, health care, and civic and political life.' This project is a series of thematically linked investigations of the impact of the internet. Recent reports have included a study of bloggers and online banking. In contrast to the US World Internet Project this approach enables more detailed investigation of particular issues and uses but doesn't provide as clear an overview. The focused nature of these surveys doesn't facilitate the investigation of the relationship between various online (and off-line) activities and uses.

All partners in the WIP have their own funding source although the US partner in particular has played a key role in advising new partners and meeting with prospective funders. Another challenge to the development of the project has been in developing a consistent approach for partners with greatly varying funding arrangements both in terms of quantum and funding mix. This year will see the first international report published out of the project that will include data on a dozen countries. 


\section{Appendix II}

\section{About $\mathbf{C C l}$}

The ARC Centre of Excellence for Creative Industries and Innovation $(\mathrm{CCl})$ was established in 2005 to focus research and development on the contribution that the creative industries and their contributing disciplines can make to a more dynamic and inclusive innovation system.

Funded by the Australian Research Council from 2005-13, CCI is acknowledged as a global leader in this emerging field. It is a broadly-based, cross-disciplinary, internationally focused Centre embracing both fundamental theoretical and highly applied research in media, cultural and communication studies, law, education, economics and business and information technology, addressing key problems and opportunities arising for Australia, the Asian region, and for the wider world, from innovation in both the creative economy and the broader service economy. It addresses the nature of the field as rapidly-moving and internationally-focused, with extensive research links and international nodes established or planned in Britain, Singapore and China.

The Centre plays a significant role in theoretical and strategic debates with academic, policy, and industry interlocutors, as well as working extensively on new empirical and technical methodologies, including, for example, the creation of new statistical approaches to measuring the creative economy, new software solutions for creative enterprise, and ethnographic action research.

The Centre gratefully acknowledges the support of the Australian Research Council in providing core funding to establish the Centre, 2005-13. 


\section{Appendix III}

\section{Research Methods}

\section{Sampling Design and Procedures}

A random sample of 1,000 Australians was interviewed.

Household telephone numbers were sourced through Sampleworx (http://www.sampleworx.com.au/household_rdd.html). This is a Sydney-based company which randomly computer generates phone numbers and validates each one before adding it to their data base.

Information provided on the Sampleworx website indicates that numbers are re-validated every 6 months to refresh the available sample pool. In addition, Sampleworx states that because numbers are randomly computer generated, the sample pool includes not only published phone numbers, but also numbers in new exchange areas and VOIP numbers, thus providing a greater coverage of numbers. Sampleworx phone numbers are profiled to Australian Communications and Media Authority (ACMA) Districts and Zones including a "best guess" postcode. The Sampleworx household sample selection is weighted approximately to ABS population statistics based on post code.

The numbers randomly drawn from the Sampleworx number pool were classified into urban (capital city) and rural (balance of state/territory) based on ACMA Districts and Zones.

There were three quota requirements - age ( 5 groups) $x$ gender $x$ location (capital city / balance), resulting in 20 quota groups. The number of respondents requested in each quota group, and the actual number of respondents is presented in Table 1.

In a number of categories the actual number of interviews does not match the required number of interviews. There were three main reasons for this occurring.

1. The age of the respondent was not asked until the end of the interview. Although we kept a close watch on the quotas as they were filling up, and took measures to avoid over-sampling within categories, in some instances more than one interviewer was speaking to a respondent in the same quota category and this was not discovered until the interview was completed and the CATI software updated the quota numbers.

2. Since the survey was quite long, we had many instances where respondents stopped the interview part way through due to time constraints. In these cases we made appointments to complete the interviews - in some cases making multiple call backs before completing the interview. In a few cases this meant that the completion of the survey took us over for a quota number for that category. Given the difficulty in obtaining participants, it was deemed more appropriate to complete interviews that were partly done than to abandon those surveys in favour of trying to get another participant. 
Table 1

Quota Categories for WIP Sample

\begin{tabular}{|c|c|c|c|c|c|c|c|c|c|c|c|c|c|}
\hline & \multicolumn{2}{|c|}{$18-24$} & \multicolumn{2}{|c|}{$25-34$} & \multicolumn{2}{|c|}{$35-49$} & \multicolumn{2}{|c|}{$50-64$} & \multicolumn{2}{|c|}{$65+$} & \multicolumn{2}{|c|}{ Total } & \multirow[t]{2}{*}{$\begin{array}{c}\text { Grand } \\
\text { Total }\end{array}$} \\
\hline & $M$ & $\mathrm{~F}$ & $M$ & $\mathrm{~F}$ & M & $\mathrm{F}$ & M & $\mathrm{F}$ & $M$ & $\mathrm{~F}$ & M & $\mathrm{F}$ & \\
\hline Urban & $\begin{array}{c}54 \\
\text { (43) }\end{array}$ & $\begin{array}{c}49 \\
(41)\end{array}$ & $\begin{array}{c}69 \\
(62)\end{array}$ & $\begin{array}{c}51 \\
(61)\end{array}$ & $\begin{array}{l}100 \\
(93)\end{array}$ & $\begin{array}{c}95 \\
(94)\end{array}$ & $\begin{array}{c}73 \\
(71)\end{array}$ & $\begin{array}{c}77 \\
(73)\end{array}$ & $\begin{array}{c}48 \\
\text { (47) }\end{array}$ & $\begin{array}{c}62 \\
(58)\end{array}$ & $\begin{array}{c}344 \\
(316)\end{array}$ & $\begin{array}{c}334 \\
(327)\end{array}$ & $\begin{array}{c}678 \\
(643)\end{array}$ \\
\hline Rural & $\begin{array}{c}13 \\
(21)\end{array}$ & $\begin{array}{c}14 \\
(19)\end{array}$ & $\begin{array}{c}15 \\
(29)\end{array}$ & $\begin{array}{c}29 \\
(28)\end{array}$ & $\begin{array}{c}38 \\
(50)\end{array}$ & $\begin{array}{c}51 \\
(50)\end{array}$ & $\begin{array}{c}45 \\
(45)\end{array}$ & $\begin{array}{c}45 \\
(44)\end{array}$ & $\begin{array}{c}35 \\
(33)\end{array}$ & $\begin{array}{c}39 \\
(38)\end{array}$ & $\begin{array}{c}144 \\
(178)\end{array}$ & $\begin{array}{c}178 \\
(179)\end{array}$ & $\begin{array}{c}322 \\
(357)\end{array}$ \\
\hline Total & $\begin{array}{c}67 \\
(64)\end{array}$ & $\begin{array}{c}63 \\
(60)\end{array}$ & $\begin{array}{c}84 \\
(91)\end{array}$ & $\begin{array}{c}80 \\
(89)\end{array}$ & $\begin{array}{c}138 \\
(143)\end{array}$ & $\begin{array}{c}146 \\
(144)\end{array}$ & $\begin{array}{c}118 \\
(116)\end{array}$ & $\begin{array}{c}122 \\
(117)\end{array}$ & $\begin{array}{c}81 \\
(80)\end{array}$ & $\begin{array}{l}101 \\
(96)\end{array}$ & $\begin{array}{c}488 \\
(494)\end{array}$ & $\begin{array}{c}512 \\
(506)\end{array}$ & $\begin{array}{c}1000 \\
(1000)\end{array}$ \\
\hline
\end{tabular}

Note: Numbers in brackets are the quotas originally suggested by the client. Numbers outside brackets represent the actual number of respondents 
3. Traditionally recruiting rural respondents is more difficult than recruiting urban respondents. In addition, recruiting younger respondents is more difficult than recruiting older respondents. Therefore recruiting younger rural respondents can be particularly challenging, and therefore proportionally significantly more expensive. Towards the end of the survey, due to budget constraints, and in consultation with the chief researchers, more emphasis was placed on recruiting respondents of an appropriate age in favour of respondents in rural areas. Therefore there is some oversampling of urban respondents in the younger age groups.

Although not specifically requested by the client, sample numbers were further grouped by state and territory urban (capital city) and rural (balance) regions, with the aim of having proportionately greater numbers in NSW, VIC and QLD, in order to provide data that was more representative of the Australian population.

On this basis, the greatest number of respondents should have been in NSW. However, extreme weather conditions over an extended period of time (detailed in the section relating to survey dates below) resulted in the necessity to under-sample in NSW and therefore compensate with respondents from other locations. The number of surveys completed in each state/territory location is presented in Table 2.

Table 2

Number of Respondents in State and Territory Urban and Rural Locations

\begin{tabular}{lccccccccc}
\hline & ACT & NSW & NT & QLD & SA & TAS & VIC & WA & Total \\
\hline Urban & 30 & 107 & 15 & 142 & 58 & 26 & 268 & 32 & 678 \\
Rural & - & 58 & 10 & 63 & 36 & 20 & 119 & 16 & 322 \\
Total & 30 & 165 & 25 & 205 & 94 & 46 & 387 & 48 & 1000 \\
\hline
\end{tabular}

Note: Urban (capital city); Rural (balance)

\section{Recruiting Younger Respondents}

After completion of approximately 350 surveys, the recruitment strategy was changed slightly to maximise the potential to reach younger respondents. At that stage we had completed surveys with only 32 urban respondents aged 18-34 and six rural respondents in the same age groups.

Up to that point we had been asking if the person who answered the phone was willing to participate in the survey. If not, we asked whether anyone else in the household would be willing to participate.

As the older age quotas filled up, we were referred to younger people in the same household - children or grandchildren of the people who answered the phone, and who were living in the same household.

At that stage we were still only using landline telephone numbers.

After discussion with the chief researcher (Scott Ewing), we decided to ask for recommendations of people to call who might be outside the household we had contacted.

We accepted mobile phone numbers to call as well as landlines. We also accepted referrals of people who were in different states from the state we had called - provided they were in the same region - i.e. urban to urban; rural to rural.

After completing 852 surveys, it was evident that we needed to further refine our recruitment strategy for younger respondents. We were now only seeking females aged 18-34 and males aged 18-49 and were not getting enough respondents in these categories through random sampling, or through the referrals from the cold calls.

Following discussion with Scott Ewing, we sought referrals from CATI staff, and from the Psychology and Statistics staff (collectively classified as 'internal' referrals). We also maintained our cold calls and focussed on rural areas with these since many of the 'internal' referrals were for respondents from urban areas. Using these strategies, the final 148 surveys were completed using a combination of cold calls, referrals from the 
cold calls and 'internal' referrals (which included respondents in VIC urban, VIC rural, NSW urban, QLD urban, NT rural, and ACT). The vast majority of referrals were for mobile numbers rather than land line calls.

Once we started accepting referrals outside the original sample frame, we manually kept records of completed surveys that resulted from these referrals. The strategy of requesting referrals from respondents in the original sample frame was less successful than recruiting from 'internal' referrals. Overall, approximately 100 surveys were completed from referrals, with about $75 \%$ of these being from 'internal' referrals.

\section{Survey Dates and Call Times}

- A pilot shift was conducted by the CATI manager, with phone calls being made by 3 supervisors and 5 interviewers on $3^{\text {rd }}$ October 2013

- Interviews were conducted between $4^{\text {th }}$ October and $23^{\text {rd }}$ November 2013.

- The CATI facility runs 11 shifts per week

o Monday - Thursday: 2 shifts per day (10am - 3pm; 3pm - 8pm)

o Friday: 1 shift (10am $-5 \mathrm{pm})$

o Saturday: 1 shift (10am - 6pm)

o Sunday: 1 shift (11am - 6pm)

- The CATI facility has 10 interviewer workstations, a supervisor workstation and the manager's workstation. The maximum number of simultaneous interviews is either 10 or 11 , depending upon whether the manager's workstation is available for interviewer use.

- The shift times and the number of interviewers working during a shift were varied over the course of data collection, based on the particular respondents we were trying to reach. In particular, as younger respondents were sought, shifts were focussed in weekends and the latter part of each weekday.

o In the first week, weekday morning shifts were run with 4-5 interviewers and evening shifts were run with 9-10 interviewers.

o In the second week weekday morning shifts were run with just 2-3 interviewers, and evening shifts were run with 10 or 11 interviewers.

o In the fourth week, evening shifts were extended to $9 \mathrm{pm}$.

- From the fifth week no weekday morning shifts were run, and evening shifts were run with 10 or 11 interviewers until $9 \mathrm{pm}$.

o All weekend shifts were run with 10 or 11 interviewers.

\section{Non - Call Dates and Reasons}

- No calls were made on Saturday $5^{\text {th }}$ October and Sunday $6^{\text {th }}$ October due to technical difficulties.

- No calls were made on Tuesday $5^{\text {th }}$ November due to public holiday in Melbourne (Melbourne Cup Day).

- No calls were made in NSW (urban and rural) or ACT from Thursday $17^{\text {th }}$ October (afternoon shift) until Friday $25^{\text {th }}$ October (inclusive) due to extensive bushfires in those regions.

- Calls were resumed in ACT on Saturday $26^{\text {th }}$ October

- Calls were resumed in NSW urban on Monday $28^{\text {th }}$ October

o Calls were resumed in NSW rural on Saturday $2^{\text {nd }}$ November

- No calls were made In NSW rural or QLD rural on Saturday $16^{\text {th }}$ November and Sunday $17^{\text {th }}$ November due to severe storms across the regions. Weather conditions included damaging winds (including a tornado in NSW), thunderstorms and heavy rain which affected power and telephone lines, and damaging hail stones the size of tennis balls and cricket balls in both NSW rural and QLD rural. 


\section{Interviewers}

- Calls were made by 45 different people.

- The CATI manager conducted over 30 interviews.

- There were 7 supervisors (one or two supervisors on duty each shift) who also conducted some interviews during their shifts. All supervisors are current or past Swinburne students employed as research assistants. They have long-standing dedicated expertise in supervision and interview technique.

- The majority of calls were made by 37 interviewers. Most interviewers are current undergraduate and postgraduate Swinburne Social Science students.

- All interviewers were trained and monitored by the CATI manager and the supervisors.

\section{Survey Length}

o Across all 1000 interviews, survey time ranged from 4 minutes 18 seconds to 1 hour 20 minutes 21 seconds ( $M=36$ minutes 18 seconds, $S D=10$ minutes 11 seconds).

o Interviews for internet users $(n=907)$ ranged from 4 minutes 18 seconds to 1 hour 20 minutes 21 seconds $(M=37$ minutes 56 seconds, $S D=9$ minutes 6 seconds $)$

o Interviews for non-internet users $(n=93)$ ranged from 11 minutes 49 seconds to 40 minutes 13 seconds $(M=20$ minutes 17 seconds, $S D=5$ minutes 7 seconds $)$

Please Note: Very short survey time occurs because the software calculates the length of the final call to complete survey. In cases of incomplete surveys, the final call to survey completion was often quite short.

\section{Interviewing Operational Criteria}

\section{Callbacks}

The number of callbacks for each telephone number was set to a maximum of 7 in the CATI software. Therefore, each number could be called a maximum of 7 times in repeated attempts to reach a potential respondent before being automatically removed from the active phone numbers in the sample. The timing of each callback attempt was programmed into the CATI software to allow for maximum contact potential. However, after completing approximately 850 surveys, staff manually removed numbers that had been called three times with no response. This was done to bring up new numbers more frequently and therefore maximise the potential to connect with younger respondents.

In the cases where a survey was partially completed, the automatic removal of the telephone number was manually overridden. In these cases respondents were called as many times as was necessary to complete the interview. The highest number of call backs recorded for this survey in this category of call was 18 call backs to complete the interview.

The number of calls to complete a survey ranged from 1 to $18(M=3.37, S D=2.53)$, with substantial variations in call rates across the different locations. The number of phone numbers used and the number of calls made in each location are presented in Table 3. 
Table 3

Number of Telephone Numbers Used and Number of Calls Made in Each Location

\begin{tabular}{lcccccc}
\hline Location & $\begin{array}{l}\text { Number of } \\
\text { Surveys } \\
\text { Completed }\end{array}$ & $\begin{array}{l}\text { Total } \\
\text { Phone } \\
\text { Numbers } \\
\text { Used }\end{array}$ & $\begin{array}{l}\text { Average } \\
\text { Number of } \\
\text { Phone } \\
\text { Numbers Used } \\
\text { to Gain a } \\
\text { Completed } \\
\text { Survey }\end{array}$ & $\begin{array}{l}\text { Total } \\
\text { Number of } \\
\text { Calls } \\
\text { Made }\end{array}$ & $\begin{array}{l}\text { Average } \\
\text { Number of Calls } \\
\text { Made to Gain a } \\
\text { Completed } \\
\text { Survey }\end{array}$ & $\begin{array}{l}\text { Average } \\
\text { Number of } \\
\text { Calls on an } \\
\text { Individual } \\
\text { Number per } \\
\text { Completed } \\
\text { Survey }\end{array}$ \\
\hline NSW-U & 107 & 5,153 & 48 & 13,466 & 126 & 3.07 \\
NSW-R & 58 & 2,281 & 39 & 5,667 & 98 & 2.78 \\
ACT & 30 & 587 & 20 & 1,503 & 50 & 2.77 \\
NT-U & 15 & 268 & 18 & 816 & 54 & 2.93 \\
NT-R & 10 & 240 & 24 & 607 & 61 & 3.20 \\
QLD-U & 142 & 4,630 & 33 & 12,894 & 91 & 3.66 \\
QLD-R & 63 & 2,488 & 39 & 6,396 & 102 & 3.17 \\
SA-U & 58 & 1,412 & 24 & 3,829 & 66 & 3.90 \\
SA-R & 36 & 1,392 & 39 & 3,482 & 97 & 2.83 \\
TAS-U & 26 & 478 & 18 & 1,280 & 49 & 3.65 \\
TAS-R & 20 & 795 & 40 & 1,740 & 87 & 2.25 \\
VIC-U & 268 & 4,556 & 17 & 14,480 & 54 & 3.78 \\
VIC-R & 119 & 3,031 & 25 & 8,518 & 72 & 3.16 \\
WA-U & 32 & 1,655 & 52 & 4,283 & 134 & 3.22 \\
WA-R & 16 & 909 & 57 & 2,522 & 158 & 2.56 \\
\hline TOTAL & $\mathbf{1 , 0 0 0}$ & $\mathbf{2 9 , 8 7 5}$ & $\mathbf{3 0}$ & $\mathbf{8 1 , 4 8 3}$ & $\mathbf{8 1}$ & $\mathbf{3 . 3 7}$ \\
\hline
\end{tabular}

\section{Response Rates}

The Swinburne CATI Facility developed the following approach to the calculation of response rates. We believe this method gives a detailed account of all call categories.

\section{"Telephone Listing Report" Definitions}

- $\quad$ Active - These numbers are still available in the system. For example, there are 642 answering machine numbers that the system is holding in memory that would be brought up again if the survey were continuing.

- Dead - These numbers are finished with and would not be used again. This file includes the completed surveys and any numbers that have been sent to the 'kill' file because they are unusable for the purposes of the survey (eg fax numbers; business numbers; invalid (not connected) numbers).

\section{Calculation of Response Rates}

Total Tries $=81,483$. This is the total number of calls made by the interviewers, including all categories of calls 
$\underline{\text { Total phone numbers used }=29,875}($ dead $28,714+$ active 1,161$)$.

Of these, 9,792 were ineligible; 8,880 were non-responses; and 11,203 were eligible (see Tables 4 to 6 for full details).

Of the ineligible calls, some phone numbers were ineligible and some participants became ineligible once age and sex quotas had been filled (see Table 4).

Table 4

Number of Ineligible Calls in Various Categories

\begin{tabular}{lr}
\hline Ineligible & \\
\hline Invalid number & 2362 \\
Business Number & 3849 \\
Fax machine & 1381 \\
Age quota full & 2165 \\
Sex quota full & 9 \\
Failed screen & 26 \\
\hline Total & $\mathbf{9 , 7 9 2}$ \\
\hline
\end{tabular}

Table 5

Number of Non-Response Calls in Various Categories

\begin{tabular}{lr}
\hline Non Responses & \\
\hline No answer & 642 \\
Answering machine & 425 \\
Engaged & 94 \\
Hung up & 767 \\
Number called too many times & 6952 \\
\hline Total & $\mathbf{8 , 8 8 0}$ \\
\hline
\end{tabular}

Table 6

Number of Eligible Calls in Various Categories

\begin{tabular}{lr}
\hline Eligible & \\
\hline Completed & 1000 \\
Refused & 9460 \\
Language barrier & 523 \\
Out of survey time & 21 \\
Respondent stopped interview & 17 \\
Interviewer stopped interview & 9 \\
Do not call & 173 \\
\hline Total & $\mathbf{1 1 , 2 0 3}$
\end{tabular}

Failed Screen: These were respondents who indicated they were willing to take part in the survey, but upon clarification, it was discovered that they were under 18 and therefore not eligible to participate.

Communication Difficulty: These were calls where the respondent was unable to complete the survey because they could not understand English, or because they were so hard of hearing or the telephone line was so bad, that it was impractical to attempt a telephone interview.

Hung Up: These were calls where the respondent hung up the phone before the interviewer had a chance to give any details about the survey.

Do Not Call: These were respondents who listened to the introduction but as well as declining to do the survey requested to be removed from any further call lists.

Out of Survey Time: These were calls made in the last few days of the survey where the respondent would have been willing to participate had the survey continued for a few more days.

Respondent Stopped Interview: These were calls where the respondent stopped the interview part way through and they were unwilling to complete the interview at a later time. 
Interviewer Stopped Interview: In a small number of cases the interviewers (in consultation with the CATI manager or the supervisor on duty) deemed it appropriate to terminate the interview. This was done in cases where the respondent clearly did not understand the questions or was behaving in an inappropriate way towards the interviewer. In such cases, interviewers are trained to tell the respondent "That was the last question. Thank you very much for your time."

If the communication difficulty and 'out of survey time' responses are deemed ineligible, this leaves 10,659 eligible responses.

The response rate is then the proportion of completed calls from the total valid eligible responses $(1000 / 10659) * 100=9.38 \%$ 


\section{Appendix IV}

\section{The World Internet Project - International Contacts}

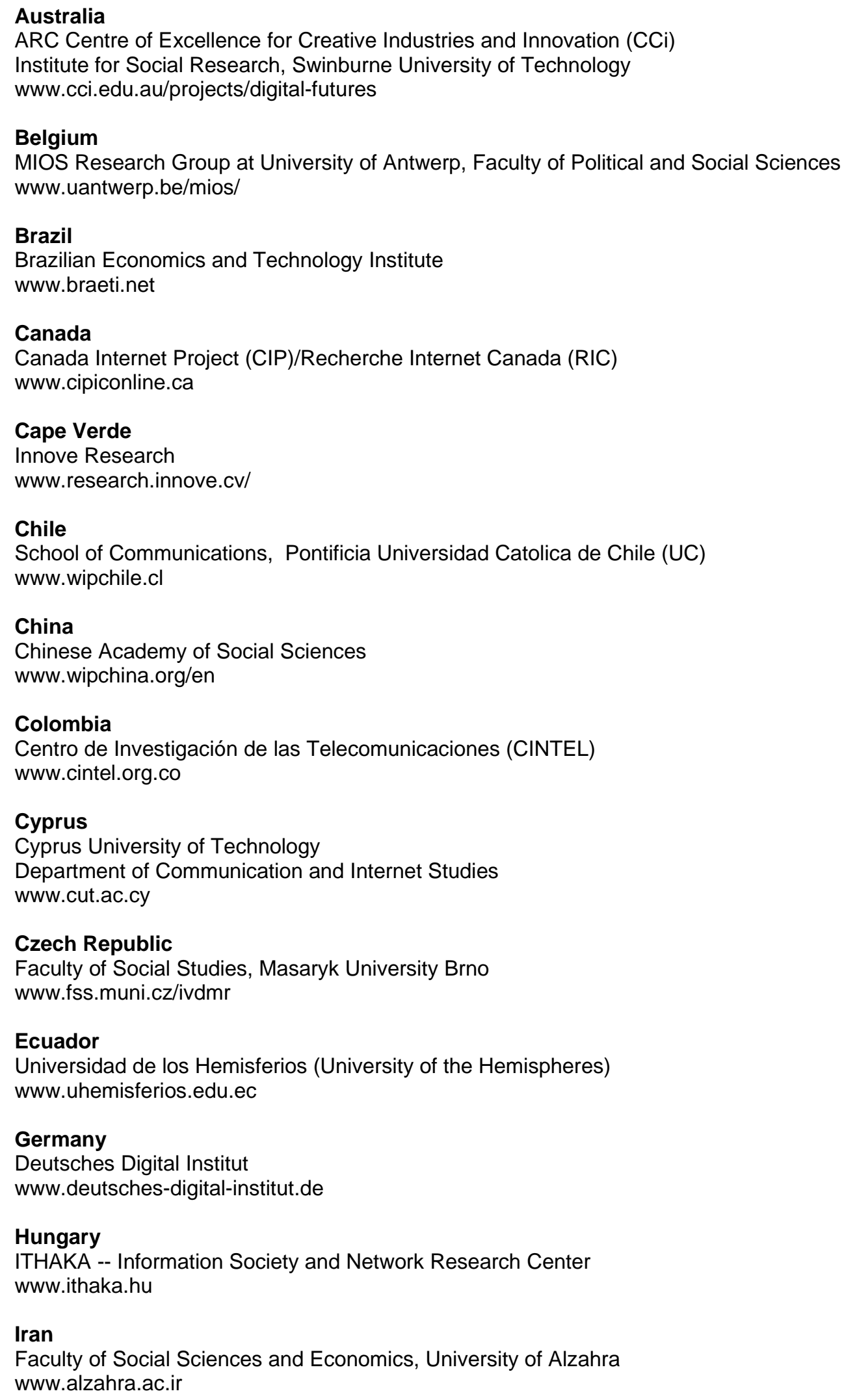

\section{Ecuador}

Universidad de los Hemisferios (University of the Hemispheres) www.uhemisferios.edu.ec

Germany

Deutsches Digital Institut

www.deutsches-digital-institut.de

Hungary

ITHAKA -- Information Society and Network Research Center www.ithaka.hu

Iran

Faculty of Social Sciences and Economics, University of Alzahra www.alzahra.ac.ir 
Israel

The Research Center for Internet Psychology (CIP)

Sammy Ofer School of Communications, The Interdisciplinary Center (IDC)

www.idc.ac.il/communications/cip/en

Italy

SDA Bocconi, Bocconi University

www.sdabocconi.it/home/it/

Japan

Department of Media and Communications, Toyo University

www.soc.toyo.ac.jp/ mikami/wip/en/index.html

\section{Macao}

University of Macau, ERS E-Research (Lab)

Macao Internet Project (MIP)

www.macaointernetproject.net

\section{Mexico}

Tecnológico de Monterrey, Proyecto Internet

www.wip.mx

\section{New Zealand}

Institute of Culture, Discourse and Communication, AUT University of Technology

www.wipnz.aut.ac.nz

\section{Poland}

Gazeta.pl Research and Analyses Unit

http://badania.gazeta.pl

\section{Portugal}

Lisbon Internet and Networks International Research Programme (LINI)

www.lini-research.org

\section{Qatar}

Northwestern University in Qatar

www.qatar.northwestern.edu

\section{Russia}

Sholokhov Moscow State University for the Humanities

www.mggu-sh.ru

\section{Singapore}

Singapore Internet Research Centre (SiRC), Wee Kim Wee School of communication and Information, Nanyang Technological University,

www.ntu.edu.sg/sci/sirc/

\section{South Africa}

South Africa Network Society Survey

www.journalism.co.za

\section{South Korea}

Yonsei University

www.yonsei.ac.kr

\section{Spain}

Internet Interdisciplinary Institute (IN3)

Open University of Catalonia (UOC)

www.uoc.edu/in3/pic/eng/communication.html

\section{Sweden}

World Internet Institute (WII)

www.wii.se 
Switzerland

Division on Media Change \& Innovation

IPMZ - Institute of Mass Communication and Media Research

University of Zurich, Switzerland

www.mediachange.ch

\section{Taiwan}

Taiwan e-Governance Research Center

Department of Public Administration, National Chengchi University

www.teg.org.tw

United Arab Emirates

Mass Communication Department, American University of Sharjah, www.aus.edu

\section{United Kingdom}

Oxford Internet Institute

www.oii.ox.ac.uk/microsites/oxis

\section{Uruguay}

The Universidad Catolica del Uruguay

www.ucu.edu.uy

\section{United States}

Center for the Digital Future

USC Annenberg School for Communication \& Journalism

www.digitalcenter.org 